\title{
REVIEW AND DECISION SUPPORT OF OPTIONS FOR THE REMOVAL, TREATMENT AND DISPOSAL OF STORMWATER SEDIMENTS
}

\author{
By \\ Panagiotis Koumoulas
}

B.A. in Geography, York University, 2008

\author{
A Professional Project Paper \\ Presented to Ryerson University \\ In partial fulfillment of the \\ Requirements for the degree \\ Master of Applied Science \\ In the Program of
}

Environmental Applied Science and Management

Toronto, Ontario, Canada, 2015

(C) Panagiotis Koumoulas, 2015 


\section{Author's Declaration}

I hereby declare that I am the sole author of this Masters Professional Project Paper (MPPP). This is a true copy of the MPPP, including any required final revisions.

I authorize Ryerson University to lend this MPPP to other institutions or individuals for the purpose of scholarly research. I further authorize Ryerson University to reproduce this MPPP by photocopying or by other means, in total or in part, at the request of other institutions or individuals for the purpose of scholarly research.

I understand that my MPPP may be made electronically available to the public. 


\title{
Review and Decision Support of Options for the Removal, Treatment and Disposal of Stormwater Sediment
}

\author{
Panagiotis Koumoulas \\ Master of Applied Science, 2015 \\ Environmental Applied Science and Management, Ryerson University
}

\begin{abstract}
Stormwater management (SWM) ponds are a widely used option to control runoff, decrease flooding potential, reduce erosion rates in receiving waters and improve water quality. Although dredging and disposal are accepted practices, there is a need to consider alternative removal techniques, since 1) overall costs for a single pond can be substantial, and 2) a large number of ponds are approaching their operational capacity. It is evident that numerous remedial and beneficial reuse options are more economically viable and environmentally stable than current options. The intent of the current research was to develop guidance for municipalities and operators when faced with contaminated stormwater sediments. This paper presents a review of potential removal, treatment, disposal and beneficial use options and offers a simple decision support methodology to aid in the selection of options.
\end{abstract}




\section{Acknowledgments}

I would like to first thank my supervisor and mentor Dr. Darko Joksimovic for his motivation, guidance and support for the entirety of the program.

Furthermore, I would like to thank the Toronto and Region Conservation Authority for their contribution and involvement with the project. In particular, a special thank you to Kristina Delidjakova and Tim Van Seters for their continued direction throughout the writing process.

In addition, I would also like thank Melissa Ryan from the City of Kitchener for her assistance with invaluable resource acquisition.

Finally, I would like to thank the many Faculty members who I was privileged enough to meet. You encouraged and inspired me, facilitated my priceless education and provided unforgettable life lessons. 


\section{Dedication}

To my family and friends for their love and support. 


\section{Table of Contents}

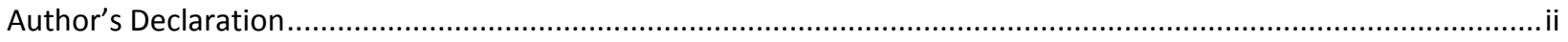

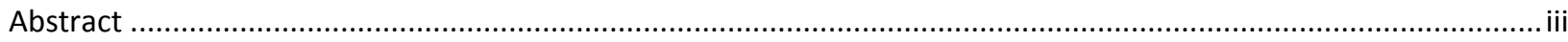

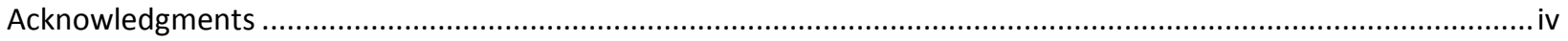

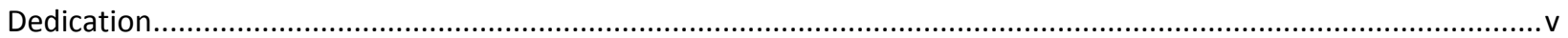

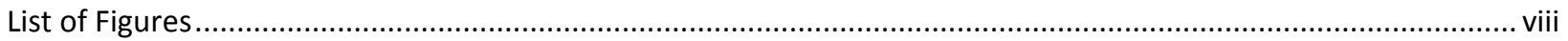

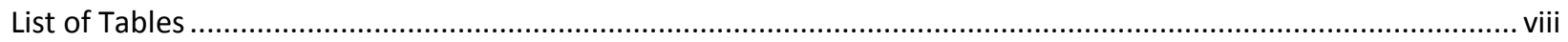

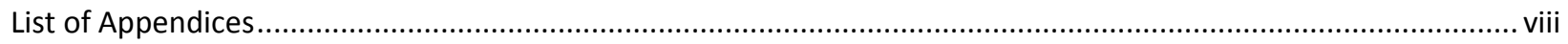

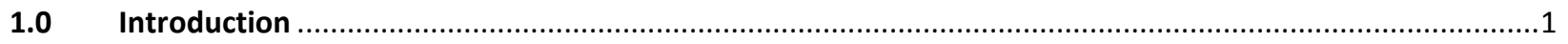

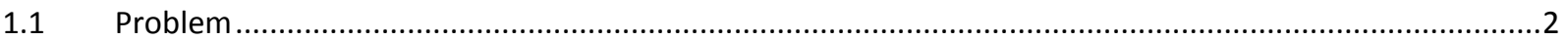

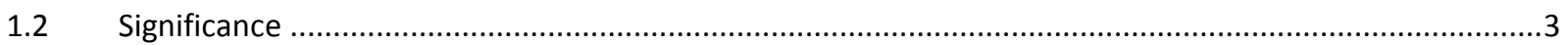

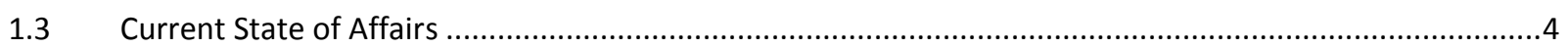

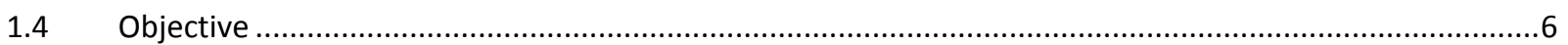

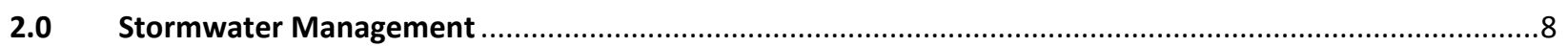

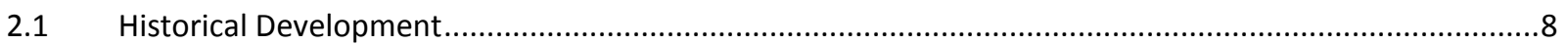

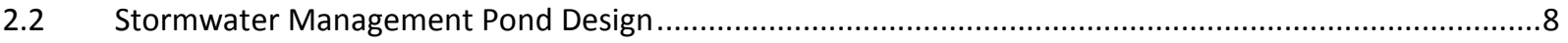

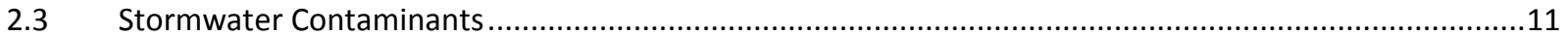

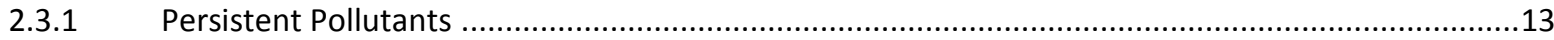

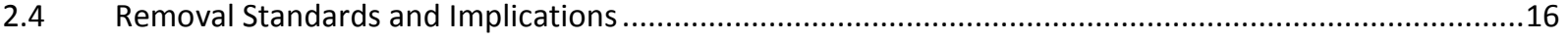

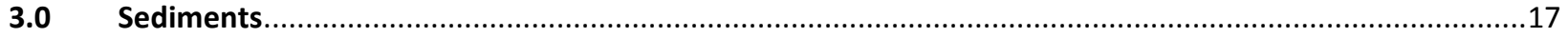

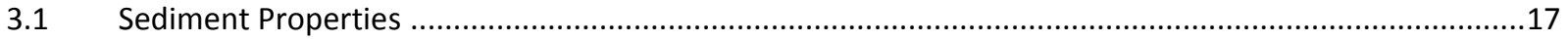

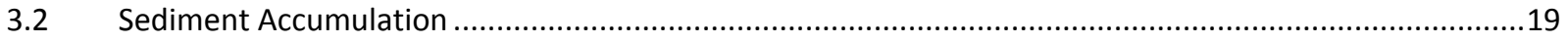

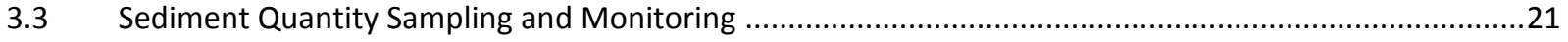

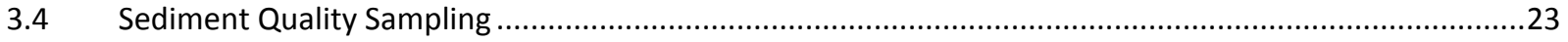

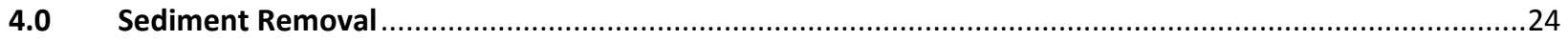

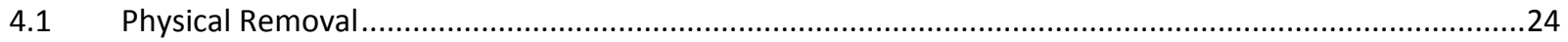

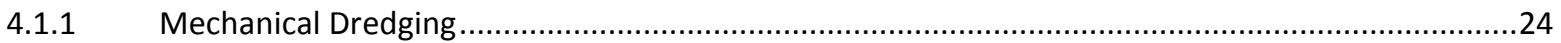

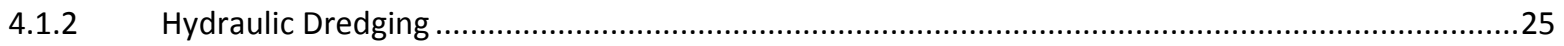

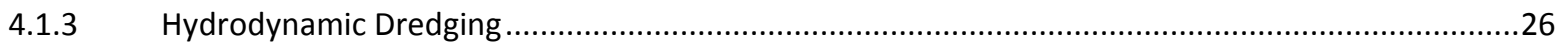

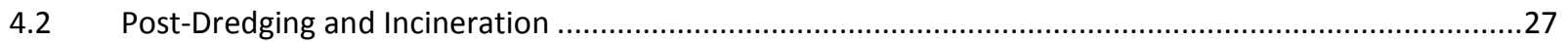

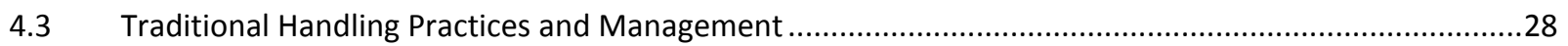

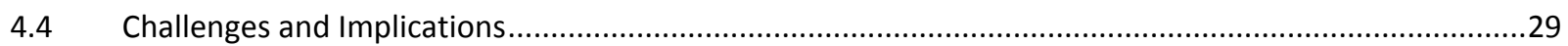

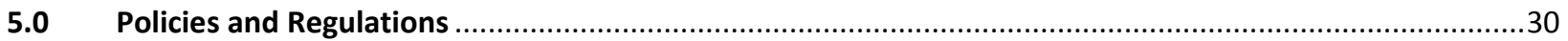




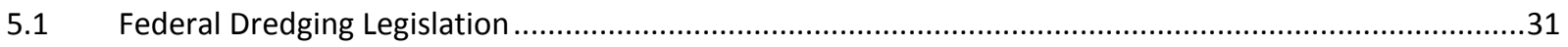

5.2 Provincial Legislation (Ontario) With Reference to Dredging ......................................................32

5.3 Federal and Provincial Remediation Policies, Regulations and Legislation.........................................35

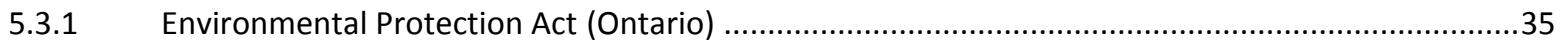

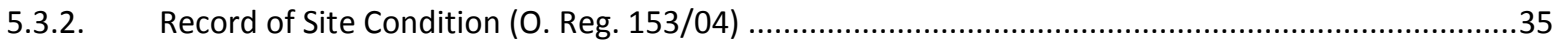

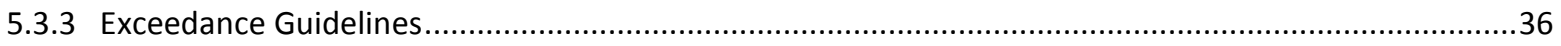

5.3.4 Canadian Council of Ministers of the Environment (CCME) Guidelines ......................................39

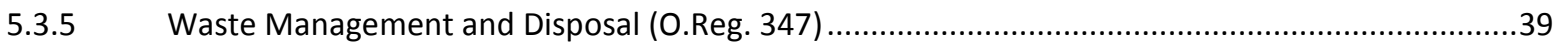

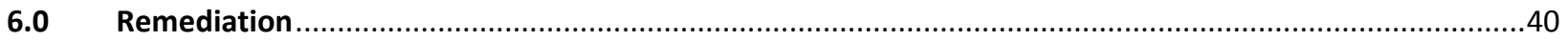

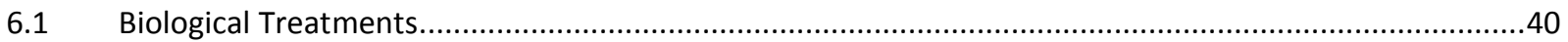

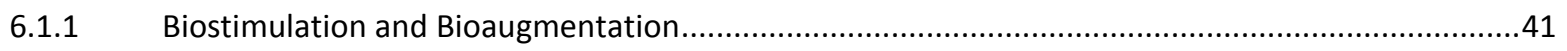

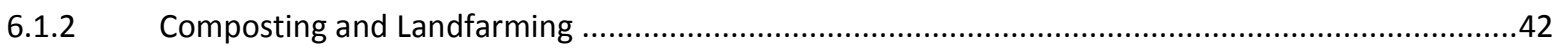

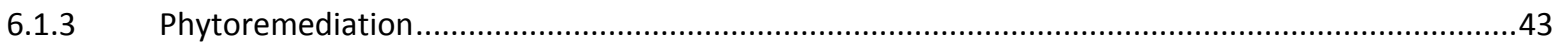

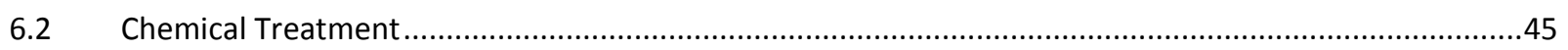

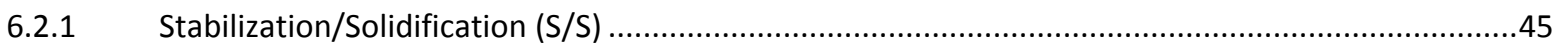

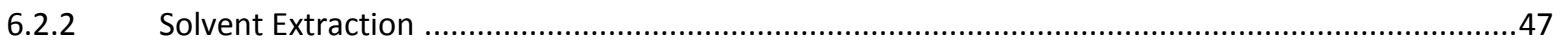

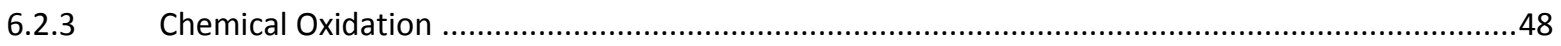

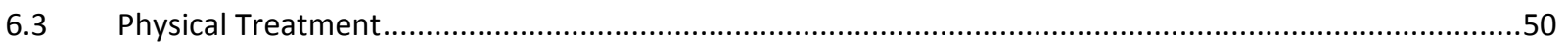

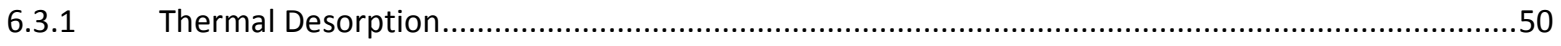

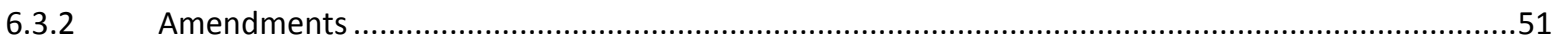

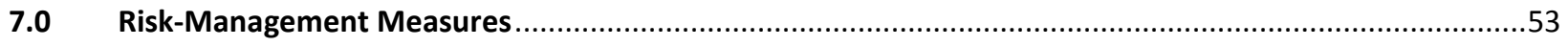

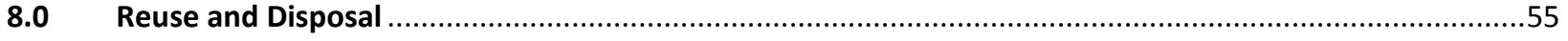

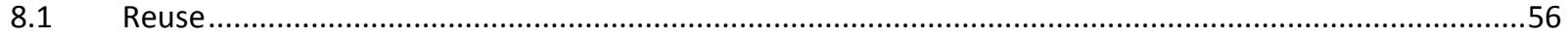

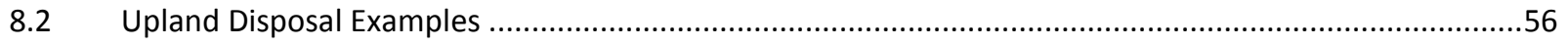

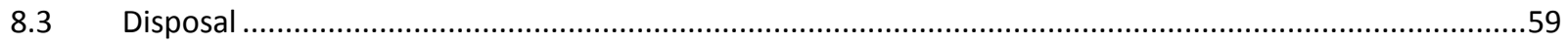

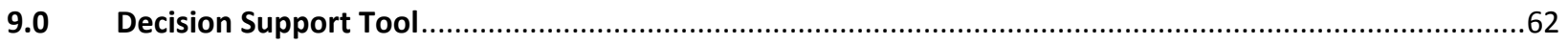

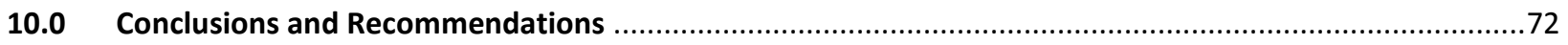

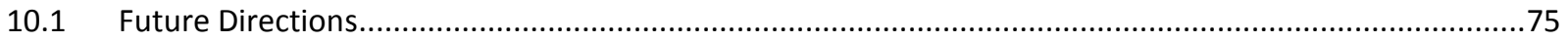

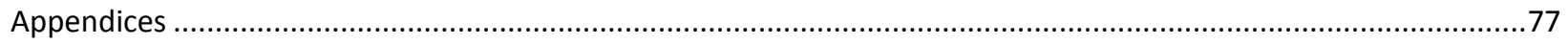

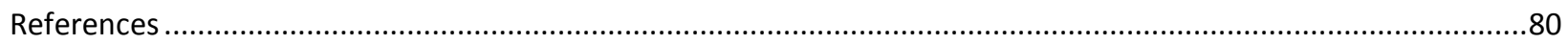




\section{List of Figures}

Figure 1: Age distribution of SWM ponds within Southern Ontario ...................................................................

Figure 2: Sediment quantity and quality sampling trends in Southern Ontario .......................................................

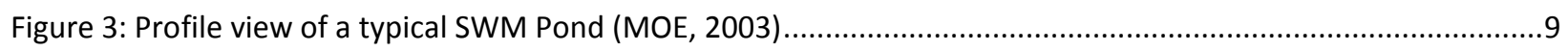

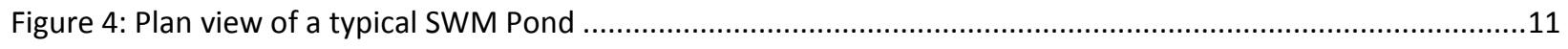

Figure 5: Pond volume reduction for a 5\% reduction in TSS removal (Marsalek et al., 2008) .................................20

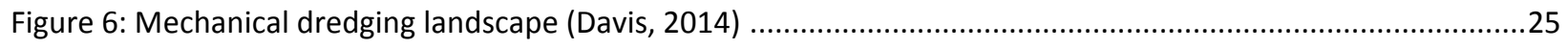

Figure 7: Hydraulic dredging landscape (Davis, 2014) ....................................................................................26

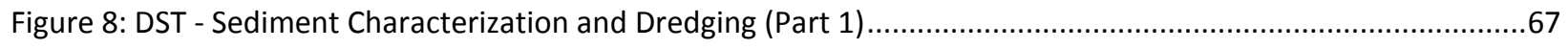

Figure 9: DST - Options for Beneficial Reuse, Remediation and Disposal (Part 2)...............................................69

\section{List of Tables}

Table 1: Adapted FRTR screening matrix for the remediation of SWM pond sediments .64

Table 2: Criteria definition of terms used in screening matrix (FRTR, 2008) .64

\section{List of Appendices}

Appendix 1.1: Full Depth Background Site Condition Standards (MOE, April 2011) 


\subsection{Introduction}

Stormwater management is a growing concern within urbanizing cities. With the increase of impervious surfaces, drainage systems must be designed to facilitate the movement of water away from cities to reduce flooding, maintain water balances, and prevent undesirable stream erosion. Ultimately, stormwater management should aim to maintain the natural hydrologic cycle and protect the water quality for environmental and biological purposes. To prevent the negative impacts of stormwater runoff, a combination of preventative measures are employed, often part of a larger management strategy. In particular, source controls, conveyance, and end-of-pipe treatment options are available and their selection largely depends upon a series of factors, such as economic feasibility or the characteristics of the subcatchment area.

With continual urbanization and the expansion of road networks and other paved surfaces, stormwater runoff has become a major proponent of water quality degradation within receiving waters. Stormwater management (SWM) ponds offer relief, as contaminant-laden sediment falls out of suspension. However, many of these sediments have heavy metals and hydrocarbons sorbed to their surfaces, which often present a risk for all trophic levels (USEPA, 2006). Furthermore, SWM ponds require maintenance and periodic dredging to sustain their design level of sediment removal efficiency (Marsalek, 1992). The accumulation of sediment within a given area is largely dependent on the natural topographical features, relative imperviousness of the subcatchment and the presence of potential construction activities. For example, the construction of subdivision will greatly increase the amount of sediment deposited on roads and subsequently increase the rate of maintenance required within proximate SWM ponds. Maintenance schedules are habitually open to interpretation of various accumulation models and are often left to the care of regional municipalities (Graham and Lei, 2000). To assist with the maintenance of sediment, Municipalities can employee various methods, such as streetsweeping and catchbasin cleaning, which have the ability to direct sediment away from SWM ponds. In addition, the accumulation rates and composition of sediment are dependent upon the location of stormwater ponds, whether in residential or industrial areas (Drake and Guo, 2008). Currently, dredging is most common sediment removal option, but its costs can be quite high, particularly when transportation and associated disposal fees are included (USEPA, 2005).

Currently, sediment removal and stormwater maintenance guidance in Ontario is provided by the Storm Water Management Facility Sediment Maintenance Guide (GCl, 1999), which was written for the City of Toronto, Ministry of Transportation (MTO), Ministry of the Environment (MOE), Credit Valley 
Conservation Authority (CVC), Toronto and Region Conservation Authority (TRCA) and various municipalities within the Greater Toronto Area (GTA). The document not only highlights policies, regulations and design criteria, but also sampling techniques and removal methods (GCI, 1999). However, since its creation, cities and regulatory authorities have adjusted the conceptual framework of sediment removal and disposal. In particular, sediment remediation has become an important method, as 'clean' sediment not only reduces removal and disposal costs, but can be used as fill and substrate for other constructive endeavours, while promoting sustainable practices.

\subsection{Problem}

Municipal estimates of complete stormwater pond clean-out are within the range of $\$ 200,000$ $\$ 500,000$ (Drake and Guo, 2008). Not only does this highlight the variability of cost, which depends on size of pond, depth of sediment, volume of forebay, etc, but also the high cost of even the smallest stormwater ponds. Furthermore, stormwater pond maintenance affects or will affect a majority of municipalities in southern Ontario given the number of constructed facilities over the last decades. For example, a recent survey reported that Richmond Hill has 112 ponds with 32 planned, London has 178 with another 118 planned; and Vaughan has 327 with 207 future ponds planned (Drake and Guo, 2008). Current estimations place the number of stormwater ponds in the GTA at 1500, with less than $1 \%$ receiving full pond clean-out since their initial construction. Many municipalities have either allotted no funding for sediment removal, developed underestimated projected budgets or allocated money for pooled stormwater management accounts, instead of specific projects. For example, while the City of Waterloo has allocated $\$ 1.1$ million for future sediment removal, consultant estimates place the figure at $\$ 5.4$ million (Drake and Guo, 2008). In addition, the City of Guelph has also indicated a funding shortfall within its own inventory and maintenance report published in 2008 (TSH, 2008). The significant gap in allocated funding is ongoing throughout many municipalities within the Greater Toronto Area.

This project, conducted in consultation with the Toronto and Region Conservation Authority (TRCA), presents a simple decision support methodology to aid municipalities in the clean-up of their SWM ponds. Furthermore, this project highlights current removal, treatment and disposal options for contaminated sediment, and place a particular emphasis on remedial options available for the clean-up of contaminated sediment found within SWM ponds. 


\subsection{Significance}

Although stormwater ponds are designed to collect the runoff from roads and other impervious surfaces and improve water quality, sediment maintenance and removal is required to sustain their capacity. According to the MOE design manual, ponds within Ontario have a life span from 10-25 years, with clean-out required every 5-25 years (MOE, 2003). However, a vast majority of municipalities have not prepared logistically and economically for these impending costs. Once stormwater ponds are assumed by a municipality from developers, clean-up and/or dredging costs will be conveyed to the tax payer. Current annual maintenance costs are higher for smaller ponds; maintenance costs can be up to $10 \%$ for stormwater ponds costing $\$ 10,000-\$ 25,000$ and up to $5 \%$ for ponds that cost over $\$ 100,000$ to construct (Houle et al., 2003). Further maintenance cost estimates from Narayanan and Pitt (2006) have an approximate range of $\$ 2,000-10,000$ for ponds sized between 3 and 5 ha (6-11 acres), without including dredging and removal costs. In another example, the excavation of a forebay in East Gwillimbury cost $\$ 2.2 \mathrm{M}$ including design, consulting and construction fees (LSRCA, 2009). The issue is that annual maintenance budgets for stormwater ponds often only account for vegetation maintenance and pipe clean-out, while the sediment removal costs would comprise a large portion of the budget. Since ponds have rarely required sediment removal due to their infancy, municipalities have not created contingency plans for sediment removal or estimated potential future capital costs.

Another issue with cost estimating is determining accumulation rates and clean-out frequency. Generally, municipalities are required to design Level 1 or Enhanced protection stormwater management facilities, which provide $80 \%$ removal of suspended solids. Various other end of pipe storage controls can be designed as Level 2 or normal protection ( $70 \%$ removal) and Level 3 or basic protection (60\%); however, stormwater ponds are held to the highest standard sediment removal standards (MOE, 2003). A recent study by the Lake Simcoe Region Conservation Authority (LSRCA) reported that the efficiency of over $50 \%$ of surveyed ponds in the jurisdiction decreased from Level 1 to Level 2 (LSRCA, 2010). Although the age of the pond can exacerbate sedimentation rates, it was noted that a majority of the ponds that dropped in efficiency, did so in a relatively short amount of time. As a result, 5-20 year accepted clean-out rate will inherently fluctuate due to catchment and sub-catchment land-use patterns, such as construction activities that can accelerate sediment accumulation. Consequently, the report suggested the clean-out of sediment every 10 years to avoid dropping efficiency levels, regardless of catchment characteristics (LSRCA, 2010).

As stormwater pond permanent pool volumes continue to decrease and dredging becomes the 
only viable solution, municipalities require a guideline to not only direct ongoing maintenance but also present cost-effective options for sediment management. Although many papers and journal articles have been written describing sampling techniques, maintenance requirements and general soil and groundwater remediation methods, very few have emphasized their use within stormwater retention ponds. A framework for municipalities describing various related regulations, sediment removal techniques, treatment options, and disposal considerations will provide vital information and tools to streamline an industry largely dependent on best-management practices and introduce sustainable approaches to conservative stormwater management concepts.

\subsection{Current State of Affairs}

A small survey was distributed to a total of 15 municipalities within Southern Ontario to assess the age of their SWM management ponds within their jurisdiction, the frequency of monitoring activities and the range of ponds for which data is collected and analyzed. The individual municipalities and townships will not be disclosed, however, they collectively contain 896 ponds in their respective jurisdictions. The first set of questions concerned the age distribution of SWM ponds (Figure 1).

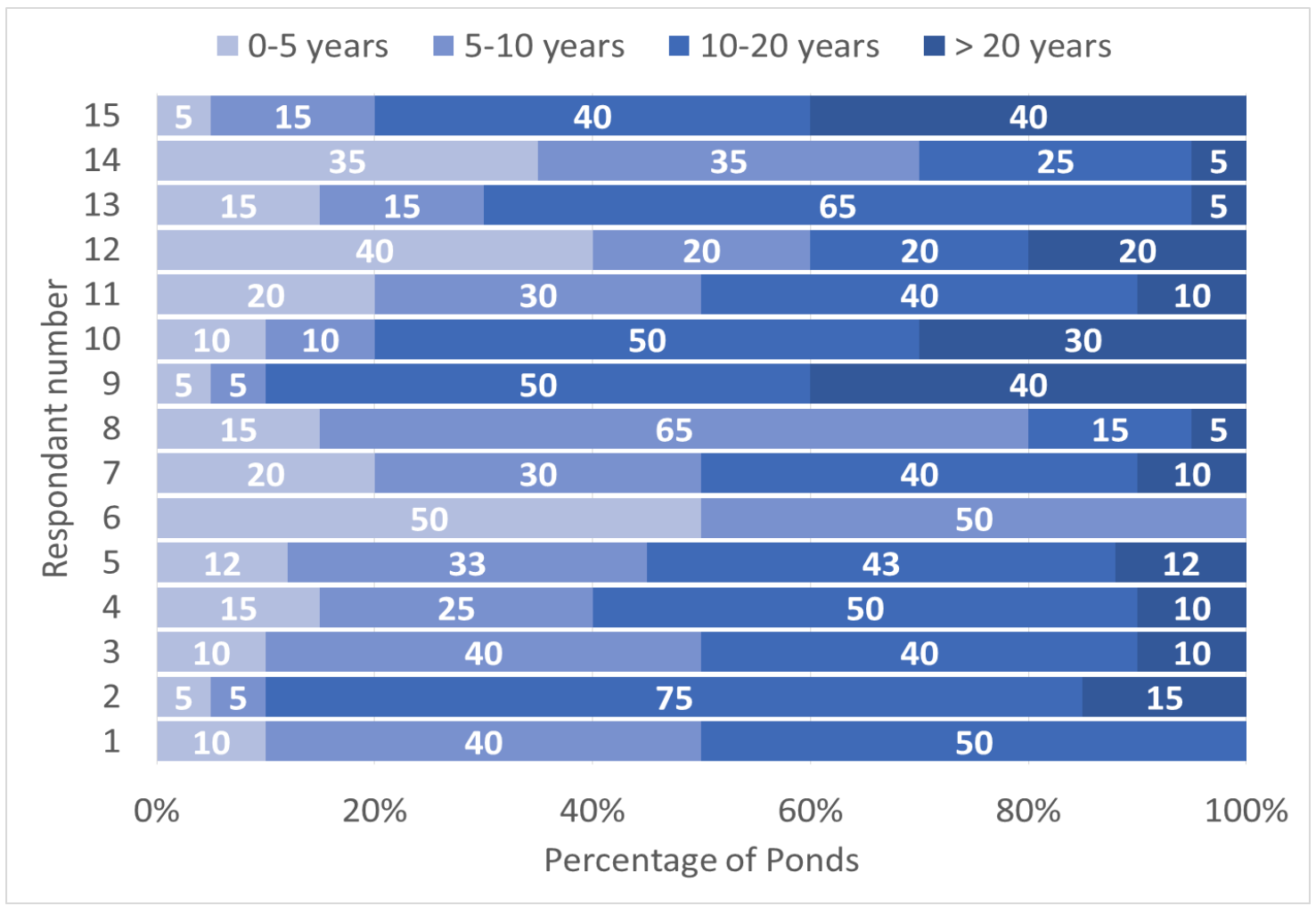

Figure 1: Age distribution of SWM ponds within Southern Ontario 
Most Municipalities and Townships in Southern Ontario generally contain a large number of ponds which require maintenance, with regards to MOE's clean-out guidelines. More than $55 \%$ of all ponds (896) encompassed within the survey were over 10 years in age, with $16 \%>20$ years of age (Figure 1). Under MOE's clean-out guidelines (every $10-25$ years), more than $50 \%$ of all ponds in Ontario may currently require clean-out, which highlights the need for continued monitoring programs. With regards to monitoring programs, Municipalities and Townships were also asked to comment on the percentage of ponds within each jurisdiction that contain sediment quantity and quality estimates, and inflow/outflow grab samples (Figure 2).

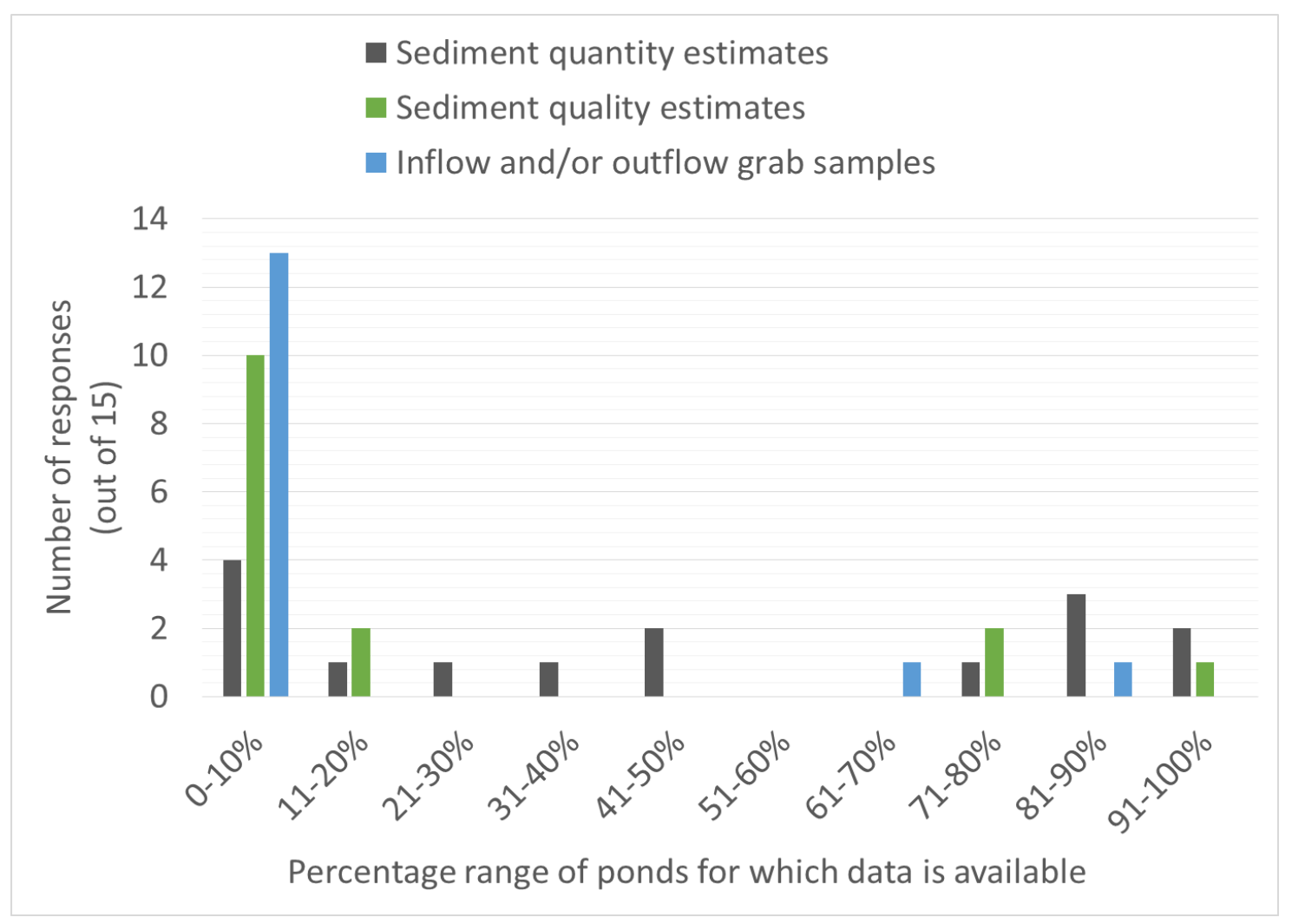

Figure 2: Sediment quantity and quality sampling trends in Southern Ontario

It is interesting to note that a vast majority of respondents indicated that $<10 \%$ of all their ponds contain data related to sediment quality or inflow and/outflow grab samples. Given the propensity for contaminants to sorb to fine sediment particles, the monitoring of sediment quality is imperitive to protect downstream habitats. In particular, outflows provide ample opportunity to assess sediment quality, as they are locations of increased sediment accumulation. The figures shown do not present a complete picture of SWM pond-related issues facing municipalities within Southern Ontario, but instead 
provide a basis for discourse on the patterns which have developed. In particular, the intention is to highlight the impending clean-out costs which Municipalities will soon face and, subsequently, develop and assess alternatives to standard dredging methods.

\subsection{Objective}

The purpose of this project is to compile a review of current and potential remedial options available to remediate stormwater pond sediments and subsequently develop a decision support tool that municipalities can utilize in management of their own SWM ponds. The project is undertaken with the impetus to improve and update the Storm Water Management Facility Sediment Maintenance Guide(1999) currently utilized by the TRCA to monitor, inspect and direct SWM sediment removal within their jurisdiction. Over the previous two decades, the development of brownfield lands has become of particular importance, as formerly zoned industrial areas are converting to commercial and residential developments. Small and large-scale clean-up projects have developed and continuously improved specific in-situ and ex-situ remedial methods, but rarely have they been applied to the field of stormwater management (Graham and Lei, 2000). In particular, there is a need within the environmental industry to not only employ sustainable methods and technologies within clean-up methodologies, but also potentially reuse material once destined for hazardous landfills (Graham and Lei, 2000). Consequently, special importance is placed upon reviewing and assessing remedial options available to clean-up contaminated sediment. Ultimately, the purpose of the review and compilation is to accumulate an extensive literature review into one cohesive guideline that can be used to evaluate options for stormwater ponds requiring impending dredging. The review is focused on the treatment, removal and disposal regulations/guidelines in a North American context. The review of remedial options highlights their applicability to stormwater ponds or contaminated sediment.

The second objective is to develop a decision-support matrix that the practitioners can use to evaluate potential options depending on the size of the catchment, volume and quality of sediment that requires removal and/or treatment and cost considerations. Furthermore, an importance is placed on reviewing existing guidelines regarding the monitoring and inspection of stormwater detention facilities. Guidelines from municipalities in the GTA are compiled, along with frameworks existing in other Canadian cities, as well as potential additional US State guidelines. It should be noted that a series of 'decisions' are required to be completed prior to utilization of the matrix and flow chart presented in this paper. In particular, a Municipality and contractor should make a concerted effort to complete an 
initial site assessment to determine the visible condition of their SWM ponds and subsequently prioritize the specific ponds that require further maintenance. Nonetheless, the prioritization of SWM ponds and the impetus to clean-out and dredge can be based on a series of parameters, such as a loss of removal efficiency, reduction of design storage volume, amount of accumulated sediment or the decrease of the categorized level of protection. The assumption of the DST and flowchart requires the Municipality to initially assess and identify the specific SWM ponds that require clean-out and identify factors which may influence their remedial option, such time to remediate, budget requirements, or area allotment. Each factor will be discussed throughout the project and highlighted within the matrix, but the onus is on the Municipality to develop an internal ranking system of each individual decision variable (multicriteria analysis) to provide a foundation for the selection of remedial technique.

The general organization of the report begins in Chapter 1.0 with a review of the current state of SWM pond management and the scope of the project. Subsequently, Chapter 2.0 describes the historical evolution of SWM, the accepted design of SWM ponds and their associated removal standards. Furthermore, Chapter 2.0 also introduces the types of potential contaminants that can be found within the sediment of SWM ponds and also provides a classification of each contaminant, which is the basis for the decision support tool found later within the report Chapter 3.0 highlights the significance of sediment particles, their rate of accumulation within SWM ponds and methods to sample sediment quantity and quality. Chapter 4.0 describes the removal and dredging options commercially available. In addition, each dredging type will be evaluated and assessed in accordance with general site characteristics (i.e. the use of mechanical dredging vs. hydraulic dredging). Subsequently, Chapter 5.0 provides a background of the associated Provincial and Federal policies and regulations related to SWM pond clean-out and remediation standards. Henceforth, Chapter 6.0 presents a large portion of the review and highlights treatment options available in situ and ex situ and dependent upon the specific compound requiring treatment in stormwater pond sediments (i.e. PAHs, heavy metals, organics, or PCBs). Chapter 7.0 describes disposal procedures for contaminated sediment and whether the material would require landfilling and/or hazardous landfilling. Consequently, Chapter 8.0 will introduce the decision support tool, including its development and its potential uses with regards to SWM pond sediment remediation. Finally, Chapter 9.0 provides a series of recommendation with regards to current maintenance practices and potential future research opportunities. 


\subsection{Stormwater Management}

\section{$2.1 \quad$ Historical Development}

The initial use of SWM ponds in Ontario was largely dependent upon the evolution of stormwater management. Following the damage incurred from Hurricane Hazel in 1954, stormwater management measures largely fell under the dominion of flood protection and control techniques. Initially, the Metro Toronto and Region Conservation Authority's (MRTCA) flood control program was responsible for the construction of planned control dams, the commencement of an erosion control program for and led to the amendment of the Conservation Authorities Act. Following the creation of a series of conservation authorities in the early 1970s, stormwater management focused on the control of runoff flow rates, as new residential and commercial developments were erected within the Greater Toronto Area. The continued urbanization of Toronto led to a greater focus on receiving water quality in the 1980s and monitoring the effects of implemented stormwater controls on receiving waters in the 1990s. To reduce the effects introduced by increased imperviousness and runoff, the 1980s saw the implementation of stormwater ponds to detain peak flows (dry ponds), which were further designed to remove suspended sediment from incoming flows utilizing permanent pools (wet ponds) in the 1990s. The stormwater pond has since become a mainstay in Ontario municipal stormwater management and regional watershed plans and continues to be the main control implemented to reduce the cumulative

effects of runoff on receiving waters. However, as stormwater ponds continue to remove sediment from runoff, its accumulation in the permanent pool will lead to reduced removal efficiency. Current contingency plans rely on dredging operations, but legislation does not mandate clean-up; only policies and guidelines are provided if sediment removal were to be undertaken. As a result, without periodic maintenance, stormwater ponds will not only become ineffective at sediment removal but become sources for the re-suspension of sediment that may enter downstream receiving water.

\subsection{Stormwater Management Pond Design}

Stormwater ponds are designed in a way to mimic the flow rate, timing, and pollutant load of pre-existing conditions (New York DEP, 2010). Stormwater ponds maximize the storage of water, as storage can reduce peak runoff and lower the potential for local flooding (Florida DER, 2005). Many manuals highlight the need to use existing spaces, including lakes and open areas, which could enhance 
storage opportunities for municipalities. In addition, a detention pond should be planned for construction operations that limit the grading of natural topography (Maryland DEP, 2009). Erosion and sedimentation play an imminent role in the effectiveness of a pond, as well. A properly designed stormwater pond will reduce velocities throughout the pond, allowing increased infiltration and improved filtering of pollutants (Marsalek, 1997). Ultimately, the optimum design of a stormwater pond should utilize nature's approach to route and filter stormwater, as it is largely capital, energy, and maintenance free (Marsalek, 1992).

Optimum design of stormwater ponds is dependent on its inherent ability to reduce peak flows, improve water quality, and limit downstream erosion (Figure 3). Wet detention ponds address stormwater quantity requirements through their design to control post-development peak discharge rates to pre-development rates (Florida DER, 2005). In general, the pond is designed to control multiple design storm, such as 2-year and 10-year storms and be able to endure 100-year and regulatory storm events (McRae, 1996). However, specific criteria can change depending on the type of watershed. For example, Etobicoke Creek has a provision which states that peak flows must be controlled to $85 \%$ of predevelopment flows for all storms, including regulatory storms (TRCA, 2012).

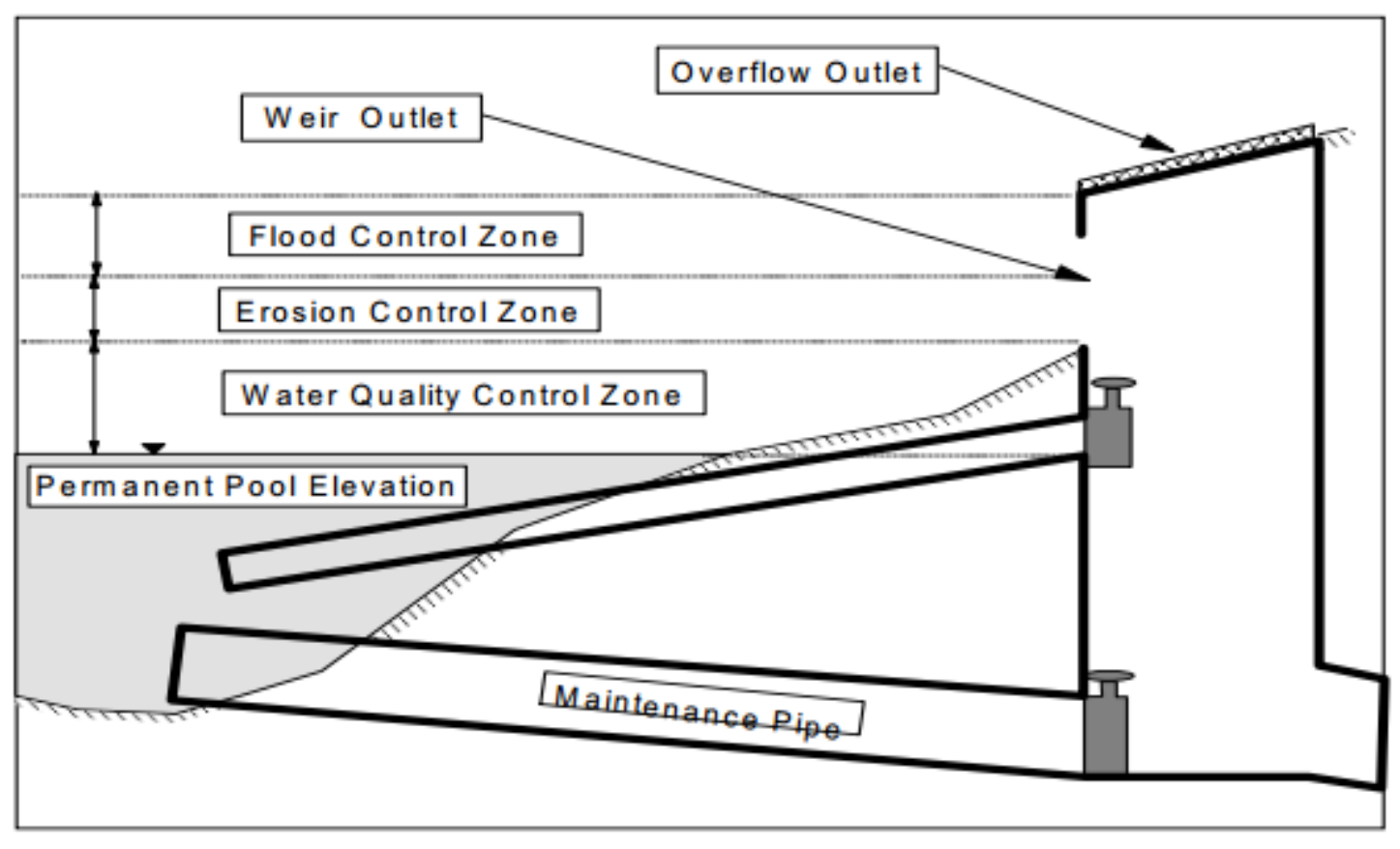

Figure 3: Profile view of a typical SWM Pond (MOE, 2003)

Water quality control is achieved through pollutant removal in the permanent pool (Figure 4). 
The pond is designed to increase the amount of time that stormwater runoff resides in the pond, or hydraulic residence time, and to promote both sedimentation and biological uptake processes (Figure 4)(Butler and Davies, 2011). In particular, wet detention ponds are designed to remove a certain percentage of a variety of particulate matter and contaminants, such as total suspended sediment (TSS), total nitrogen (TN), total phosphorus (TP), and biochemical oxygen demand (BOD). Many provincial and state standards are quite similar with respect to TSS removal, with the range between $80-90 \%$; SWM ponds in Ontario require a Level $180 \%$ removal of TSS, while $85 \%$ removal is required within the State of New Jersey (New Jersey DEP, 2004), for example. Even though many studies have highlighted the capacity for retention ponds to remove TSS, certain pollutants have much lower removal efficiencies (Marsalek, 1992; Marsalek, 2003; Stanley, 1996). For example, Total Nitrogen (TN) and Total Phosphorus are not toxic contaminants is small concentrations, but excess amounts can lead to eutrophication and water-quality issues (USEPA, 2009). Furthermore, urban sources such as fertilizers, pet wastes, and septic system and sewage leaks continuously contribute to TN and TP loads, which subsequently enter SWM ponds through runoff (Collins et al., 2010). SWM ponds can increase the amount of TN and TP they remove through the planting of perimeter vegetation and through the increasing of length-to-width ratio of the pond itself. However, TN and TP are less likely to bind organic sediment and short-circuiting often promotes a decrease in nutrient up-take. As a result, TN and TP removal estimates are $20-30 \%$ and 60-85\%, respectively (Koch et al., 2014; Ontario MOE, 2003; LSRCA, 2007; LSRCA, 2011). 


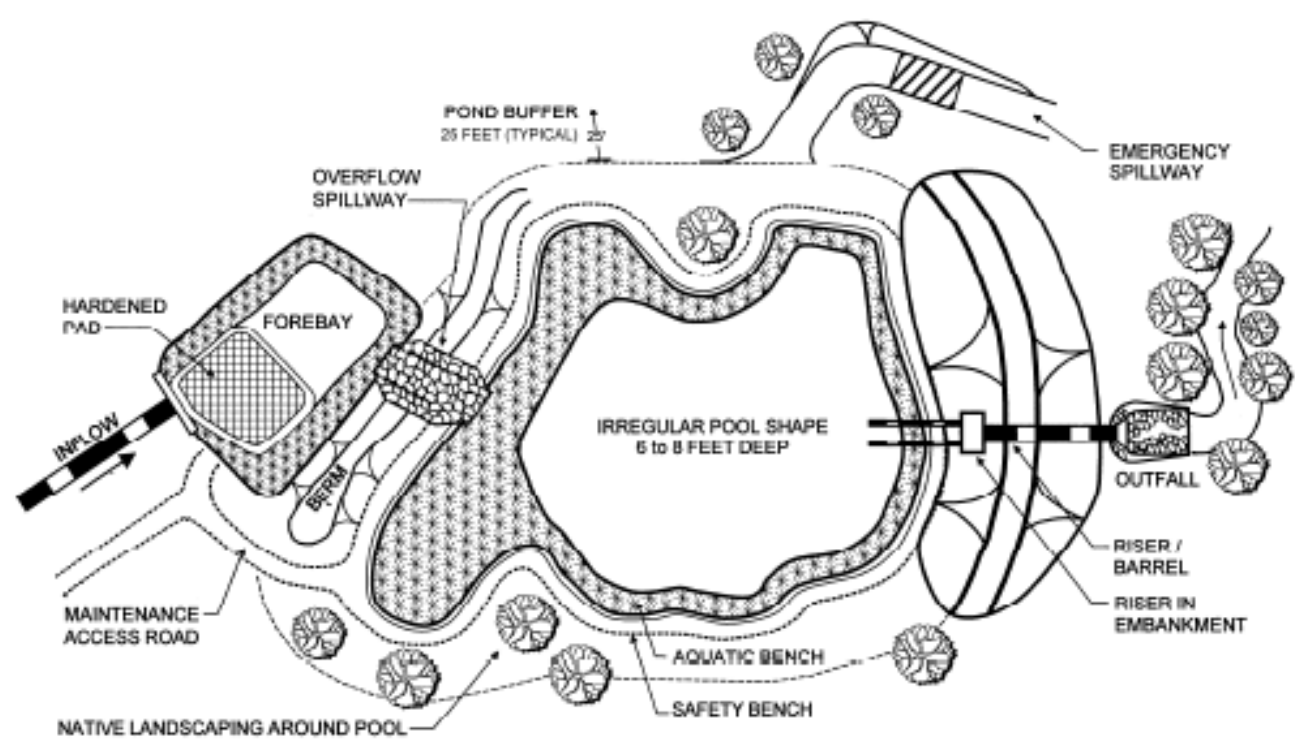

Figure 4: Plan view of a typical SWM Pond

\subsection{Stormwater Contaminants}

A variety of contaminants can enter stormwater ponds depending on the catchment activities (e.g. construction, vehicular traffic), size and land-use. Generally, pollutants sorbed to sediments in stormwater ponds are present at low concentrations and in the order of ppm (parts per million), ppb (parts per billion) and ppt (parts per trillion). Furthermore, pollutants can appear in different phases, such as a gas phase, in an aqueous solution or in a solid state. Using a very broad characterization, pollutants present in stormwater ponds can be organic or inorganic, in nature. Under a more detailed classification, the pollutants can be divided into six groups: biodegradable organic matter, nutrients, heavy metals, organic micropollutants, suspended solids and pathogens (Hvitved-Jacobsen et al., 2012).

Biodegradable matter is an important pollutant to consider, as it can indirectly affect the efficiency of drainage systems. The matter will inherently consume dissolved oxygen (DO) and its depletion can lead to decrease of water quality within receiving waters and potential blockages within stormwater pond outlets (Hvitved-Jacobsen et al., 2012). The second group of pollutants come directly from reactive nitrogen and phosphorus, which account for eutrophication within water bodies. In particular, total concentrations are routinely measured in urban drainage but special attention should be made to ammonia, due to its toxic effects, nitrates and nitrite, due to their potential to lead to algal blooms, and proper distinction between soluble and particulate forms of phosphorus. A third group of pollutants, heavy metals, can have acute and cumulative impacts on organisms exposed to them. The 
most common heavy metals found in urban waterways are copper, lead, zinc and cadmium (Butler and Davies, 2010). Furthermore, nickel and chromium have also been documented, but they do not pose biological threats at concentrations found within urban runoff and ultimately SWM ponds (HvitvedJacobsen et al., 2012). Due to the wear and tear of vehicular components, including tires, brakes and oil tanks, heavy metals have become the largest group of contaminants found in stormwater ponds (Butler and Davies, 2010). In addition, it important to note that although iron is a heavy metal, it has not been included in many analyses as its high concentrations in urban stormwater samples can essentially classify it as a substance on its own with an ability to adsorb contaminants (Hvitved-Jacobsen et al., 2012).While stormwater managers and regulators have historically measured heavy metals in terms of total concentrations, the toxicity of a substance is determined by its solubility and its potential to form new complexes with other substances (Hvitved-Jacobsen et al., 2012).

Pathogens pose a unique threat to the water quality in urban areas, as their inputs can be attributed to multiple sources, such as wastewater treatment plants (WWTP) and wildlife. The test for the presence of pathogens, fecal indicator bacteria (FIB), is employed to ascertain the occurrence of disease-causing organisms (UWRRC, 2014). In particular, the most commonly used FIBs are Escherichia coli (E. coli), enterococci and fecal coliform (UWRRC, 2014). The issue with pathogens is that, unlike chemical compounds, their occurrence in receiving waters is extremely difficult to control, as their propensity to grow, multiply and/or die-off is dependent upon prevailing, local environmental conditions (UWRRC, 2014). Furthermore, as traditional contaminants often have a visible source, pathogens can enter receiving waters through the urban runoff of fecal matter. As a result, pathogens present on landscapes and within catchbasins and sewers have the potential to enter SWM ponds. Consequently, due to their chemical properties, pathogens are not readily sorbed to sediment and often travel unfiltered through such ponds and into receiving waters (UWRRC, 2014). Another potential concern is the abundance of combined sewer overflows (CSOs) in urban areas, which, when loaded over design capture capacity, will cause sewage to overflow into receiving waters (UWRRC, 2014). Such discharges pose direct threats to wildlife and humans, due to their high volumes and lack of treatment.

A potentially hazardous set of pollutants are organic micropollutants, which are also known as xenobiotic organic pollutants (XOCS). Most of the pollutants in this group are directly or indirectly created as a result of anthropogenic activities, or present in small amounts in buried sediment or deposits. Furthermore, these contaminants 'persist' and are difficult to breakdown naturally, as natural enzymes are not available and, as a result, highly expensive and invasive techniques are required to promote mineralization. Numerous reports have identified the presence of many organic 
micropollutants in urban drainage systems (Hvitved-Jacobsen et al., 2012). In particular, a study by Eriksson et al. (2005) showed that stormwater runoff has a potential to facilitate the transfer of over 600 micropollutants. The sheer number of potential pollutants with runoff makes testing quite difficult and, as a result, selected substances can be used as indicator compounds for entire groups of chemicals. According to Hvitved-Jacobsen et al. (2010) two bulk parameters can used to test for screening purposes; AOX (adsorbable organo-halogen compounds) and EOX (extractable organo-halogen compounds). The ability to identify halogenated compounds is quite important as the presence of a halogen atom not only signifies a potential micropollutant, but also points the need for a more complex remediation process. In particular, halogenated compounds often require high-intensity incineration with a treatment of off-gases to entirely destroy the substance (Hvitved-Jacobsen et al., 2012).

\subsubsection{Persistent Pollutants}

The design of SWM ponds can effectively remove TSS, phosphorus and suspended solids, but their structure do not promote the removal of XOCs, which are also known as persistent pollutants. Persistent pollutants can undergo a series of chemical and biological processes, such as photooxidation, biodegradation, biotransformation and hydrolysis, which can result in their transformations to other compounds and increase toxicity (CCME, 1999). The larger concern is their propensity to undergo physical processes such as adsorption, desorption, solubilisation, volatilization and bioaccumulations, which are subsequently responsible for the cycling of these contaminants throughout aquatic environments and result in their persistence (CCME, 1999). In particular, their propensity to be persistent, bioavailable and cause acute and long-term health effects to aquatic biota, organisms and humans requires discourse on potential redesign of stormwater management measures and ways of controlling source inputs. Given that SWM ponds are often within close proximity to urban and suburban areas and industrial complexes, the potential presence of organic micropollutants within receiving waters will increase risks to ecological receptors and human health, which is a growing concern.

Federal and Provincial governments have become quite aware of the issue, as Ontario has recently banned the use of pesticides. However, carcinogenic pesticides such as DDD and DDE have been identified in numerous SWM Ponds located in Arizona in a 2000 study (Parker et al.), even after their ban in the 1980s (Weinstein, 2008). A main factor could be attributed to their long half-life and 
historic use in agricultural fields, which may become an issue in the Greater Toronto Area (GTA) as urban sprawl encroaches on farm habitats. However, certain pollutants, such as polycyclic aromatic hydrocarbons (PAHs) are quite prevalent in SWM Ponds in North America (Weinstein, 2008; Weinstein, 2010; Crane, 2014) and were identified in the LSRCA's Toxic Pollutant Screening Program as the most common pollutant in Lake Simcoe tributaries and stormwater runoff (LSRCA, 2011). Furthermore, PAHs propensity to be relatively non-volatile and poorly soluble will promote their presence within bottom sediments of SWM Ponds and initiate physical processes that will inherently affect aquatic and biotic communities. In a study by Marsalek et al. (2002), sediment sampled within a SWM pond in a commercial Canadian centre was contaminated with PAHs and heavy metals, which were not suitable for beneficial reuse, were found to be toxic and required immediate disposal (Marsalek et al., 2002). Sediments are the most important exposure route for many aquatic and benthic species and can be acutely toxic or carcinogenic depending on the molecular structure of the compound, with PAHs as a direct example (CCME, 1999). As a result, a thorough understanding of the physical and chemical properties and chemical and biological pathways of persistent pollutants is required to direct clean-up measures.

The United States Environmental Protection Agency (USEPA )has divided and categorized XOCs into eight distinct groups (FRTR, 1999):

\section{Nonhalogenated VOCs}

A nonhalogenated pollutant is a contaminants that does not contain a halogen atom, such as fluorine, bromine or chlorine. Generally, nonhalogenated compounds have been found to be toxic and carcinogenic to humans, but the lack of a halogen makes these compounds more susceptible to bioremediation practices (FRTR, 1999). Common pollutants include: methyl ethyl ketone (MEK), carbon disulfide and tetrahydrofuran.

\section{Halogenated VOCs}

As opposed to nonhalogenated VOCs, halogenated compounds are less affected by bioremediation methods. Furthermore, any remedial method would need to account for off-gas treatment and scrubber water treatment to account for the halogen atom (FRTR, 1999). Common pollutants include all chlorinated compounds (vinyl chloride, 1,2dichloroethane, hexachloroethane) and ethyl dibromide (EAUK, 2003). 


\section{Nonhalogenated SVOCs}

The two most common nonhalogenated SVOCs (semi-volatile) are polycyclic aromatic hydrocarbons (PAHs) and pesticides. PAHs are hydrocarbons that are composed of carbon and hydrogen. They are often found in fossil fuels and are produced following incomplete combustion of organic matter. With regards to remediation, the complete mineralization of PAH is quite slow and metabolites may be toxic, as well. Pesticides can include a large range of chemicals including insecticides, fungicides and herbicides.

\section{Halogenated SVOCs}

The most common halogenated SVOCs are polychlorinated biphenyl (PCBs), which contain 209 congeners (Gomes et al., 2014). They were originally used in Aroclor mixtures but have been found sorbed to soil particles due their mobility in air and water (EAUK, 2003). Pentochlorophenols (PCPs) have been found in wood-preserving sites, due to their reluctance to decompose at boiling points. This inert and volatile compound is quite soluble in water, which can increase mobility in various mediums (FRTP, 1999). In addition, specific types of pesticides can also be classified as halogenated SVOCs, such as DDT.

\section{Fuels}

Most fuels share characteristics with nonhalogenated SVOCs (FRTP, 1999). Here, LNAPLs (light non-aqueous phase liquids) are distinguished from DNAPL (dense non-aqueous phase liquids) and NAPL due to their densities; LNAPLs are lighter than water, while NAPLs are heavier (EAUK, 2003). As a result, LNAPLs will migrate vertically once a spill has occurred and will rest on the top layer of the water table. Furthermore, they are quite volatile when exposed to upper soil surfaces and will partition to the air phase (ITRC, 2009). The most common LNAPLs are collectively known as BTEX (benzene, toluene, ethylbenzene and xylene).

\section{Inorganics}

See heavy metals above.

\section{Radionuclides}

Radionuclides are quite similar to heavy metals, but are radioactive in nature. Many radionuclides are quite volatile and will require off-gas treatment at extreme temperatures. 
It is important to note that radionuclides cannot be completely destroyed, only separated from the medium they are bound to, stabilization or volume reduction (FRTP, 1999).

\section{Explosives}

Generally not applicable to urban drainage, explosives refer to propellants (nitroglycerine), explosives (i.e. TNT) and pyrotechnics (PEP). The issue is that soils inundated with explosive material can be susceptible to further initiation by heat or shock (FRTP, 1999).

\subsection{Removal Standards and Implications}

Stormwater ponds' incapacity to remove all pollutants highlights the need to address the effect of stormwater management on receiving water, but also to address the issue of an increase of contaminants within road runoff and ultimately within the bed of sediment ponds. SWM ponds are reliant on a large enough storage volume to allow suspended sediment, often sorbed to many contaminants, to fall out of suspension and settle along the bed. However, the more efficient the pond, the more sediment will accumulate along the bed, which ultimately reduces the storage volume available within the pond (Graham and Lei, 2000). As a result, the maintenance of ponds and, in particular, the periodic removal of sediment is imperative to the continued performance of the ponds. Under Section 53 of the Ontario Water Resources Act, owners of stormwater ponds are required to ensure the removal of sediment to prevent and mitigate potential downstream impacts within receiving waters. According to the Stormwater Management Planning and Design Manual (MOE, 2003), a 5\% reduction in the annual sediment removal efficiency from the Ontario provincial standard ( $80 \%$ removal) are grounds to dredge the bed and remove the accumulated sediment. For example, if ponds are designed to remove $80 \%$ of sediment, a reduction to $75 \%$ removal efficiency 'should' lead to dredging (Drake and Guo, 2008). Furthermore, if an increase in storage (i.e. larger permanent pool) resulted in a removal efficiency of $90 \%$, a reduction of $15 \%$ would be required before sediment removal is recommended. The issue here is that accurately forecasting sediment accumulation is quite difficult, in addition to monitoring continued pond performance not being practically feadible. Ponds are subject to conditions within their own individual catchments; they are affected by level of surrounding imperviousness, climatic conditions, such as rainfall, and drainage area characteristics (Graham and Lei, 2000). In theory, MOE guidelines ponds are designed to have an operational life cycle of 5-15 years, however, the inherent life cycle range leaves much to be answered during the forecasting process. 


\subsection{Sediments}

\subsection{Sediment Properties}

Sediment physical properties can generally be described using two properties: bulk density and grain size distribution. Bulk density will generally describe the degree of sediment consolidation, which directly translates to the mass of sediment and water in a given volume of bed material. The bed of a river channel can be composed of many types of particles, but SWM ponds are quite predictable in composition. In a majority of ponds, beds will be laden with primarily silt and clay; however that can be altered given specific catchment and sub-catchment characteristics (Butler and Davies, 2010). According to literature, the density of sediment is approximately $2.65 \mathrm{~g} / \mathrm{cm}^{3}$, which is due to quartz and clay particles that make up a majority of their composition (Hvitved-Jacobsen et al., 2012). Particle size distribution is also important to mention, as it is used to describe the arrangement of particles within the bed. Sediment sizes are determined from a grain size scale which consists of range from very fine clay $(0.24 \mu \mathrm{m})$ to large boulders, which are larger than $0.5 \mathrm{~m}$ in diameter (Hvitved-Jacobsen et al., 2012). With respect to SWM ponds, the ranges of particle sizes are generally between clays and fine gravel. Furthermore, when a particle size is determined, sediment can further be classified as being cohesive or non-cohesive (Butler and Davies, 2010). Cohesive sediments carry a large attraction to each other due to inter-particle forces and can be up to $200 \mu \mathrm{m}$ in diameter. Conversely, non-cohesive particles lie within the range of fine to medium sand are larger than $200 \mu \mathrm{m}$ in diameter (Hvitved-Jacobsen et al., 2012). Studies have shown that contaminants are closely linked and associated with finer, cohesive particles and, with SWM ponds consisting of primarily clay and silts, they can become sinks for various aqueous phase pollutants (Hvitved-Jacobsen et al., 2012; Landrum and Robbins, 1990; Axtmann and Luoma, 1991)).

The adherence of pollutants to sediments is an important phenomenon in urban drainage. Adsorption is the mechanism that binds chemical substances from a liquid or gas phase to a solid particle or interface. Furthermore, given the aggregation of small particles, or colloids, within SWM ponds, pollutants have a large likelihood of binding to inorganic clay particles and organic humic substances (Hvitved-Jacobsen et al., 2012). Colloidal substances have a large specific surface area and a high affinity for soluble species, which improves binding and subsequent transport capacity. The neutral $\mathrm{pH}$ of most water systems promote conditions where hydroxyl particles and acidic substances will cause the transfer of protons and an ensuing negatively charged colloid (Hvitved-Jacobsen et al., 2012). This 
colloidal surface is prime for contact with cations, which form heavy metals. Under normal conditions, colloidal groups and aggregates are required to increase potential binding surfaces for organic and inorganic pollutants, as turbulent flow can decrease binding capacity. However, the relatively tranquil conditions of SWM ponds provide stable conditions for sediments and individual colloids to attract a relatively high amount of pollutants, such as heavy metals, nutrients or organic micropollutants (Hvitved-Jacobsen et al., 2012). In addition, the amount of dissolved oxygen can also play a significant role in the binding capacity of certain contaminants. Phosphorus, for example, generally has a strong affinity for iron, which results in an incorporation within stormwater sediments. Under hypoxic or anoxic conditions, iron levels are reduced and phosphorus is subsequently released into the water column and becomes a source of loading for the pond and receiving waters (LSRCA, 2011). In Ontario's SWM pond design guidelines, a maximum depth of 2.5-3 m is prescribed; however, LSCRA has reported hypoxia in SWM ponds with a depth of less than 2 m (LSRCA, 2011). Consequently, an increase of air temperature associated with climate change will inherently promote low oxygen conditions and potentially make SWM ponds a source of nutrients, instead of nutrient sinks.

The particle size distribution of sediments in stormwater runoff will directly affect the rate of accumulation within stormwater ponds and potential resuspension following maintenance operations. Generally, stormwater runoff contains sediments which vary from colloids (1-1000 nm) to fine sand (62.5-125 $\mu \mathrm{m}$ ). As SWM ponds are end-of-pipe SWM solutions and at lower elevations, geomorphic sorting will promote the settling of smaller particles within such ponds. Sediment particle size distribution within SWM ponds will largely depend upon native soils within the vicinity of the ponds and land-use patterns of the catchment area. In particular, a study submitted to the TRCA and DFO stated that $80 \%$ of sediments, within a series of residential SWM ponds north of Toronto, were smaller than 75 $\mu \mathrm{m}$, which are within the very fine sand range according to the Wentworth classification (Clarifica, 2003). However, particle size distribution will invariably fluctuate due to sorting within the pond itself. For example, a sediment mass entering a SWM pond through an inlet would generally be expected to contain high percentage ( $>50 \%)$ of particles in the silt range $(4-62.5 \mu \mathrm{m})$. The composition of sediment exiting the outlet, though, will primarily contain clays and colloids, as a large proportion of the silt and fine sand in the bulk would have 'settled' prior to discharge from the SWM pond. In addition to particle size distribution, the settling velocity of a particle will directly affect bed accumulation rates, TSS and potential resuspension of SWM pond bed material following dredging activities. The settling velocity of a particle is primarily based on Stokes' Law and given that SWM ponds will typically contain particles $<100$ $\mu \mathrm{m}$, the following settling velocities can be utilized for SWM pond sediments: fine sands (62.5-125 $\mu \mathrm{m})$ 
are expected to settle at $\sim 1.82 \mathrm{~m} / \mathrm{hr}$; coarse silts $(31-62.5 \mu \mathrm{m})$ at $0.427 \mathrm{~m} / \mathrm{hr}$; fine silts $(8-16 \mu \mathrm{m})$ at $0.031 \mathrm{~m} / \mathrm{hr}$; and clays $(<4 \mu \mathrm{m})$ at $0.17 \mathrm{~m} / \mathrm{h})$ (Clarifica, 2003; Schueler and Lugbill 1990).

\subsection{Sediment Accumulation}

According the Graham and Lei (2000), forecasting maintenance operations within SWM ponds requires knowledge of the total storage volume within the SWM pond and, specifically, the minimum volume needed to satisfy the removal guidelines. These two parameters can often be obtained from original design drawings, although the experience has shown instances of significant discrepancies between the design and as-built facilities, or the volume calculated from existing drawdown times (GIC, 1999). The third piece of information, the rate of sediment accumulation, is the most difficult to obtain and predict. It has been noted that operators of SWM ponds in Ontario have a certain level of liberty with regards to clean-out. According to Marsalek et al. (2008) clean-out is required when the SWM pond TSS removal efficiency is reduced by $5 \%$ (MOE, 2003) or when the design storage volume has been reduced by $10 \%$ (Yousef et al., 1994). A scenario was developed within the same report to highlight a sediment removal action trigger, in which the curves of storage volume (V) were compared against TSS removal $(R)$ for three different imperviousness scenarios (i), and could be described as $V=f\left(R_{d}\right)$ (Figure 5). Furthermore, a reduction of TSS removal by $5 \%$ was assumed and the corresponding reduction in storage volume was expressed as:

$$
\Delta \mathrm{V}=100 \cdot\left[f\left(\mathrm{R}_{\mathrm{d}}-f\left(0.95 \mathrm{R}_{\mathrm{d}}\right)\right] / f\left(\mathrm{R}_{\mathrm{d}}\right)\right.
$$

and plotted vs. TSS removal, as shown in Figure 5. The figure describes scenarios where either a reduction in pond efficiency or design storage would lead to sediment removal (i.e. $\Delta R=5 \%, \Delta V=10 \%$ ). The figure can be utilized for maintaining ' $R$ ' at $>95 \%$, while $\Delta V$ can be concluded from monitoring programs within each municipality (Marsalek et al., 2008). 


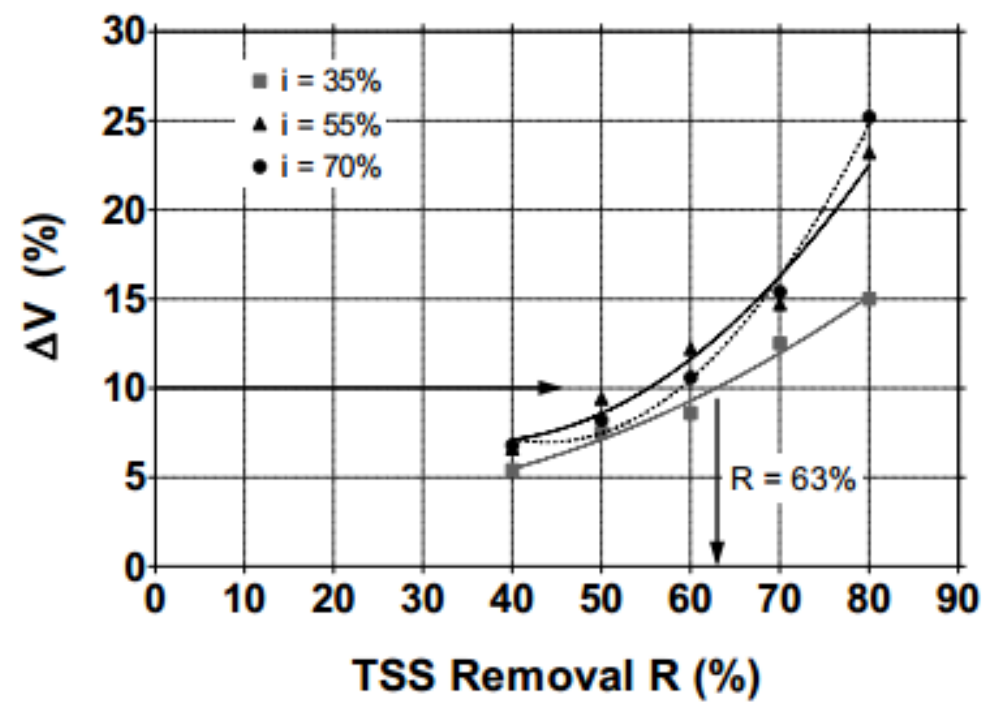

Figure 5: Pond volume reduction for a 5\% reduction in TSS removal (Marsalek et al., 2008)

Annual sediment accumulation ranges of $0.2-5.8 \mathrm{~m}^{3} /$ ha/year have been reported by Greenland International Inc. (1999) and, using data from a SWM pond in Richmond Hill, a sediment accumulation model reported a value of $4.52 \mathrm{~m}^{3} / \mathrm{ha} /$ year (Richard, 2012). However, recent field data in Aurora, ON show a much higher rate of $0.4-36.2 \mathrm{~m}^{3} /$ ha/year, which presents a need to prioritize SWM pond cleanouts in watersheds that contain the highest sediment accumulation rates (LSRCA, 2010). With regards to real-time forecasting, current practices involve sampling either on an annual or a multi-year basis, with accumulation rates extrapolated from on-site surveys. Conversely, simulated sediment forecasting has become quite prominent within the field; however, succinct model development may be difficult (GIC, 1999). In addition, studies have shown that proper sediment accumulation model development requires historical annual rainfall, including intensity, duration and inter-event time of rainfall events (Richard, 2013; Yousef, 1996; Yousef, 1994). This element points to sediment accumulation forecasting being site-specific in nature and largely dependent on catchment and sub-catchment characteristics, such as hydrology and relative imperviousness. A recent study aimed to assess stormwater sediment loading rates of a 2.2 ha SWM pond within the City of Hamilton (Gregory, 2014). In the analysis, the pond exhibited a removal efficiency of $88 \%$, which falls within the design guidelines for enhanced water quality protection. Furthermore, the average sediment volume of $47 \mathrm{~m}^{3}$ corresponded to a sediment accumulation rate of $1.3 \mathrm{~m}^{3} /$ ha/year for the time period between April-October (Gregory, 2014). For the winter time period, simulated computations estimated an accumulation rate of $2.6 \mathrm{~m}^{3} /$ ha/year, which 
equates to a total sediment volume of approximately $3-4 \%$ of the permanent pool (Gregory, 2014). The aforementioned simulated studies fall within the originally reported range of $0.2-5.8 \mathrm{~m}^{3} / \mathrm{ha} / \mathrm{year}$, but more frequent, long-term monitoring that includes hydrological processes (e.g. precipitation, snowfall, snowmelt, etc.) and drainage area activities (e.g. construction, street sweeping, road maintenance, catchbasin cleaning, etc.) should be undertaken to develop detailed estimates.

\subsection{Sediment Quantity Sampling and Monitoring}

There are a series of sediment accumulation and monitoring techniques available to consultants and contractors when sediment sampling is required. The most common technique can be completed with a boat and a staff. This simple method is accomplished rowing around the pond, while measuring the depth to the sediment layer at pre-defined points, using the original known design volume elevation as a datum. Even though this method is considered a standard technique, its success depends upon the skill of the operators, as attaining an accurate sedimentation depth can be quite difficult. As a result, a series of measurements along transects are often employed to identify increased build-up within specific bed locations and to acquire an average sedimentation depth within the entire permanent pool (GCl, 1999). Another common sediment monitoring technique is the use of a dipstick or rod, which has been utilized in monitoring sedimentation in stormwater ponds and wastewater sludge ponds. In this method, the disc and rod are lowered to the bed to settle on top of the sediment layer, whereby the water depth is recorded. Subsequently, the rod is lowered into the loose sediment until it meets the native soil (NTA, 2010). It may be difficult to access all parts of the pond using this method and the operator often would require a boat or the ability to enter the stormwater pond. In addition, successful measurements require an initial permanent pool depth and care needs to be taken not to compact the sediment layer once the disc is initially lowered ( $\mathrm{GCl}, 1999)$. Nonetheless, both methods are classic depth measurement techniques; however, increased accuracy and detail may be required to determine depths for potential dredging volumes with reduced uncertainty.

Recently, additional methods have been developed to assess sediment accumulation within SWM ponds. The company Endress \& Hauser in Christchurch, New Zealand has created two devices to cope with needs to measure depths for solids and liquids (NTA, 2010). First, there is a guided radar level, which can continuously measure water levels or granular bulk solids. This device can be used within natural and synthetic environments and has not been reported to be clogged by dust, which allows for deployment in online SWM ponds currently on active construction sites (NTA, 2010). The second device 
developed by Endress \& Hauser is the ultrasonic level, which is a continuous non-contact level that can measure fluids, sludge and fine to coarse bulk materials. This sensor can be used to monitor SWM ponds remotely and can subsequently be used within open channels and weirs. Another quite common sediment sampling method is the stick/gum spear option, which consists of a probe that is pressed into the sediment at various locations within a SWM pond (NTA, 2010). The depth of sediment is determined by measuring the known permanent pool elevation to the top of sediment or from the known design base elevation to the top of the sediment. Furthermore, bathymetry can be utilized to attain a quite detailed bed survey using total stations with Global Positioning System (GPS) technology (GCI, 1999). Among common methods, bathymetric surveys are the most accurate; however, they can be expensive and are often sub-contracted to third party engineering firms. Given the depth of sedimentation in some GTA SWM ponds, it is not recommended to enter the pond without some knowledge regarding potential substrate type and possible depth.

There are additional techniques that have yet to be used in mainstream sedimentation monitoring with promising capacity. Using a Canadian example, Markland Specialty Engineering LTD has developed a device called a Manual Blanket Level Detector (MBLD), which can detect sediment levels using a probe sensor and the end of cable (NTA, 2010). The cable is lowered until it reaches the sludge or sediment bed, where it sets a datum and allows the user to read the depths on the cable as it is continuously lowered. The MBLD has an accuracy of $2 \mathrm{~cm}$ with a maximum sampling depth of $2.4 \mathrm{~m}$. In addition, the Liquid Sediment Detection Pole can be used the same way as the MBLD. Nonetheless, the method is quite useful as it does not require the operator to collect core samples. Depending on the size of the SWM pond, GPS or Ecosounders could be utilized (NTA, 2010). Sediment surveys have been carried out using GPS systems in India, where the water depth and position of the boat are measured and then subsequent measurements can be compared within the same location. Generally, annual bathymetric surveys are required for long-term monitoring projects $(\mathrm{GCl}, 1999)$. Conversely, Ecosounders create a density map of the bed using sensors that identify sediment layers. This can be quite expensive and should only be utilized for very large ponds and or reservoirs.

Currently, there are no general accepted practices with regards to SWM pond monitoring. Furthermore, there no standard practices which assess the efficiency of the SWM pond and sediment accumulation. It has been noted by Drake and Guo (2008) that monitoring programs would need to assess accumulation of sediment, water quality and hydraulic functioning. Richmond Hill, Ontario has employed these principles into their own SWM pond monitoring and inspection program, which has been in use from 2000 (Drake and Gu0, 2008). This program has allowed Richmond Hill to assess the 
performance of each one of their ponds and the ability to ultimately predict accumulation and eventual clean-out. The development of programs have been slow to come to fruition as many municipalities do not have accurate counts of SWM ponds, as bodies of water exist that initially aided in flood control but that predate the Ontario stormwater pond design standards of 2003 (MOE, 2003).

In addition, it is important to note that monitoring programs are the responsibility of contractors and land developers prior to the assumption of the pond. Until stabilization of the site, the SWM pond design, operation and maintenance lies with the builder. Construction practices have been shown to introduce large amounts of sediments within stormwater ponds in a short amount of time and many municipalities do not require developers to perform one final clean-out prior to site occupancy (Drake and Guo, 2008). However, there have been some in-roads into ponds located within construction development: Mississauga mandates a clean-out unless bathymetric surveys exhibit an acceptable level of accumulation; and Waterloo requires a 2 -year monitoring period by developers following a $90 \%$ buildout of the drainage area (Drake and Guo, 2008).

\subsection{Sediment Quality Sampling}

To dissuade from conventional in-situ sampling (i.e. grab samples), remote sensing and radiometric sedimentology have been developed to determine sediment origin and sediment composition ex-situ (Eekelma, 2008). Remote sensing operates by using radar, which transmits microwave energy to a certain location and then backscattered to the receiver once again (Schott, 2007). Remote sensors can be mounted on to satellites or aircraft and can be active or passive by design. Passive sensors record radiation reflected by the Earth's surface and can only be used during daylight hours, while active sensors utilize a laser beam and measure the time taken to reflect back to the receiver (Schott, 2007). With regards to sediment analysis, remote sensing has been used to identify bed roughness and has led to the use of radiometric sedimentology, which has been used to identify origins of sand deposits and particularly accretion rates of tidal flats. In a study by Gouleau et al. (2000), long-term sedimentation rates were able to be determined from measuring the relative half-lives of isotopes within buried sediments.

A recently developed method has utilized measuring the concentrations of radionuclides as a proxy for contaminant concentrations (Van der Graaf et al., 2007). Current methods call for simple dredging or sediment grab sample collection, followed by geochemical analyses. However, concentrations of radionuclides in sediment, such as caesium, potassium, thorium and uranium are 
strongly correlated to the distribution of heavy metals and organic pollutants, which would allow for the indirect measurement of a wide range of contaminants including PAHs and PCBs, as well (Van der Graaf et al., 2007). Dutch researchers have developed the Multi-Detector System for Underwater Sediments (MEDUSA), which operates by measuring gamma-rays emitted by decaying radio-active isotopes bound on sediment particles (Eekelma, 2008). The most common gamma-ray emitting nucleotides in the natural environment are ${ }^{238} \mathrm{U},{ }^{232} \mathrm{Th}$ and ${ }^{40} \mathrm{~K}$ and are generally utilized due to exhibiting half-lives equivalent to the earth's existence (Van Wijngaarden et al., 2002). As a result, these radionuclides become great indicators for sediment properties. The system works by dragging a metallic tube, which houses the gamma-ray detector, behind a boat and can subsequently sample a few thousand locations along the bed every hour of operation (Van Wijngaarden et al., 2002). Van der Graaf et al. (2007) reported the system requires 1-10 seconds to accumulate enough data to discern between the various radionuclides in the bed and gamma ray attenuation can successfully map the pollution within the top $30-50 \mathrm{~cm}$ of the bed. In another study, De Groot et al. (2002) used the system PANDORA to investigate sediment characteristics in salt marshes and sediment transport characteristics. Sediment quality sampling utilizing gamma radiation and radionuclides offers another alternative to quality testing in-situ.

\subsection{Sediment Removal}

\subsection{Physical Removal}

The removal of sediment from SWM ponds often occurs in the form of dredging, which can be defined as the physical, mechanical movement of sediment from the bed of a pond or along its banks. There are three common approaches used to dredge material from riparian environments; mechanical, hydraulic, and recently, hydrodynamic dredging.

\subsubsection{Mechanical Dredging}

Under most conditions, mechanical dredging is utilized in small rivers and wetlands where an area can be dewatered and emptied and the bed material is allowed to dry (USEPA, 2009) (Figure 6). However, mechanical dredging can either be done in wet or dry conditions, with the intention to expose the bed material to dry or frozen conditions (WMI, 1997). Conventional earthmoving equipment such as bulldozers, backhoes and scraper are used to remove the sediment and they can either be operated 
from the shore or on the dry bed. Once the sediment is removed, it is then either stockpiled onsite for future removal, or directly deposited for transportation to landfill and hazardous landfill sites (Bray, 1997). Conversely, wet mechanical dredging can occur without drawdown or dewatering and the sediment removal ensues from a floating barge. Ultimately, mechanical dredging is used for small-scale projects, such as dredging bays, lakes, sediment ponds and shorelines (USEPA, 2009). As a result, it is less expensive than hydraulic dredging; however, it is ineffective in the removal of saturated bed material and can disrupt the biological function of the riparian environment with associated drawdown.

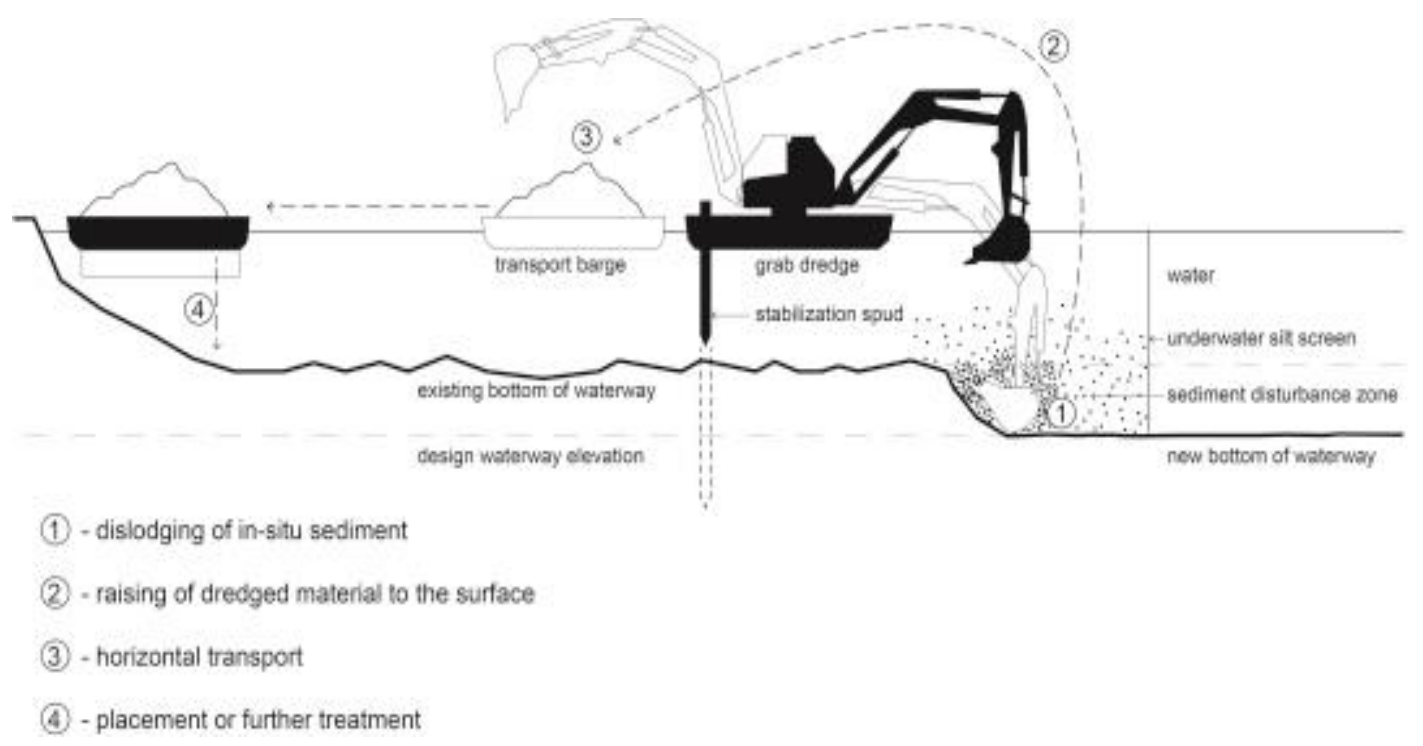

Figure 6: Mechanical dredging landscape (Davis, 2014)

\subsubsection{Hydraulic Dredging}

Hydraulic dredging utilizes a centrifugal pump to suction material on the bed of water bodies and discharges the material on land using a type of conveyance system (USEPA, 2009). The dredging machinery is incorporated onto a floating hull, where drawdown and dewatering of the water body is not required (Figure 7). Generally, a cutter with steel blades will dislodge the bed material and centrifugal pump on the barge will pump the material to the surface (Bray, 1997). Subsequently, the resuspended material is removed through hydraulic suction or the use of draglines from barges in large ponds (NRC, 2007). In particular, two types of hydraulic dredges are utilized: horizontal auger and cutterhead dredges (Pennekamp et. al, 1996). A horizontal auger dredge utilizes a rotating auger to loosen sediments, whereby less water is removed from the waterbody. These types of dredges can 
remove large amounts of silt, but are limited to a depth of $8 \mathrm{~m}$ and 50 cubic metres of silt per hour (Pennekamp et al., 1996). Conversely, a cutterhead drill uses a rotating basket with blades to dislodge bed sediment. In this configuration, there is a greater control of cutting depth, the ability to remove vegetation, and higher production rates of sediment (Blazquez et al., 2001). Due to the removal of large volumes of water (with the sediment), hydraulic dredging requires a stable volume of water beneath the barge to keep operations afloat; the slurry removed typically has a ratio of water to solids from 10:1 3:1 (NRC, 2007). Following the dredging and collection of bed sediment, the particulate must be assessed for moisture content prior to potential dewatering.

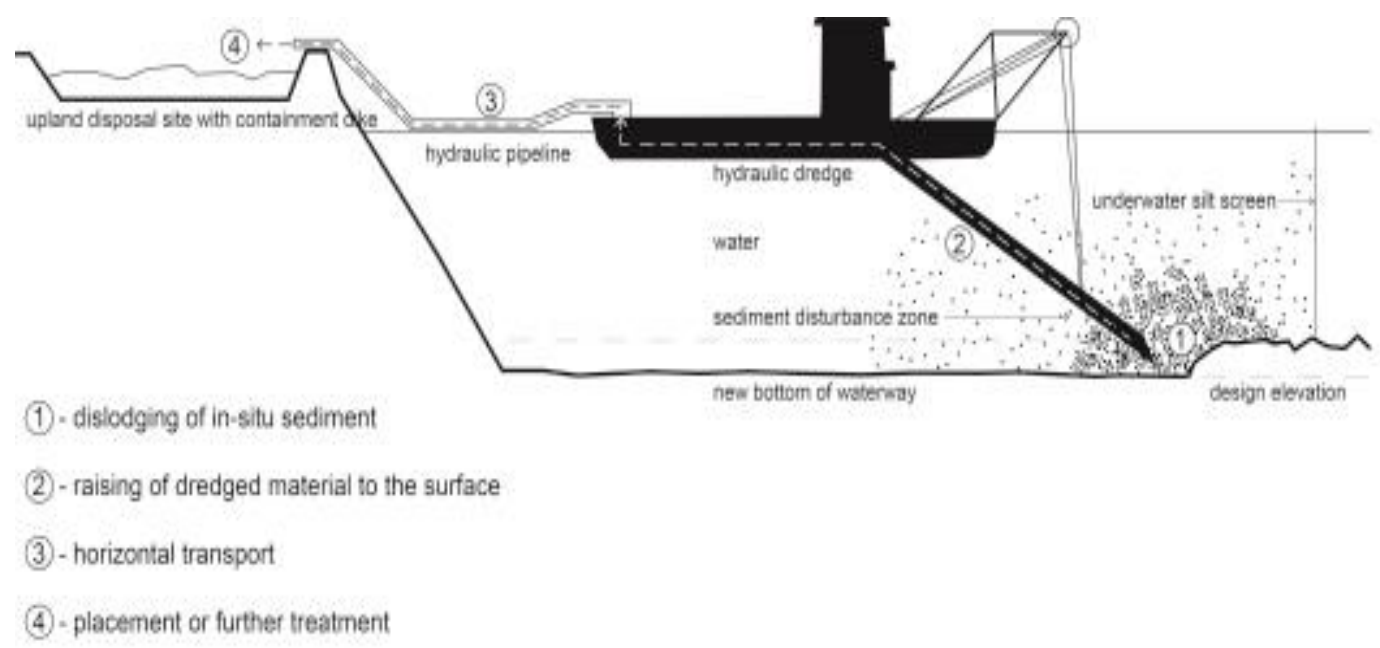

Figure 7: Hydraulic dredging landscape (Davis, 2014)

\subsubsection{Hydrodynamic Dredging}

Hydrodynamic dredging, sometimes referred to as silt suspension, is a method where bed material is placed into suspension in the water column, without the physical removal of the material from the water body (USEPA, 2009). In this method, high powered jets of water are pumped into the bed in the hopes of re-suspending settled material and, once in suspension, the flow of water downstream is expected to move the dredged material from the site. This type of dredging can also be accomplished by dragging a heavy fixed device along the river bed to displace the armouring layer of sediments (USEPA, 2009). Hydrodynamic dredging is quite efficient with regards to the removal of 
sediment, however, if the sediment is deemed contaminated, the disposal methods are limited. If the sediment is conditioned for removal off-site, Toxic Contaminant Leachate Procedures (TCLP) are undertaken to determine whether the material should be considered hazardous waste, due to the inherent concentrations of pollutants (Bray, 2009). Depending on the results, the sediment can be sent to a landfill or hazardous waste landfill.

\subsection{Post-Dredging and Incineration}

Although measures are taken to limit the mobilization of previously stable contaminated material, sediment beds disturbed during dredging operations can negatively affect the water quality and organisms within riparian habitats (Baron et al., 2005). Initially, there is an immediate risk to operators of the machinery and nearby communities through the volatilization of previously stable contaminants within sediment. Subsequently, safety measures must be undertaken to handle the contaminated sediment once water columns are disturbed until final disposal at regulated hazardous waste facilities (Baron et al., 2005). In addition, benthic communities are often destroyed during dredging, which can cause ecological imbalance, and the removal of sediment will eradicate in-situ ecological habitats. However, the most pressing issue is the inherent contaminant transport following agitation of the stormwater pond bed, which can deposit sediment and introduce contaminants in downstream environments. Nevertheless, SWM ponds designed with bypass channels could be utilized to limit concerns related to resuspension of sediments and residuals. Although off-line channels are not as prevalent as on-line channels, their implementation could support and provide sustainable solutions for issues encountered during dredging operations.

Most chemical treatment processes are quite expensive and costs have been known to exceed $\$ 1000 / \mathrm{m}^{3}$ (Magar, 2003). Furthermore, dewatering and particle-size separation can be employed the reduce the volume of materials that require treatment or disposal; however, these processes are undertaken in confined disposal facilities and landfills, which are limited in number and carry an increased risk of exposure and accidents during handling (Murphy, 1999). As a result, incineration is often employed prior to final disposal, but comes with its own issues. Even though it is the most conventional treatment option contaminated sediment deemed hazardous following initial dredging, it is the most expensive remedial option, with costs exceeding $\$ 1000$ per tonne (EC, 2002b). To achieve necessary destruction and removal efficiencies, incinerator temperatures generally must be greater than $400{ }^{\circ} \mathrm{C}$ and long residence times may be required (Murphy, 1999). Furthermore, air discharge and other 
permits also may be required depending on the location and type of waste in addition to potentially expensive off-gas treatment requirements. With incineration comes the possibility for the creation of dioxins and furans, which can be deposited throughout the surrounding area. Although not utilized in residential and commercial SWM ponds, the presence of dioxins within industrial SWM pond bed samples, coupled with incineration, could further exacerbate contamination issues.

\subsection{Traditional Handling Practices and Management}

Recently, specific procedures have been developed to address dredged sediment from SWM ponds. The first example is centralized treatment, which results in containment of the sediment on site in a temporary storage area prior to release to a sanitary sewer. The release of sediment will coincide with dry, low flow conditions and promote flow equalization through timed release (USEPA, 1999). Care must be taken when selecting this method, as large influxes of sediment and associated contaminants can enter and clog sewer systems, with a high potential for additional pumping and clean-up costs, as well as potential upset of wastewater treatment processes. Another practice utilizes the handling of sediment and storm water solids at satellite treatment facilities, which take into account the high solids content and varying water quality of stormwater runoff (USEPA, 1999). Due its varying flow and low organic content, it may be beneficial to treat stormwater sediment using specific ex-situ remedial options to decontaminate the bulk. A third option is to employ onsite and in-situ methods to treat stormwater sediment. In particular, this method would reduce transportation and landfill costs; however, removal of residuals and lowering of the water content would be required prior to treatment. If other options have been exhausted, disposal at either a hazardous or non-hazardous landfill can be utilized to deposit the sediment. The remedial and disposal options are discussed in detail later in the document, but below are examples of handling processes utilized in the United States.

The State of Maryland has employed a series of methods to handle their stormwater sediments. Since the 1990s, counties within the Baltimore area have used oil and grit and separators to remove stormwater sediment from runoff and subsequently treated at offsite facilities. In addition, Prince George County in Maryland has utilized dredged material from SWM ponds for construction-specific uses (USEPA, 1999). Other counties, such as Montgomery County, have updated management guidance which requires operators to remove sediment once storage capacity reaches $30 \%$ (USEPA, 1999). In general, Maryland requires SWM pond inspection every three years and allows disposal of dredged material on site if non-hazardous. In particle, since the late 1990s, it has become common practice in 
Maryland to use dredged stormwater sediments as a soil amendment (USEPA, 1999). Other examples include the State of Delaware, which have a set of operation and maintenance guidance documents, and the State of Florida, which recommends testing all dredged sediment for hazardous exceedances prior to disposal (USEPA, 1999).

\subsection{Challenges and Implications}

The dredging of soils and bed material is commonly used with projects related to land development and recently, remediation. When dredging to remove contaminated sediments, the resuspension of sediment can often release buried pollutants or merely allow the dredged contaminates to relocate downstream. With regards to contaminated sediment, dredging is the most common method used, which is followed by treatment of the bed sediment and subsequent land filling (NRC, 2007). Within small water bodies, such as SWM ponds, any type of dredging would have to be employed in shallow water with limited equipment access and must be conducted in a slow, deliberate manner. In addition, once machinery is on site, controls such as silt screens and water surface covers would be required to limit the re-suspension of contaminated sediment and their potential volatilization (NRC, 2007).

Another issue facing potential dredging operations is the type of SWM pond encountered. Generally, SWM ponds are designed to be on-line or off-line. On-line ponds involve the construction of an embankment, which allows the stormwater management facility to control water from a specific subcatchment. This not only allows for the removal of pollutants but can also assist with flood control when higher flows are encountered (MPCA, 2000). Conversely, off-line ponds receive flow that is purposefully diverted to them and, consequently, flows that bypass these structures will receive little sediment or pollutant removal (MPCA, 2000). In addition, off-line ponds can also be useful in the reduction of peak-flows, as during high flows, a portion of the discharge can be diverted and bypasses into such storage areas. The issue is that, although off-line ponds will assist in the reduction of downstream erosion impacts, runoff from small events will constitute a majority of annual run-off volume and any contaminants within their flow will go untreated (MPCA, 2000). With regards to dredging, off-line pond sediment removal would greatly decrease impacts on downstream receiving waters, as the resuspension of previously buried material would be significantly minimized, with respect to on-line ponds. Conversely, precautions for on-line pond dredging would require care to limit resuspension and the presence of a bypass channel to divert all flows, which increases the cost of 
dredging.

It is likely that risks to human health and ecological receptors may increase due to increased exposure to contaminants re-suspended or released to the surface water. Following re-suspension, sediment particles may settle in the area being dredged or transported downstream into environments that the ponds are intended to protect. Estimates of re-suspension from environmental-related dredging projects range up to $10 \%$ of the mass of sediment dredged (Patmont, 2006). In addition, residuals are contaminated sediment that remains following dredging. The two types of sediment are generated residuals (contaminated sediment that is dislodged and later deposited) and undisturbed residuals, which have been uncovered but not removed (Palermo et al., 2006). There a series of reasons for the presence of residuals, including: incomplete characterization, inaccuracies, and mixing of targeted material. Often limited to the upper layer, residuals can be subject to physical consolidation and chemical processes including redox reactions (NRC, 2007). Recent estimates have indicated residuals ranging from 2-9\% of the total mass of the contaminant dredged (Patmont, 2006); however, further research is required. In 1995, Grasse River (Superfund Site) was tested for contamination pre and post dredging activities designed to remove PCB from bed sediments. Caged fish deployed along the perimeter of a set of 3 silt curtains for 6 weeks showed significant increases in PCB concentrations compared to those observed prior to dredging operations. In addition to the effects of releases within the general vicinity, re-suspended and released contaminants have a high possibility to be transported downstream from the site. In another study at the Fox River Deposit 56/57 dredging project, $2.2 \%$ of the mass of contaminants dredged were released downstream and collected (Magar, 2003).

\subsection{Policies and Regulations}

Dredging and remediation of SWM ponds in Ontario would require an adherence and compliance with an extensive list of federal statutes and provincial regulations. Prior to construction activities commencing, a series of necessary approvals and permits are obligatory to ensure the protection of environmental habitat, ecological receptors and human health. Failure to comply with environmental legislation, policies and regulations could result in various penalties including: shutdown of construction activities, increased legal costs, monetary fines, resignation of permits and potential imprisonment. For the purposes of this study, only legislation, policies and regulations relating to dredging and remediation has been described. With respect to stormwater management, regulations 
can be obtained from the local municipality and Conservation Authority (CA).

\subsection{Federal Dredging Legislation}

The following Acts apply to Canadian federal statutes requiring approval prior to dredging operations within SWM ponds.

\section{Canadian Environmental Assessment Act}

The Canadian Environmental Assessment Act (CEAA, 1992) requires stakeholders to undertake environmental assessments where the federal government is the proponent or the action is taken on federally-owned parcels (OMOE 2011). If a SWM pond is located within federally-owned lands, an environmental assessment would be required per the Act (GGHA, 2006). In particular, if a federal authority proposes the project, funds the project, grants interest in land to a project or exercises a regulatory duty (i.e. issuing a permit), an environmental assessment would also be required.

\section{Canadian Environmental Protection Act}

The Canadian Environmental Protection Act (CEPA, 1999) defines responsibilities for the management of pollutants and contaminants that may pose a threat to humans and the environment (OMOE, 2011). To assess the toxicity of a contaminant or sediment bulk, a Toxicity Characteristic Leaching Procedure (TCLP) test is performed by a registered laboratory (cited under Reg. 347 Schedule 4 in Ontario and US EPA Method 1311). Under this test method, sediments are assessed for their toxicity and deemed either non-hazardous or hazardous, Leachate Toxic, for disposal purposes. The purpose of the test is to determine the leaching capability of compounds found within a load of waste and subsequently utilizes acidic solutions to extract contaminants. If a SWM pond has exceeded pollutant guidelines during TCLP tests, the Act would potentially apply to subsequent dredging and disposal activities (OMOE, 2004).

\section{Fisheries Act}

The Fisheries Act (1985) governs the protection of fish habitat and any activities than can be potentially detrimental to fish habitat (OMOE, 2011). According to the Erosion and Sediment Control Guidelines, the Fisheries Act applies to all Canadian waters that either provide fish habitat or support fish habitat at any stage of life. Another section of the Act that directly applies to dredging activities is 
subsection 36(3), which prohibits the intentional or unintentional release of a deleterious substance. Under the Act, deleterious substance is any substance that degrades or alters the water quality to the detriment of the fish or fish habitat (GGHA, 2006). As a result, all dredging activities within SWM ponds, including potential contaminated sediment removal, would have to comply with both subsections (GGHA, 2006). The Act not only applies to both permanent and non-permanent water bodies, but also man-made structures or habitats that have the ability to provide spawning grounds, food supply or migratory routes.

\section{Navigable Waters Protection Act}

The Navigable Waters Protection Act (1985) is a federal statute that regulates all work that could potentially affect travelled waters. Generally, coastal and inland water with the ability to facilitate transportation and recreation are considered navigable under Canadian law (OMOE, 2011). Under the Handbook of dredging in Ontario, this Act is defined to include projects that involve the dumping of fill or the excavation of materials from the bed of navigable waters, as well as dredging or disposal operations (OMOE, 2011). SWM ponds could fall under the statute, but Transport Canada would have to review the project prior to granting approval (GGHA, 2006).

\section{Canada Water Act}

The Canada Water Act (1985) is a statute that regulates the conservation, development and utilization of water resources (OMOE, 2011). The second part of the Act does address water quality and pollution; however, this would only apply to SWM ponds if they are located on federally-owned land.

\subsection{Provincial Legislation (Ontario) With Reference to Dredging}

The following Acts require regulatory approval and compliance as per the Province of Ontario when undertaking dredging activities within SWM ponds.

\section{Ontario Water Resources Act}

The Ontario Water Resources Act (1990) is responsible for safeguarding the quality and quantity of surface waters and ground water in Ontario (OMOE, 2011). Under subsection 1(3), the Act prohibits the disposal and discharging of material within any watercourse or water body with the potential to degrade any water (GGHA, 2006). An impairment of water can refer to any of the following instances: a 
material that may interfere with the development or life of an organism that comes into contact with water or soil or sediment that may come into contact with water; or a material that can impair the appearance of water, along with its odour or taste. In addition, under S. 30-33, the Act requires an approval regime when addressing stormwater management issues (GGHA, 2006). Furthermore, certain dredging operations may require a Permit to Take Water under section 34 (GGHA, 2006).

\section{Public Lands Act}

The Public Lands Act (1990) regulates the management, sale and disposition of public lands. Under the Ontario Ministry of Natural Resources, this regulation concerns the development, construction and alteration of any public shorelands, including river and lake beds and floodplains, which may be considered as receiving waters (OMOE, 2011). Any dredging projects within such areas may be subject to a Work Permit.

\section{Conservation Authorities Act}

The Conservation Authorities Act (1990) regulates the management of all water, land and natural heritage sites within jurisdictional watersheds (OMOE, 2011). Through the powers within the Act, Conservation Authorities are involved in the technical review of all construction and developmental matters related to wetlands, floodplains and the alteration of watercourses (GGHA, 2006). Under Section 28, potential filling, construction of structures and the modification of watercourses must come into compliance, which will apply to the dredging of sediment from SWM ponds (OMOE, 2011). In particular, s. 28 (1), Development, Interference with Wetlands and Alterations to Shorelines and Watercourses Regulation, requires a permit from the local Conservation Authority when there is a potential alter the existing morphology of a water body, diverting a channel's flow or detrimentally affecting its water quality (GGHA, 2006).

\section{Beds of Navigable Waters Act}

The Beds of Navigable Waters Act (1990) regulates projects involving beds of navigable waters (OMOE, 2011). It has been noted that the Act restricts title to navigable water beds and ownership of lands may supersede Act requirements. Historically, the Act has rarely been applied to dredging operations (OMOE, 2011).

\section{Planning Act}


Wetland protection and management within land use planning is regulated by the Provincial Wetlands Policy Statement, under the Planning Act (1990)(OMOE, 2011). Furthermore, under this Act, municipalities are required to issue permits regarding all land-disturbing activities, stormwater management and erosion and sediment control (GGHA, 2006). Generally, the conditions for approval require the contractor to specify the predetermined percentage of cost to implement, maintenance throughout the entire process and eventual decommission, if applicable (GGHA, 2006). All dredging activities, especially those conducted within SWM ponds, must satisfy conditions under the Planning Act. In addition clearing and grubbing maintenance within SWM ponds may require compliance with the Act, as well.

\section{Lakes and Rivers Improvement Act}

Under the OMNR, the Lakes and Rivers Improvement Act (1990) regulates the detention and diversion of naturally running water (OMOE, 2011). With respect to SWM pond dredging, the Act would directly apply to the construction of coffer dams, water bypass flumes or dams during dredging operations.

\section{Drainage Act}

Under the Ontario Ministry of Agriculture and Rural Affairs, the Drainage Act (1990) regulates all construction activities related to agricultural drainage networks (OMOE, 2011). If SWM pond dredging has a potential to interfere with the maintenance or construction of drainage works, compliance of the Act would be required (OMOE, 2011).

\section{Nutrient Management Act}

The Nutrient Management Act (2002) has been implemented to regulate the management of nutrients with the intention to protect the natural environment (OMOE, 2011). If water from SWM ponds discharges to receiving water which traverse agricultural lands, the resuspension of previously buried sediment may increase turbidity and the potential for eutrophication. 


\subsection{Federal and Provincial Remediation Policies, Regulations and Legislation}

The following Acts and Regulations directly apply to site remediation and documentation of such sites. Their potential applicability to SWM pond dredging projects is reviewed in this section.

\subsubsection{Environmental Protection Act}

The remediation and clean-up of contaminated sites in Ontario are subject to federal and provincial laws. The revitalization of specific lands is subject to the Environmental Protection Act (EPA), which includes provisions that pertain to assessing the environmental condition of a property, the standards to be met and completion of a record of site condition (OMOE, 2004). In Ontario, the EPA generally pertains to brownfield sites, which are defined as underutilized, derelict or vacant contaminated sites needing clean-up (MMHA, 2007). With regards to SWM ponds, this condition may not apply as their continual use does not meet brownfield categorization; SWM ponds will lose efficiency over the course of their useful lifetime, but underutilization is not an issue (OMOE, 2004). Regardless, SWM ponds would (and should) be subject to a class EA (environmental assessment), to determine the extent of contamination, and a record of the successful remediation of their sediments. In 2004, two specific amendments were made to the EPA: Part XV. 1, which highlights the steps needed to clean-up a site and documenting a record of site condition; while Part XV. 2 contains provisions to reduce the liability for municipalities and stakeholders who may need to undertake investigative actions on brownfield sites (OMOE, 2004). A record of site condition can only be filed once a qualified person (QA) under the Act, such as professional engineer or geoscientist, has certified the site to meet the standards (OMOE, 2004). Furthermore, Ontario Regulation 153/04 under the EPA was created in conjunction with Part XV.1 to not only assist with site registry, but also assist with applicable assessment requirements and standards related to clean-up practices (MMHA, 2007).

\subsubsection{Record of Site Condition (0. Reg. 153/04)}

An environmental site assessment is used to determine the presence of contaminants on the surface and the subsurface of a parcel of land. According to Part XV.1 of the EPA, an environmental site assessment (ESA) is required to file a Record of Site Condition (RSC) in Ontario. A Phase 1 ESA is used to determine the likelihood of a contaminant presence on site, while a Phase 2 ESA is conducted to 
determine the location and concentration of contamination within the same site (OMOE, 2004). A Phase 2 ESA can only be completed if a Qualified Person under O. Reg 153/04 deems it necessary and must include a planning and site investigation report with a soil and sampling analysis (OMOE, 2004). Section 47 of O. Reg. 153/04 requires the collection, sampling and analysis of samples is in accordance with the Protocol for Analytical Methods Used in the Assessment of Properties under Part XV.1 of the $E P A$. With regards to clean-up, two types of approaches can be utilized; to remediate the site to meet soil, groundwater and sediment standards or to conduct site-specific assessment. The exceedance standards will change depending upon the intended site use. For example, a residential development will require more stringent standards than industrial or agricultural uses (MMHA, 2007). A riskassessment approach requires the examination of potential health-effects to develop contaminant levels specific to each site. Furthermore, a risk-assessment approach can be utilized to address a contamination at full depth or under stratified conditions when contamination changes suddenly. Although it may be more expensive than conventional remediation, it is useful for small sites such as SWM ponds and if remedial options cannot meet the standards.

The standards utilized in O.Reg. 153/04 can address various property uses including residential, commercial, industrial and agricultural (OMOE, 2004). Each specific zoned property type contains its own exceedance levels for specific pollutants, which is based on the likelihood of contaminant exposure to humans and the environment (MMHA, 2007). Furthermore, a distinction is made within the guidelines for soil, groundwater or sediment contamination deeper than $1.5 \mathrm{~m}$ below the datum, as the upper reaches are more likely to have a higher potential for exposure. In these instances, a stratified approach has been utilized where the upper $1.5 \mathrm{~m}$ are subject to more stringent clean-up procedures than any contaminants below this level (OMOE, 2004). Lastly, a separate provision is made with regards to environmentally sensitive sites, which include areas near water bodies, shallow soil and areas of natural significance (OMOE, 2004). SWM ponds would be expected to fall under the environmentally sensitive site criteria with their close proximity to receiving waters.

\subsubsection{Exceedance Guidelines}

In Canada, environmental exceedance standards are set by Soil, Ground Water and Sediment Standards for Use under Part XV.1 of the Environmental Protection Act (2011). In particular, the values contained in the document provide full depth background site condition standards for soil and sediment and site conditions standards for potable and non-potable groundwater. The soil standards derived from 
the Environmental Protection Act have been derived from the Ontario Typical Range values for land uses and are considered upper-limits of concentrations not contaminated by point sources (EPA, 2011). With regards to groundwater, standards were derived from the Provincial Groundwater Monitoring Information System (PGMIS) and from groundwater well surveillance data (DWSP). Finally, sediment exceedance ranges were developed from the Guidelines for the Protection and Management of Aquatic Sediment Quality in Ontario (MOEE, 1993) and are considered to provide a level of human health and protection to the background conditions of 'sensitive ecosystem' levels (EPA, 2011).

Exceedance values are based upon the land use of a particular area. Within Ontario, Table 1 (refer to Appendix 1.1) criteria outline the Full Depth Background Site Condition Standards, which consequently contains an exceedance concentration for a list of contaminants identified under the Ontario Ministry of the Environment (OMOE, 2011). Furthermore, each contaminant will contain an exceedance value for each type of land use, of which there are four: agricultural, residential/parkland, commercial and industrial. Agricultural land use describes a parcel of land that it utilized for primary production of crops and other plants or for the purposes of housing livestock. Residential and parkland use can either be related to an area in which dwelling have been constructed or any type of public land (or adjacent watercourses) primarily used for recreational activities. Commercial land is referred to as a parcel of land whereby the trading, buying or selling or good is ongoing, and industrial land refers to an area used to manufacture or store materials.

The criteria also encompass three media: soil, groundwater and sediment. Although the soil and groundwater exceedance standard values are quite comprehensive, the nature of sediment-related values can be problematic. Contaminant exceedance guidelines were revised in 2011; however, sediment standards have not been changed from the 1996 standards (OMOE, 2011). The issue arises when sediment is grouped with soils during earthworks construction or excavation activities. In Table 1, the exceedance value of sediment is taken as a mean and not an upper limit value, which poses a potential concern. Initially, if mean values were to be used as upper limits, a great deal of contaminated sites would require risk assessments and subsequently fail the criteria. In addition, sediment guidelines were developed irrespective of the various land use types associated with soil criterion (i.e. industrial or residential); contaminants found within sediments have one exceedance value and do not take into account different land uses. Subsequently, as SWM ponds can be designed to treat industrial or residential water, the range of contaminants within their sediments can be great. It is interesting to note that many contaminants have NV (no value) measurements for a majority of the contaminant exceedance values within sediments. It should also be noted that Table 2 conditions, which address site 
conditions adjacent to potable water sources, and Table 3 conditions, which address site conditions adjacent to non-potable sources, do not have exceedance value for sediments. It is generally understood that sediments can be grouped with soils and will often meet Table 2 and Table 3 standards; however, if sediments are mixed with soil, it becomes difficult to identify clean soil and to determine the degree of cleanliness. Ultimately, if sediment does not meet Table 1 standards, it must be further assessed or taken to a clean-up site and remediated in accordance with the Guideline for Use at Contaminated Sites in Ontario (1997). Under the OMOE Guideline for Use at Contaminated Sites in Ontario (1997), sediments fell under soil remediation criteria. In particular, exceedance values developed for each contaminant were present under two land use types, residential/parkland and industrial/commercial.

Furthermore, with respect to beneficial reuse, sediments fell under Table $F$, which outlined the Ontario Typical Range Soil Concentrations (OMOE, 1997). Consequently, excavated sediments could be deemed acceptable for beneficial reuse provided they passed one of two land use contaminant concentration criteria; sediments intended for agricultural land use or all other land use types. Under the new OMOE Guidelines (OMOE, 2011), although sediments were given an individual category, only 33 out of the 118 contaminants contain exceedance values for sediments, specifically. Consequently, there is a concern that all NV exceedances could be applied to the conditions utilized for excess soils by uninformed operators, which can become problematic due the unique properties of each particle. Furthermore, it important to note that the OMOE is not concerned with the presence of contaminant, but their ability to potentially cause an adverse effect. In addition, the Guidelines infer that chemical concentrations of contaminants are considered safe for human exposure within each land use type and could further be used as the upper limit criteria for soil disposal (Golder, 2003). The dredged SWM pond sediments could therefore be disposed of in an approved area given a certain level of contamination.

Another approach utilized by the OMOE is to forego individual chemical analysis and undertake a comprehensive risk assessment of the material (Golder, 2003). This approach allows stakeholders and operators to develop site-specific criteria with the OMOE and be utilized when sediment exceeds one or more of the criteria for a specific land use (Golder, 2003). Furthermore, this approach takes into account the complexity of different sediment types; organic fine-grained material can sorb easier to coarsegrained materials, which subsequently makes heavy metals less bioavailable. In addition, dredged sediments can be used for disposal in lakefill structures given compliance with the Fill Quality Guide and Good Management Practices for Shore Infilling in Ontario (OMOE, 2011). Under the guidelines, docks, stream banks, shoreline and coastline stabilization and in-stream bioengineering projects are all 
considered lakefilling. Many lakefilling projects would fall under the jurisdiction of Conservation Authorities, as they would encompass waterways and/or waterbodies.

\subsubsection{Canadian Council of Ministers of the Environment (CCME) Guidelines}

The CCME is a group comprised of the 14 Canadian Environmental Ministers, which has taken the responsibility to address environmentally-related issues. With regards to contaminated site remediation, the CCME continuously updates the Canadian Environmental Quality Guidelines (CEQGs), which are nationally endorsed criteria that direct provinces and territories use to develop their own standards. Although each province and territory (through their minister) has the ability to develop their own standards, the CEQG must be adhered to when addressing site remediation on federal land. In particular, the CCME has developed the Canada-Wide Standards for Petroleum Hydrocarbons in Soil, which are significant as over $50 \%$ of all contaminated sites have some presence of petroleum hydrocarbons. This is an important detail to consider as the most common type of contaminant found within SWM ponds are PAHs, which are hydrocarbons themselves (LSRCA, 2011). Given the prevalence of hydrocarbon exceedences within contaminated sites and brownfield developments and their mere presence in urban stormwater facilities, the afformentioned standards have been subsequently adopted by Ontario and implemented into O.Reg. 153/04.

\subsubsection{Waste Management and Disposal (0.Reg. 347)}

The disposal of contaminated sediment falls under the O. Reg. 347 of the EPA. The handling and disposal of any substance considered as waste will fall under the Ontario Waste Management Regulation (OMOE, 2004). Initially, a TCLP test is required to determine the toxicity of the sediment slated for disposal, which is used an indicator to highlight the potential for contaminants to leach from a landfill (GCl, 1999). Following an exceedence of a contaminant in a lab analysis, the results obtained from the TCLP test will be compared to the leachate quality criteria under Schedule 4 in O. Reg. 347 (OMOE, 2004). If the values obtained exceed the Provincial standards for leaching, the waste is considered to be toxic and must be disposed of at a hazardous landfill (GCI, 1999). If a SWM pond is located in a historically industrial area or within close proximity to gas stations or brownfields sites, a TCLP test may be suggested to deem the sediment non-hazardous. This regulation does not directly apply to contaminated site remediation; however, care must be taken when off-gas treatment is required, or disposal of contaminants. 


\subsection{Remediation}

Remediation techniques can largely be grouped into two initial categories, in-situ and ex-situ technologies. In-situ clean up refers to the remediation of soil, sediment or groundwater on site, which can occur following dredging or removal. Conversely, ex-situ methods encompass the removal of contaminated material or water, either for off-site disposal, or for immediate treatment at an adjacent site. Further categorization will then determine the type of remedial option and whether it will involve the use of physical/chemical process or biological treatment. As a result, a consultant can choose to utilize a physical/chemical or biological remedial option on site or an off-site setting. There are numerous types of remedial options currently used and continuously upgraded; however, there are certain known 'staple' methods often utilized in Southern Ontario for which a considerable application experience exists. The review of the following techniques will describe potential uses for the remediation of stormwater sediments, as very few have actually been employed in pilot tests. Examples are generally taken from options used to remediate contaminated sediment from Superfund sites and marine dredged sediment from harbours. It is important to note that the following remediation techniques are intended to be complimentary to dredging and sediment removal options. By-pass channels and pumping can be employed for some in-situ remedial options; however, most techniques require weeks to months prior to sediment decontamination. Furthermore, given the land constraints of some methods, planning and technology selection would have to take into account access and site storage.

\subsection{Biological Treatments}

Bioremediation describes the process of contaminant degradation in the environment by biological methods using the metabolic potential of microorganisms to break down a large variety of pollutants. Microorganisms can either mineralize the compound directly into harmless inorganic molecules, such as carbon dioxide and methane, or convert the compound to another chemical, which may be more toxic and recalcitrant to further degradation (ICSCS, 2006). The main advantage with bioremediation is its relative low cost compared with other remediation techniques. Furthermore, the complete mineralization of the pollutant with non-invasive measures makes biological treatment a permanent solution for many contaminants (ICSCS, 2006). Generally, bioremediation technologies can be utilized in-situ or ex-situ and ultimately depends upon site conditions and the amount of material 
requiring remediation. The interesting note with bioremediation techniques is their ability to be used consecutively, concurrently or within combination of each other.

\subsubsection{Biostimulation and Bioaugmentation}

Due to the lack of pore space exhibited within sediment, anaerobic metabolism is the mechanism used to naturally degrade dredged material. The lack of oxygen requires additional electron acceptors such as sulfate and manganese, which have been shown to degrade hydrocarbons in many instances (Parsons, 2004). Biostimulation serves as method to promote the efficiency of the indigenous microbial population by influencing factors that affect its growth. For example, the injection of methanol and acetate provide existing microbial populations with electron donors (Gomes et al., 2013). Conversely, bioaugmentation relies on the introduction of microorganisms to assist the indigenous population with degradation (ESTCP, 2005). The most important aspect of bioaugmentation is the selection of the correct strain and the ability to sustain suitable $\mathrm{pH}$ and temperature to aid aerobic degradation (USEPA, 2000). Bioaugmentation has historically been successful at treating marine sediments, which have increased salinity (ESTCP, 2005).

Given that stormwater sediments and sediment ultimately dredged from detention ponds will be saturated in nature, biostimulation methods should be explored. However, without availability to the contaminant, microorganisms will not be able to break down the compound, regardless of the relative aerobic or anaerobic conditions. In these instances, surfactants can be utilized to enhance the solubility and removal of contaminants from soil and sediments (Mulligan et al., 2001). Surfactants are amphiphilic compounds that reduce the free energy of a system by replacing the bulk molecules of higher energy at an interface (Mulligan et al., 2001). Historically, surfactants have been used in the petroleum industry to enhance oil removal applications through the reduction of interfacial tension. Within an environmental engineering context, surfactants are useful in displacing hydrocarbons by reducing tension and utilizing capillary forces to restrict contaminant mobility in groundwater or saturated sediments (Paria, 2008). In particular, the use naturally occurring (or grown) biosurfactants, sodium taurochlate and synthetic surfactants, have demonstrated to increase the bioavailability of PAHs (Paria, 2008). Current cost estimates for in-situ biodegradation can be anywhere between $\$ 150-$

$\$ 450 /$ tonne depending on the specific biodegradation option used (EC, 2002a). 


\subsubsection{Composting and Landfarming}

Bio-pile/composting is a technique that involves combining contaminated soil with nonhazardous organic compounds, such as agricultural wastes (Gan et al., 2007). The presence of these organic materials supports the development of a rich microbial population and elevated characteristic of composting. Composting has potential use for treatment of stormwater sediments, as public acceptance would be quite high due to its prevalence within the public spectrum. Composting (Petavy et al., 2009) is a managed system that uses microbial activity to degrade raw organic materials, such as yard trimmings, so that the end-product is relatively stable, reduced in quantity (when compared to the initial amount of waste), and free from offensive odors (Gomes et al., 2013). Composting can be done on a wide range of scales, with the management requirements and intensity increasing dramatically as system size increases. In its simplest form, compostable material is arranged in long rows (windrows) and turned periodically to ensure good mixing (Besaltapour, 2012). This process can handle large quantities of input, such as yard trimmings of up to $75,000 \mathrm{~m}^{3}$ per year, on only a few hecatares of land (USEPA, 2000). However, as an ex-situ treatment option, composting requires not only excavation/dredging and transport, but also serviceable land to install windrows and general maintenance. Given the amount of material requiring remediation in stormwater ponds, composting may be difficult in certain jurisdictions due to land constraints. However, many municipalities (regional level) currently own and operate active composting facilities and, with a few minor alterations, such facilities could be made available to treat sediments from SWM ponds. If not, similar facilities could be developed and dedicated toward the treatment of sediments dredged from municipally-owned ponds, which has the potential to be quite inexpensive.

Landfarming is a bioremediation treatment process performed ex-situ in biotreatment cells. Contaminated soils, sediments or sludges are incorporated into the soil surface and periodically turned over to aerate the mixture (Tabe and Loehr, 1997). The major advantage with landfarming is that the associated costs are moderate, as it is a biological process. Furthermore, amendments can be added to speed up the degradation of contaminants and a series of pilot scale studies have highlighted its effectiveness on organic contaminants with slow degradation rates (Gomes et al., 2013; Straube et al., 2003). In 2000 a pilot scale land biotreatment was tested with $1500 \mathrm{~kg}$ dry weight of sediment from industrial lagoons containing wastewater with PCB mixed an additional $1500 \mathrm{~kg}$ of clean sand (Ghosh et al., 2000). Results showed that PCB congeners, which are less leachable, were highly degraded over the course of one month. A further multi-year pilot-scale land treatment project for poly-aromatic 
hydrocarbons (PAHs) and PCB placed approximately $1 \mathrm{~m}^{3}$ sludge/sediment mass in a land treatment unit (Liu et al., 2007). The results showed that that complete biostabilization can be achieved when reversibly sorbed PAH and PCB are biodegraded or irreversibly sequestered. The cost of composting and landfarming largely depends upon the water content within the bulk material and as a result is classified as either solid-phase biological treatment (SPBT) or slurry-phase biological treatment (SLBT): SLBT cost $<\$ 150 /$ tonne while SLBT range from $\$ 80-\$ 230 /$ tonne (EC, 2002b).

\subsubsection{Phytoremediation}

Phytoremediation is a relatively new treatment technology option that allows for the in-situ treatment of sediments, soil and groundwater. Once material is dredged, biota can be planted within a contained site, whereby plant roots can sequester, degrade, immobilize or metabolize a series of contaminants in place (Dietz and Schnoor, 2001). Furthermore, specific plants can be selected to remove individual pollutants, such as organic pollutants, hydrocarbons or heavy metals (IRTC, 2009). Due to the presence of contaminant in stormwater pond sediments, phytoremediation can be useful due to its applicability, relative low costs and aesthetic appeal. There is a series of mechanisms that can be utilized for such use; contaminants can be taken up by the plant (phytoextraction); contaminants may be degraded internally or externally by enzymes (phytodegradation); plants can be used to uptake groundwater and contain contaminated zone (hydraulic control); and plant roots can immobilize or adsorp contaminants (phytostabilization) (Bert et al., 2009).

For any of these mechanisms, organic chemicals must initially sorb to roots, or bind to the root structure and cell walls (USEPA, 2001). In particular, hemicellulose is the lipid layer which binds hydrophobic chemicals quite effectively (Dietz and Schnoor, 2001). Furthermore, higher lipid contents have revealed an increased affinity for hydrocarbons. Current measurements for root uptake efficiency rely on the root concentration factor (RCF), which is defined as the ratio of organic chemicals sorbed onto the root (milligrams per kilogram of plants tissue) to organic chemicals within solution (milligrams per litre) (Burken and Schnoor, 1998). The hydrophobic nature of many organic chemicals and their hydrophobicity are inherently related to the octanol-water coefficient ( $\left.\log \mathrm{K}_{\mathrm{ow}}\right)$ of the organics. As a result, the greater the $\log \mathrm{K}_{\mathrm{ow}}$ of the contaminant, the greater its potential to partition from the aqueous phase and sorb to plant roots (Dietz and Schnoor, 2001). Once binding has occurred, the contaminant can then be transported into the plant. In particular, direct uptake of organics by plants is an efficient removal mechanism from shallow contaminated sites with organic pollutants (i.e. TP and 
TN), as well (Dietz and Schnoor, 2001). The advantage of this approach being applied to dredged stormwater sediments is that such options have already been utilized in stormwater management in the form of low impact design (LID) principles and methods. For example, pond retrofits and enhanced removal design options can facilitate the development of site conditions to aid with the removal of BTEX (benzene, toluene, ethylbenzene, xylene) and chlorinated solvents, specifically.

Phytostabilization has been utilized within many studies for different purposes; reducing availability of pollutants; roots sequestering pollutants; reducing pollutant cycling through uptake; and improvement of sediment properties (Bert et al., 2009; Mendez and Maier, 2008; Cunningham and Berti, 2000)). Hybrid poplars and willows have successfully intercepted contaminated runoff, dewatered dredged sediments and sequestered pollutants within root systems through various studies (Bert et al., 2009; Berti and Cunningham, 2000). In addition, valorization has been a success in the case of landdeposited dredged sediments, which offers an exciting opportunity to apply such methods to dredged stormwater sediments (Bert et al., 2005). In addition, the fast growth, high evaporation rate and deep root system of have led to their use for phytoextractive purposes. Furthermore, poplars and willows can not only remove contaminants, but have the ability to be cultivated within pollutant-laden sediments (Dietz and Schnoor, 2001). Recent studies have exhibited their ability to utilize dredged sediment contaminated with heavy metals to facilitate their own growth (Schnoor 1995; Sursarla et al., 2002). The prevalence of lead within brownfield developments and former industrial sites have prompted some land developers to turn to Brassica juncea (Indian mustard) or Brassicaceae (wild mustard) to remove chemicals, rather than mechanized methods (IRTC, 2009).

There are a few limitations with phytoremediation, many of which are unavoidable. Depending on the species used, low removal rates can occur as they are limited by the growth rate of the plants. The maturity of the plant species will increase its capacity for uptake and time will be needed for the root system to fully establish. Inherently, many plant species merely sequester contaminants and transfer pollutants to the stem of leaves. Subsequently, plant removal and landfilling may be required to eradicate the contaminant off site. With regards to monitoring, tree cores for plume delineation can be used to screen for pollution within the tree bark, if mature, however, hydrocarbons have proven difficult to detect (Trapp et al., 2007). Regardless, phytoremediation is an emerging remediation method, with relative costs ranging from $\$ 100-\$ 300$ per tree and installation within restoration planting plans. (USEPA, 2001). This sustainable option not only allows for the containment of chemicals found within stormwater ponds, but can degrade them into less toxic forms at fractional costs. 


\subsection{Chemical Treatment}

Chemical treatments were first developed to treat large spills. In particular, hydrogen peroxide was first developed to treat a formaldehyde spill in 1985 and, following its success, was found to treat hydrocarbons and chlorinated solvents as well. Chemical treatments have become a mainstay within the crude oil industry and have been utilized to treat water from crude oil outfall ponds. As a result, it is important to note that many of technologies listed below should only be considered for highly polluted and contaminated SWM ponds, particularly those servicing industrial sites. Residential SWM ponds will normally contain contaminants in concentrations a few orders of magnitude lower than those normally requiring chemical treatment options.

\subsubsection{Stabilization/Solidification (S/S)}

Solidification and stabilization are two remediation methods that entomb contaminants and reduce their mobility within the environment. While these methods do not completely destroy contaminants, they impede potential leaching from the impacted site. Stabilization generally involves the addition of specific reagent cocktails to sediment to produce a chemically stable compound, which promotes immobilization (Al-Tabbaa and Perera, 2006). Conversely, solidification relies on the addition of reagents to contain contaminants in a solid form and reduce access by external forces, such as rain or air. Stabilization/solidification techniques have historically been applied to soil since their low water content (as compared with sediments) and geotechnical properties have allowed for reuse as engineered fill (USEPA, 2000). However, within soils, pollutant removal is not possible and must be combined with another technique, such as bioremediation or soil washing to attain clean-up goals. Given heavy metal and PAH affinity to sediment, S/S techniques are quite effective and can be destroyed (Barnet and Reisman, 2009). Furthermore, once pollutant leachability is reduced within contaminated sediment, the large geotechnical improvement would enable possible reuse.

The major objectives for $\mathrm{S} / \mathrm{S}$ techniques are to make materials suitable for re-use or make suitable for landfilling, which ultimately depend on regional landfilling policies and regulations (AITabbaa and Perera, 2009). Generally, Portland cement and/or lime meet solidification regulatory requirements; however, fly ashes, slags and puzzolanic materials are much more inexpensive (Paria and Yuet, 2006). Successful application ultimately depends upon a designed reagent mix, while taking into account water addition (12\%-15\% by weight) and an expected volume swell (15\%-30\%) (USEPA, 2001). 
Much of the planning into s/s procedures require ample laboratory testing, with strength, permeability and leachate test methods required. Strength testing falls under ASTM D 1633 Method B or ASTM D 2166, according to the American Society for Testing and Materials (ASTM International), which requires $>0.34 \mathrm{MPa}$ or $>50$ psi per unit stabilized (USEPA, 2000). With regards to permeability testing, ASTM D 5856 (rigid wall) and ASTM D 5084 (flexible wall) require $<1 \times 10^{-6} \mathrm{~cm} / \mathrm{sec}$ to pass. Finally, leachate testing generally utilizes the Synthetic Precipitation Leaching Procedure (SPLP, USEPA method 1312) and requires 500 clean samples to pass site-specific target levels (SSTLs) (USEPA, 2000). Following successful testing, reagents and additives can be added on site using rotary devices and hydraulic injections or off site using rotary buckets and planetary mixers (Panseart, 2008). Advantages to in-situ application allow for little excavation and dredging, but process control may be difficult, dosing accuracy may be altered and the process is debris sensitive (Barnet and Reisman, 2009).

Recently, various projects have utilized S/S techniques for the remediation of heavy metals and PAHs. In particular, full scale projects have been performed in the US, Canada, Japan, Belgium and the Netherlands. Furthermore, studies have shown PAH levels to decrease by up to $80 \%$ and, when combined with thermal technologies, up to 98\% (Abramovich et al., 1999; Gan and Lau, 2009; Rienks, 1998). However, PAH removal is dependent upon initial concentrations, which have been reported to be lower within SWM ponds (Boving and Neary, 2007; Karlsson et al., 2007). Furthermore, solidification/stabilization methods have become quite popular within the British Isles and even used to remediate 10000 tons of sediment contaminated with heavy metals for the London Olympic Stadium site (Panseart, 2008). Stormwater sediments can be treated using S/S technologies; however, its effectiveness will depend on the type of contaminant treated. Furthermore, with regards to topographical considerations, detention ponds cannot exceed the 5-7 m limit for excavator depth. Subsequently, continuous monitoring is required to detect voids in samples, identify potential fracturing, limit odours and reduce volatiles during in situ mixing (Panseart, 2008). Ultimately, smaller stormwater pond volumes are more appropriate for treatment, as costs generally range from \$70$\$ 200 /$ tonne (EC, 2002b). Nonetheless, S/S techniques have been utilized to remediate one of Canada's largest and sensitive projects, the Sydney Tar Ponds (Paria and Yuet, 2006). S/S techniques were able to remediate hundreds of acres laden with PAHs and PCBs, but promoted the redevelopment of formerly toxic land into recreation grounds. 


\subsubsection{Solvent Extraction}

Solvent extraction, or soil/sediment washing, involves the addition of a solution with the contaminated sediments to transfer the contaminants from the sediments to the wash solution (Mulligan et. al, 2001). This remediation method is very useful as heavy metals and hydrocarbons can be transferred from dredged stormwater sediments to the injected solutions. Injected fluids can be primarily water-based, but to increase the efficiency of sediment washing, additives such as acid washing (hydrochloric and sulfuric acid), chelating agents or surfactants can be added to the pile to assist with the dispersal and desorption of trace and heavy metals from the contaminated particles (Peng et. al, 2009). The most appropriate use for solvent extraction is for weaker bound metals in the form of hydroxides, reducible oxides and carbonate fractions. At $\$ 40-\$ 250 /$ tonne or $\$ 50-200 / \mathrm{m}^{3}$, washing is an inexpensive alternative; however, its use ultimately depends on particle size (EC, 2002b). Coarse material, such and sands and gravels, can be easily treated and the solution can be continuously reused to remove constituents. Residual fractions and fine sediments are quite difficult to treat and, given the propensity for stormwater ponds to collect and settle silt and sometimes clays, care must be taken to assess the intake of grain sizes and catchment characteristics prior to selecting soil washing as a remedial method (USACE, 2006).

Solvent extraction either begins by pumping ground water to the surface or dewatering saturated dredged sediments. If clean water is injected, soil washing is essentially a conventional pump and treat method which aims to remove contaminants through dilution and advection, as the hydraulic gradient is increased (USACE, 2006). With stormwater sediments often being laden with by-products of combustion and compounds from vehicle use, the injection of co-solvents are required to enhance the chemical reactions of petroleum-based and metallic pollutants (CL:AIRE, 2011). For example, hydrogen peroxide will react with petroleum hydrocarbons and degrade them to carbon dioxide and water. Furthermore, if surfactants are injected, soil washing is referred to as surfactant-enhanced aquifer remediation (SEAR) and ultimately becomes a bioaugmentation process (USACE, 2006). In particular, biosurfactants possess efficient surface active properties and, as such, present an opportunity to treat fine-grained particles (Mann et al., 1998).

An increasing number of solvent extraction studies have focused on the removal of polychlorinated biphenyls (PCBs) (Björklund, 2001; Hubert et al., 2000).These persistent organic pollutants were extensively used worldwide from the 1930s:, however Canada instituted a ban on PCB production in 1977 and their release to the environment was made illegal in 1985 . Their propensity to 
bioaccumulate in organisms is well documented and they have been detected in virtually all environmental media (Gomes et al., 2013). Although their ability to be broken down by many remedial options is somewhat difficult, a mixture of simple alkanes and alcohols has shown $90 \%$ extraction efficiencies. Japanese bench scale tests were able to remove $98.6 \%$ of Aroclor from $92 \mathrm{t}$ sample of sediment with approximately $10 \mathrm{~kg}$ of PCBs (Gomes et al., 2013). Furthermore, dimethyl ether has exhibited an ability to extract $99 \%$ of PCBS and $97 \%$ of water from contaminated sediment, which allows for concurrent removal of pollutants and dewatering of the bulk (Gomes et al., 2013). Solvent extraction can be utilized ex-situ or in-situ, but large facilities are required if attempted off site. Full scale facilities have been built by two companies (Biogenesis and Roy F. Watson) to process more than $210,000 \mathrm{~m}^{3}$ per year at a cost of $\$ 40-\$ 65 / \mathrm{m}^{3}$; however, these facilities would require capacities of greater than 400,000

$\mathrm{m}^{3}$ for installation (Mulligan et al., 2001). Nonetheless, in-situ injection could be achieved on small sites, such as stormwater ponds, but special care would be required to assure proper handling of the washing fluids and their ultimate recovery and treatment.

\subsubsection{Chemical Oxidation}

In-situ chemical oxidation (ISCO) is a relatively new remedial method which involves the injection of oxidizing agents into a saturated bulk of soil or sediment. There are many advantages with chemical oxidation; the contaminant can be destroyed in-situ with rapid destruction/degradation within weeks to months, off-gases are not released and the technology can be combined with other remedial methods (TPM, 2011). ISCO has been shown to achieve 90\%-99\% reduction in contaminant, with significant risk and mass flux reductions. There are relatively few disadvantages to ISCO, but their issues can accrue large cost complications. With respect to other remedial options, ISCO operations have an approximate base fee of $\$ 400-\$ 750 /$ tonne of treated material, with large front loaded project costs (USEPA, 2001). Canadian estimates have the technology's cost at $\$ 150-\$ 450 /$ tonne (EC, 2002b)Furthermore, dissolved contaminant concentrations may rebound within weeks or months following initial treatment if complete degradation has not occurred. Consequently, contingency costs are much higher for ISCO operations than all other remedial methods.

Integral to the success of the oxidation process is the selection of the oxidant itself. Generally, there is not a single oxidant and/or delivery approach that works for all contaminants, hydrogeology or geochemical conditions (Huling and Pivetz, 2006). The most common is permanaganate (often potassium permanganate, $\mathrm{KMnO}_{4}$ ) and it works well with chlorinated compounds, such as vinyl chloride 
or methylene chlorides. Its inability to treat BTEX means that permanganate cannot be utilized at sediments which have large petroleum deposits, but it has several advantages over other oxidants (Urynowicz, 2001). Permanganate can oxidize organics over a wider $\mathrm{pH}$ range, it can react with contaminants over a longer period of time and its lack of heat production and vapours means that few health concerns are associated with its use (TPM, 2011). Another oxidant is persulphate, which has a higher oxidation potential than $\mathrm{KMnO}_{4}$ and is more stable than hydrogen peroxide $\left(\mathrm{H}_{2} \mathrm{O}_{2}\right)$. Subsequently, if there are more organics present, persulphate will work much better than permanganate; however, chlorinated compounds are unaffected by it (Tsitonaki et al., 2008). The third most common oxidant is $\mathrm{H}_{2} \mathrm{O}_{2}$, which is primarily used to destroy petroleum hydrocarbons (Gates and Siegrist, 1995). Once selected, it is typically shipped to a remediation in liquid form at dose concentrations ranging from 5$50 \%$ by weight (TPM, 2011). When iron is present in humic soil or sediment samples, hydrogen peroxide reacts with ferrous iron $\left(\mathrm{Fe}^{2+}\right)$ to form hydroxyl ions, which are very potent oxidizers. In particular, hydroxyl radicals can break down BTEX, PAHs and methyl tertiary butyl ether (MTBE), all of which are often found in sediments dredged from stormwater ponds (Huling and Pivetz, 2006). Equally, its reactivity can limit the extent to which it is distributed within bulk samples. As a result, care must be taken to ensure oxygen concentration in sediment samples do not exceed the solubility limit of oxygen of the bulk itself.

Following the selection of the oxidant, the mass of the oxidant required must be determined, as well as its relative volume (Vironex, 2006). Mass balance essentially depends upon initial oxidant demand, potential well spacing, oxidant concentration and flow of oxidant. More often than not, spreadsheet design tools and transport modelling tools (RT3D and CORT3D) are utilized to determine the mass of injection required (Mundle et al., 2007; Siegrist, 2008). With regards to volume, successful operations tend to have longer injection duration per injection event and ultimately greater total volume of oxidant delivered. On average, $10-30 \%$ of one pore volume is average injected volume but percent reduction can increase (>90\%) with higher pore volumes injected (Siegrist et al., 2014). Subsequently, 2-3 injections are typically required to treat samples, but there are relatively few mathematical models available to determine oxidant dispersion and observational approaches are critical to determine successful application (TPM, 2011). Furthermore, as a degradation process, it is important to assess if ISCO or other bioremediation methods are useful. Generally, if there is a high level of dissolved oxygen and high flow rates, ISCO will accrue high costs and cannot guarantee degradation (Siegrist et al., 2014). Historically, the most successful uses of ISCO have utilized mass recovery using 
exaction or pump and treat and bioremediation post-polishing.

\subsection{Physical Treatment}

The following treatments involve the physical movement and removal of sediment from SWM ponds or the mineralization of contaminants using thermal technologies.

\subsubsection{Thermal Desorption}

Thermal desorption is a technology that utilizes heat to increase the volatility of contaminants for removal from a solid matrix (soil, sediment or sludge) (Rienks et al., 1998). The treatment is accomplished by one of two types of methods; low temperature thermal desorption systems heat contaminated material between 200 and $600^{\circ} \mathrm{C}$, while high temperature thermal desorption systems involve heating material between 600 and $1000^{\circ} \mathrm{C}$ (NFESC, 1998). Thermal desorption systems can be used to treat a wide range of contaminants, including petroleum hydrocarbons, PAHs, and PCBs. Low temperature thermal desorption is used for the treatment of low and middle distillate organic pollutants, such as gasoline, diesel and lubricating agents (Pen et al., 2009). Higher temperature desorption systems can treat and destroy organics heavy metals but temperatures are required to exceed $500^{\circ} \mathrm{C}$. The process works by placing contaminated material continuously into a rotary kiln (which can be constructed on site) where it is heated to temperatures sufficient to evaporate combust or volatilize the pollutant (Mulligan et al., 2001). Following the desorbing component, off-gas treatment is required to handle the waste material, ultimately separating into organic and aqueous fractions (NFESC, 1998). Such treatment options would be subject to air quality regulations, which must be in compliance with provisions set in the Record of Site Conditions. Subsequently the organic fraction can be recycled as supplemental fuel or sent to an incineration plant. Currently there are numerous issues related to sediment decontamination due to appropriate feed sizing. Furthermore, pilot tests have indicated that without dewatering, sediment becomes very difficult to treat and therefore requires longer exposure within the machinery and at higher temperatures (NFESC, 1998). Current cost estimates are approximately $\$ 50-\$ 250 /$ t for low desorption systems and $\$ 200-\$ 700$, due to increased energy expenditures (USEPA, 2001). A similar range was reported by Environment Canada with low temperature desorption $<\$ 150 /$ tonne (including design, installation, excavation and operation costs) 
and high temperature desorption between $\$ 150-\$ 450 /$ tonne (EC, 2002b).

A thermal process called Cement Lock was developed by the Institute of Gas Technology in the early 2000s to treat dredged sediment initially from New York and New Jersey harbours (Stern et al., 2000). The initial mixture, containing arsenic, mercury, lead, chromium and various other heavy metals, was fed into a rotary kiln with lime at a temperature of $1500^{\circ} \mathrm{C}$. The sediment and lime was then melted and the subsequent mixture was used to create a suitable type 1 Portland cement construction material. In addition, the decontaminated sediment was able to pass TCLP testing for all metals and all off-gases were treated with carbon air filters. The pilot testing in Newark Bay, NJ was undertaken at $\$ 25-\$ 40 / \mathrm{m}^{3}$ and demonstrated that not only were dredged sediments able to be treated, but that the pre-treatment was not required either (Stern et al., 2000). With regards to chlorinated substances, in one study, sediment contaminated with $1300 \mathrm{~kg}$ of Arcolor, was able to achieve 48-70\% decomposition from PCBladen sediment using thermal desorption (Norris et al., 1999). However, if decomposition is incomplete there is a distinct possibility for dibenzofurans to form, which could exacerbate the contamination originally present. Given a large project budget, thermal desorption can result in the complete destruction of contaminants within samples (Gan et al., 2009). Regardless of sample origin, studies have shown that hydrocarbon concentrations, in particular, are reduced when the exposure to heat or temperature is increased, which offers a potentially suitable remedial option for sediments (Durmusoglu 2010, Hosseini, 1998).

\subsubsection{Amendments}

The use of amendments has become more popular over the last few years due to their high cation exchange capacity. This physical characteristic allows amendments to not only lower mobility of contaminants in sediments, but also to decrease their bioavailability through precipitation or sorption, ultimately decreasing solubility (Ghosh et al., 2011). There are natural examples of this phenomenon, as black carbonaceous particles in sediments, such as coals or soot, bind hydrophobic organic compounds (Cho et al., 2007). Furthermore, their presence in sediments, whether from natural or anthropogenic sources, has been shown to reduce exposure and risk by one order of magnitude, as compared to natural organic matter (Ghosh et al., 2011). Activated carbon has generally been used in drinking water purification, in water and wastewater treatment plants and for poison abatements. With its great sorption capacity, activated carbon can decontaminate ponds by transferring pollutants from sediment particles to the carbon (Cho et al., 2007). Pilot tests have included studies on tidal mudflats (Gu et al., 
2013), freshwater rivers (Ghosh et al., 2011), marine harbours, deep-water fjords and marshes (Jackson and Pardue, 1999), but have not included stormwater pond sediment, as of yet (Kwon et al., 2010). Typical activated carbon dosing ranges between 2-5\% by weight of dry sediment within the top $0.25 \mathrm{~m}$ of sediment measured from the bed. Using a pilot study from Hunter's Point in San Francisco Bay, the amount of activated carbon needed to remediate a site at $5 \%$ in the top $10 \mathrm{~cm}$ of sediment was 35,000 $\mathrm{kg} / \mathrm{ha}$, which amounts to $\$ 75,000 / \mathrm{ha}$ and $\$ 2.2 / \mathrm{kg}$. In comparison, dredging and disposal costs along the Hudson River, NY have amounted to over $\$ 2.5 \mathrm{M} /$ ha (Ghosh et al., 2011). This large reduction in cost savings could potentially be applied to small and large-scale stormwater remediation projects, as well.

Geotextile tubes have long been used to contain and dewater dredge materials from river channels and harbours. In these applications, coarse-grained sediments are pumped into the geotextile tube and settle rapidly before water is discharged through holes in the top of the tube (Mastin et al., 2008). Recently, the addition of polymers and chemical conditioning agents has greatly improved the consolidation of excavated and/or dredged materials. Geotube technology has been in use globally for a variety of purposes; construction of confined disposal areas in Columbia (Fowler, 2000), Superfund site PCB clean-up, dewatering and storage of dredged pulp in Sweden (Pensaert et al., 2008) and for the purpose of removing sediment from stormwater pond in Vaughan, Ontario (Tymecki and Simpson, 2013). In particular, geotubes have many advantages over conventional techniques, including no need to drain or dewater waterways or ponds, minimal impacts on downstream watercourses, low turbidity level and low cost considerations (Simpson and Suppa, 2014). The Vaughan, Ontario project is important to note as it is an example of a direct use of remedial technologies to specifically treat stormwater ponds. The objective of the project was to remover over $3000 \mathrm{~m}^{3}$ of sediment from three SWM ponds, while utilizing the geotube dewatering technique (Simpson and Suppa, 2014). Although not a traditional amendment technology itself, the use of polymers would warrant this remedial option to be categorized as such.

Initially, sediment was dredged from the ponds using a remote controlled dredge with tow lines, which greatly minimized site disturbance. Following the deployment of the dredge, the water/sediment slurry was pumped into a hose and passing through a polymer injection system before it reached the geotube (Tymecki and Simpson, 2013). Polymer-based water clarification techniques have been wellestablished and under guidance from the TRCA, polyacrymalides (PAMs) have been recommended for use instead of synthetic cationic polymers or chitosan, which can be toxic to benthic and aquatic communities (TRCA, 2013). These polymers not only allow for the thickening of saturated soils that are otherwise difficult to handle, but allow for continued stormwater pond operation during the handling 
process (TRCA, 2013). Subsequently, following polymer injection, the geotube will continue to dewater the sediment following pumping completion and are generally left to settle for a month before they are cut open and have the sediment removed (Penseart et al., 2008). Following dewatering, the bulk must be tested for contamination before remediation or landfilling can occur (Simpson and Suppa, 2014). Furthermore, reuse of the dredged material off-site would only be permissible if it can be clearly demonstrated that the PAM or any other substance used will not cause impacts to human health or the environment.

\subsection{Risk-Management Measures}

Risk management measures (RMMs) are land use control strategies that are employed to reduce the potential risk to human and ecological receptors. Furthermore, risk management measures require continuous monitoring and inspections to ensure protection of the site (Sprenger, 2014). RMMs do include removal of contamination through remediation but can also include various other measures; elimination of exposure routes (i.e. property restrictions, building design constraints such as no basements), interception of exposure routes through the use of barriers and the containment of the contaminant through in-situ s/s techniques or groundwater capture (Sprenger, 2014). The selection of RMMs vs. other remedial techniques requires the application of remediation criteria to site specific conditions (Janes, 2014). This can be achieved using a tiered approach which highlights site-specific remediation objectives: Tier 1 - direct adoption of remedial criteria (criteria-based approach), Tier 2 adoption of remediation criteria with limited modifications (modified criteria approach) and Tier 3 - the use of risk assessment (Sprenger, 2014). The risk-based approach is often more complex and more costly, but is utilized when the project site is very large or the estimated cost of remediation is high enough that a framework site investigation would be required to derive remediation priorities.

There are few examples of RRM use with regards to contaminated SWM pond sediments, but their employment has been deemed successful. In particular, PAHs are increasingly becoming deposited within SWM ponds throughout the United States and Canada. For example, it has been noted that PAHs in South Carolina are not only present in urban areas, but significantly higher within commercially zoned areas, as opposed to low and high-density residential developments (Weinstein, 2010). SWM ponds in Minnesota also exhibited the presence of coal tar-base sealant PAHs, irrespective of the catchment land use (Crane, 2014). In both examples, RMMs were employed as an alternative to disposal at a registered 
hazardous landfill, as in-situ remediation has been shown to decrease sediment removal costs by as much as 50\% (Weinstein, 2010). However, currently, on-site disposal of sediments is only a remedial option in 16 US states. In Weinstein's study (2010), screening-level ecological and human health risk assessments proved to be successful when identifying risks to benthic organisms and carcinogenic risks to humans (Weinstein, 2010). Not only was this successful with the identification of a level of risk (medium-high), but also led to further testing and site-specific removal of the sediment. In Crane's study (2013), it was inferred that disposal costs could approach $\$ 1$ billion if only $10 \%$ of the 20,000 SWM ponds in Minnesota exceeded PAH guidelines and required removal (Crane, 2014). Tests of SWM pond sediment samples concluded that the level of PAHs exhibited in these ponds would pose a threat to human health. A non-physical measure, in the form of a statewide ban of CT-sealants, was chosen as a suitable mitigation method, which could decrease the amount of PAHs released into the environment and improve the sediment over time (Crane, 2014). Both studies were able to show that sit-specific RMM measures offer cost-effective and unique solutions to traditional disposal.

When pollutants and contaminants are present at an extremely high level or in abundance to the point where remediation is unfeasible, measures are taken to block direct contact (dermal or ingestion) for both humans and ecological receptors (Sprenger, 2014). Furthermore, dermal contact for human receptors would have to be taken into account during potential excavation activities and inhalation exposure would need to be addressed when workers come into contact with soil or groundwater migrating into enclosed structures built on the risk assessment property (Sprenger, 2014). There are two types of barriers generally used for risk-assessment projects, direct contact barriers and inhalation barriers. Direct contact barriers can either hard or soft caps that are installed to prevent direct contact with and ingestion of native soils or sediment. Soft caps thicker than hard caps and vary from 600 to $1500 \mathrm{~mm}$ due to their predisposition to animal penetration and potential piercing by plant roots (Janes, 2014). Conversely, hard caps are comprised of asphalt and concrete to a depth of $300 \mathrm{~mm}$. In both cases, geotextiles are placed as indicators below both caps. Inhalation barriers are gas permeable liners with active vapour collection systems, but should not be considered for addressing stormwater sediment (Janes, 2014). Direct contact barriers should only be considered as a potential remedial option for the decommissioning of stormwater ponds and only if contamination levels greatly exceed land development standards. This type of physical barrier has been used in Toronto to construct the Cherry Beach Sports Fields, where $30000 \mathrm{~m}^{3}$ were remediated into a recreational facility (TPLC, 2014). 


\subsection{Reuse and Disposal}

The potential reuse of SWM pond sediments is subject to the Guidelines for the Utilization of Biosolids and Other wastes on Agricultural Land (OMOE, 1996), which is a document that describes the requirements needed to facilitate the disposal of biosolids and 'other wastes' on agricultural land.

Before biosolids and other waste materials can be applied to land, certain chemical criteria must be met, along with a specific provision as to how the disposed material will benefit crop production or soil health (OMOE, 1996). Within the document, biosolids are considered to be 'sewage sludge' and other wastes which are materials not defined as biosolids, septic waste or agricultural waste under O. Reg. 347 (Golder, 2003). Consequently, dredged sediments would be classified under 'other wastes' and disposal of such materials on agricultural lands would be permitted given relative approvals. If contamination of the sediment bulk was to exceed specific values in Table 1 (2011), disposal on agricultural land could still be utilized if the bulk meets biosolids standard and the operator can demonstrate the dredged sediments would benefit plant growth and pose minimal risk to human, plant and animal health (OMOE, 1997). As SWM ponds could be assumed to contain higher concentrations of organics, dredged sediments have a high possibility of reaching acceptable standards for beneficial reuse on agricultural lands (Golder, 2003). Consequently, SWM ponds should be assessed individually, as site-specific conditions and subcatchment characteristics will affect the composition of pollutants within their sediments.

The reuse of dredged sediments would largely depend upon the physical properties of the material, as the composition of sediment will affect and limit the amount of potential uses. For example, foreign objects such as bottles and debris will have to be physically removed prior to reuse (Golder, 2003). In addition, the large amount of organic material, such as leaves and detritus, are very gelatinous and aesthetics would dissuade operators from directly applying these bulks for residential uses (Golder, 2003). Subsequently, areas near the inlet of a SWM pond should be treated first or separately from sediment dredged from other locations of the pond, as large debris and flocs would generally fall out of suspension soon after their appearance. However, given their high moisture and organic content, SWM pond sediments should be considered for the creation of organic soil amendments. A stormwater sediment amendment mixed with compost materials could be subsequently used as topsoil for parks and recreational areas or for sod-seeding purposes (OMOE, 2011). In addition, stormwater sediments can also be transferred to landfills where they would be stockpiled and contribute as daily fill (OMOE, 2014). Along with agricultural purposes, stormwater sediments have been used in various upland 
disposal options, but more innovative uses are discussed below.

\subsection{Reuse}

Dredged material can contain many contaminants at low levels, which conventional remediation techniques can reduce for the purposes of disposal. However, near complete destruction of contaminants are required prior to upland disposal or reuse. For example, the most stringent criteria apply to agricultural uses of sediment, as food contamination is possible. Subsequently, less stringent criteria apply to residential land uses, while the lowest criteria are utilized for industrial developments (Graham and Lei, 2000). In Ontario, sediment disposal is regulated by the EPA Act Regulation 347 Leachate Test and the Guidelines for Use at Contaminated Sites in Ontario (GSCO). Specifically, there are two tests; the leachate test, which assesses the suitability for transport to a landfill; and the analysis for upland disposal test, which tests for use on existing land and potential disposal in water bodies. Comparing the two tests, it is apparent that the GSCO test for upland disposal is much more stringent than the leachate test, with 118 parameters tested versus 33 parameters within the leachate test (Graham and Lei, 2000). Given that sediment planned for upland disposal has a high possibility for human and biological contact, the complete destruction of contaminants will not only require fairly expensive and powerful techniques, but continual GSCO testing prior to approval (Graham and Lei, 2000). Given enough time and energy, many remediation techniques can achieve a high degree of degradation and destruction.

\subsection{Upland Disposal Examples}

Typical disposal options are quite expensive for the dredged material. There have been recent advances within the field, as few cost-effective and sustainable reuse approaches were historically utilized. The first historic reuse of dredged material has been in the form of manufactured topsoil, or construction fill. In particular, both freshwater and marine sediments have been used to produce topsoil for various purposes, including recreational field development in Hawaii, horticultural practices in the City of Toledo, Ohio and for the use as capping material at Superfund sites (Krause and McDonnell, 2000). In the late 1990s, Scott and Sons Company developed topsoil mix for commercial sale, which consisted of dredged sediment, compost and biosolids (Jones et. al, 2000). In addition, the United States 
Army Corps of Engineers (USACE) developed manufactured soil from shredded U.S. Navy documents, marine sediments and biosolids. Another example is N-Viro Company which used sediment dredged from freshwaters, biosolids, kiln ash and fertilizer to produce a commercially viable topsoil product (USACE, 1987). In 2000, cost estimations for the topsoil product were reported as $\$ 15 / \mathrm{m}^{3}$ and demonstrated the ability to grow wetland plants (Jones et. al, 2000). Given the small-scale nature of the aforementioned projects, manufactured soil development for dredged stormwater sediments should garner significant consideration during pond maintenance. Transfer and stockpiling may be required; however, if site conditions permit, dredged material could stay on-site as the soil matrix is developed.

In the United States, the Clean Water Act (CWA) and the Marine Protection, Research and Sanctuaries Act (MPRSA) forbid the disposal of contaminated sediment at sea, which is a major issue as $50-75 \%$ of all dredged sediments from harbours are deemed to be contaminated (Dalton et al., 2004). The cost of remediation can not only be alleviated through the use of cost-effective practices but also by developing products to balance raw material costs and to potentially sell as commercial products. In 2001 , it was estimated that the United States imported $25 \%$ of the 100 million tonnes of Portland Cement put in production across the country (Portland Cement Association, 2003). In a study by Dalton et al., (2004), contaminated sediments were used to replace the raw feedstock required to produce Portland cement. Portland cement is typically made in a kiln with $1500{ }^{\circ} \mathrm{C}$ peak temperature at 30 minutes, which allows for the stabilization of heavy metals and potential for the degradation of organics (Dalton et al., 2004). It is a hydraulic binder made from a limestone and clay, sand or shale mix and it is cured using many of the materials often found within dredged sediments: calcium, iron oxides, silica and alumina. Estimates are that a composition of $15 \%$ dredged material (in Portland cement) could essentially replace all bauxite and fly ash feed-stocks generally required for production (Dalton et al., 2004). Even though quartz contents within sediments may require kiln adjustments, dredged sediments from stormwater ponds passed ASTM standards for strength and soundness, which could endorse fullscale production. Furthermore, Dalton's study has shown that chlorinated levels in dredged sediment were reduced once the cement casing had cooled. However, the significant costs of transportation to cement manufacturer, dewatering and site storage would need to be addressed prior to approval. Even so, not only could the existing facilities be utilized for cement production, but the manufacturer would be able to offset their own raw materials costs.

The reuse of dredged sediments has also been explored and employed in various European nations, as well. Holland and Belgium have had a history with dredging sediments, as coastal processes continuously erode material along their coastlines (Wang et al., 2013). France has recently conducted 
various studies to assess dredged sediment uses, as they attempt to maintain channel and harbour activities (Wang et al., 2012; Zentar et al., 2008; Siham et al., 2008). Recently, there has been a push by the French government to assess beneficial uses of dredged sediment and, in particular, evaluate construction-related uses. Dredged contaminant from the harbour of Dunkirk in northern France has been studied on numerous occasions for its potential use in road construction (Wang et al., 2013). Brittany has recently experienced a construction boom and road construction companies are in need of natural aggregates and local quarries cannot keep up with production needs. Dredged sediment from Dunkirk harbour was shown to be suitable candidates for base layers following a dewatering process, which included dilution, separation and flocculation of sediment (Siham et al., 2008). The sediment, dredged sand, calcerous sand and cement mix was able to pass the French Proctor test (European Standard, NF EN 13286-2, 2005), which determines material compaction and suitability. Furthermore, the IPI index was passed which determines a material's ability to withstand the pressure of heavy machinery (European Standard, NF EN 13286-47, 2003). It has also been shown that increased salinity has the potential to reduce mechanical strength and given the sediments were of marine origin, care must be taken to remove salt through mechanical presses (Siham et al., 2008). Even though stormwater sediments are sequestered from freshwater, seasonal salt use in Ontario could lead to higher salinity levels than initially assumed. In particular, the presence of salt in SWM ponds in Ontario has been reported to increase the concentrations of chlorides capable of metal complexation in sediment porewater (Mayer et al., 2008). This complexation capability increases the concentration of metals and can lead to further contamination in SWM ponds.

Using a local example, the Region of Waterloo has recently experimented with the reuse of stormwater sediment for the purposes of developing compost amendments and landfarming. The project focused on sediments dredged from Victoria Park Lake, an online stormwater pond that provides treatment of runoff from approximately 1400 ha of mixed residential, commercial and industrial land (Kitchener, 2011). The intention was to reduce the concentration of contaminants of the 45,000 tonnes of sediment, which required removal. Initially, wood chips were added to the dredged material to pass the slump test required for transportation to landfills, where semi-annual testing would assess contamination standards against the MOE Table 1 and Table 2 site condition standards, which set exceedance values for specific pollutants (MOE, 2011). Slight exceedances of PAHs and PHCs prompted samples to be added to test composting piles along with clean dredged material to stabilize the stockpile and provide nutrients for composting (City of Kitchener, 2011). As of 2013, the result was a reduction in contamination over two years with continuous testing planned for the future. Furthermore, the City of 
Kitchener plans in-situ quality and quantity testing of its stormwater sediments, which will help identify disposal and/or remediation needs. Future consideration within the Region is assessing the use of sawdust and other biostimulation methods that may promote degradation.

\subsection{Disposal}

According to the Handbook for Dredging and Dredged Material Disposal in Ontario, dredging is defined as the planned removal of material located below the surface of a waterbody or at the landwater interface (OMOE, 2011). Subsequently, dredging of SWM pond sediments is subject to the various permits and approvals required by municipal, provincial and federal policies and regulations (OMOE, 2008). The evaluation of dredged material must be joined with the relevant legislative requirements, prior to project commencement. Following a thorough evaluation of the dredged material, the contractor will be required to submit an application for disposal to the OMOE (OMOE, 2011). Guidelines regarding the Management of Excess Soil were recently published by the OMOE and outline best management options for 'excess soil', or soil that has been excavated during construction activities.

Under current policies and regulations, dredged sediment would qualify as excess soil in most cases, which are merely unconsolidated natural occurring mineral particles that have been broken down by physical, chemical, or biological processes (OMOE, 2014). Within Ontario, the management of excess soil is gaining headway; soil conservation and management concerns are beginning to be implemented into the planning process (OMOE, 2014). In particular, soil conservation activities not only encompass the removal of soils, but also transportation and storage of excess soils. Additionally, there are provisions for the temporary storage of excess soil at an intermediate site, as well (OMOE, 2014). The Region of Waterloo has a compost amendment pilot project and a nutrient trial project to assess the effectiveness of such temporary beneficial reuse sites (Bobechko, 2014). Under soil excess guidelines, nutrient testing trials were implemented to assess the impacts of adding nitrogen, heat retention and anoxic conditions to facilitate the breakdown of PAHs (Bobechko, 2014). It was noted that at present time, the aforementioned conditions promoted bacterial growth and facilitated the breakdown of the contaminants. In either case, it is the responsibility of the operator to ensure the 'cleanliness' of soil at the source site, during excavation, and at the receiving site, during disposal. The important this to note is that a contaminant in exceedance should not be introduced to a new site, and in addition, care should be taken to introduce invasive species within excess soil if used as topsoil (MOE, 2014). Finally, dilution of excess soil should not be employed and proper laboratory analyses and analytical procedures should 
be undertaken to determine contamination.

Prior to disposal, dredged material is subject to a classification process regulated by the Canada-Ontario Agreement Sediment Decision-Making Framework (2007). In conjunction with Environment Canada and the OMOE, this decision-support document assesses the disposal option for a given bulk of dredged material through four parameters: sediment chemistry, toxicity, benthos alteration and bio magnification potential (OMOE, 2011). The application requirements are as follows: detail of the proposed disposal site, description of the type of material to be disposed (including the results of all chemical analyses), disposal alternatives and if containment is preferred, the design of the management facility and decommissioning process are required (OMOE, 2011). Following various levels of approval within Ontario, dredged material can be disposed of in one of three ways: open water disposal, disposal on land and confined disposal (OMOE, 2008).

Once dredged material has been chemically analyzed and accepted for potential disposal, the bulk is classified into one of four categories in Ontario: suitable for open water disposal; suitable for disposal on land; transfer to a certified confined disposal facility (contaminated material with dewatering); and hazardous material disposal at a confined disposal facility, with dewatering forbidden (OMOE, 2011). If dredged material from stormwater ponds lacks any presence of contamination, unconfined open water disposal becomes an option. In this option, dredged material is transported from the site to a pre-approved location where it can be released unconfined to open waters or methodically placed on the bed of the water body (Pantazidou et al., 2009). Approval for a suitable disposal site will depend upon many factors, including: commerce and transportation routes, fishing impacts, water level fluctuations, disturbance of breeding sanctuaries, erosion and accretion patters and water quality issues (EPA, 2011). It is important to note that southern Ontario and the GTA would be subject to the Great Lakes Water Quality Agreement, which is an international agreement between Canada and the United States (OMOE, 2008). In particular, Annex 7 of the agreement regulates the development and handling processes associated with contaminated sediments in Ontario (OMOE, 2011). If, for example, Lake Ontario were deemed a suitable disposal site, there may be hindered efforts to begin disposal of sediment dredged from SWM ponds without American endorsement. Generally, disposal sites are located 1-3 km away from well-travelled navigation channels, as adverse impacts are assumed to be prevented at these distances (OMOE, 2011). Furthermore, a conscious effort to 'sediment match' has been recently undertaken to dispose dredged sediments in areas that have similar substrate characteristics. It has been noted that sediment matching can not only reduce the time for aquatic organisms to readapt to their new habitat, but also promotes stability in terms of local chemical, 
physical and biological dynamics within the immediate area.

If dredged sediments are deemed to be contaminated through chemical analyses, confined disposal is the route taken to manage dredged material (OMOE, 2008). The intention of confined disposal is to segregate contaminants from the surrounding environments (Pantazidou et al., 2009). The first way this is accomplished is through confined land disposal, where dredged material is disposed into open pits and solids consolidate at the bottom (Fredette, 2006). The intention is for nearby water to periodically wash over the disposal site and dilute and promote the overflow of water into the lake or sea (Fredette, 2006). As a result, these facilities are often constructed quite close to larger waterbodies and on coastlines, but must take into account potential recreational use, waterfront development and riparian rights (OMOE, 2011). Furthermore, confined disposal facilities can be designed for upland use, but additional design and operational considerations are required. Where dewatering is accepted, the facility should be designed to reduce the loss of fine particulate matter, as organic micropollutants have a high affinity for them (OMOE, 2008). According to guidelines, the intention is to reduce the horizontal velocity relative to its vertical velocity to increase sedimentation rates (OMOE, 2011). Subsequently, decommissioning and long-term monitoring would need to be addressed within any successful application (Pantazidou et al., 2009). In particular, the proposed site will have to ensure long-term containment if capping of the disposal facility is accepted, and potential future site use.

The final option available for the disposal of dredged sediment is disposal at landfills and/or hazardous landfills (Drake and Guo, 2008). In preparation for disposal, if dredged sediment does not meet the 'slump test' requirements, according to EPA regulation 347, dewatering of the bulk is required prior to transport (EPA, 2011). Dewatering (or bulking), in terms of dredging, is referred to the removal of water from a mass using materials that will absorb moisture (Lee, 2005). In addition, drying of the sediment can also be utilized, where sediment is spread to a maximum of $425 \mathrm{~mm}$ in depth for approximately one week (OMOE, 2011). Following dewatering, TCLP testing is required to determination the presence and level of contamination, after which registered landfill disposal (hazardous and non-hazardous) or upland disposal can be selected (GIC, 1999). Cost estimates for landfill disposal range from $\$ 20 / \mathrm{m}^{3}$ for non-hazardous material to over $\$ 800 / \mathrm{m}^{3}$ for hazardous material (GIC, 1999). Recently, a report by the Lake Simcoe Region Conservation Authority (LSRCA) reported that disposal costs for contaminated sediment is $\sim \$ 380 / \mathrm{m}^{3}$ and, using this value, would cost the City of Aurora upwards of \$18 million to bring all SWM ponds to their previously designed efficiency (LSRCA, 2010). A range of costs for SWM pond maintenance in areas within the LSCRA jurisdiction were reported as $\$ 1.6$ million to $\$ 50,000$, with the median cost as $\$ 267,000$ (LSRCA, 2010). 


\subsection{Decision Support Tool}

The intention of the project is to not only compile a list of relevant technologies and removal options for management of SWM pond sediments, but also assist municipalities and contractors with their decision-making. While decision-making tools have been available for over 30 years, their foray into the environmental field has only recently been observed. Presently, most of the relevant decisionsupport tools available to various parties engaged in soil and groundwater remediation often focus on site characterization and planning of sampling strategy, rather than on the selection of remediation technologies (Agostini et al., 2009). Canada does not have an approved method or framework to systematically study the various factors involved with the decision-making process to select a proper clean-up method with regards to contaminated sites. Conversely, various European nations have begun to develop national written standards, with a future goal of incorporating software-based decisionsupport tools into their guidelines (Sorvari, 2010). While the intention is not to create ground-breaking support systems, the presence of a remedial option support tool has the potential to save taxpayer money and, ultimately, biological habitats.

The decision-support tool utilized within this project can only be used for a specific point of the decision-making process. Prior to potential clean-out and maintenance activities, a Municipality must decide if there are other similar options that may utilized to maintain water quality and performance of the pond, such as the use of low impact development (LIDs) options or sustainable drainage systems (SuDS) to complement SWM. Once a Municipality has elected to maintain its current course of SWM, through the use of SWM ponds, an initial site assessment using bathymetric surveys and sediment characterisation will be required to develop an internal prioritization scale, which will ultimately identify SWM ponds that require expected dredging. It will be the Municipality's or consultant's responsibility to develop a prioritized list of ponds, which can be based on accumulation, impact to the function of the pond and subsequent impact to receiving waters. As a result, the criteria responsible for prioritization are an additional decision that is required prior to the use of the matrix and flow chart. There are various criteria for prioritization of SWM pond clean-out that are recommended for use, which can be used: total volume of sediment accumulation, reduction in TSS removal efficiency, or presence of contaminants. It is recommended that the operator utilizes one of the aforementioned criteria to develop their own prioritization for impending clean-out activities and identify internal management objectives. Once a specific SWM pond, or group, is deemed as requiring maintenance, the decisionsupport tool described in this report (matrix and flow-chart) can be employed. 
There are numerous tools available to select specific remedial options, such as: knowledgebased systems, expert support models and software-based multiple criteria analysis (MCA) tools. For this project, a simple matrix-based decision support tool was utilized to provide practitioners with an opportunity to conduct an informed comparison and selection of relevant technologies. In particular, the matrix presented in Table 1 is largely based on the Federal Remediation Technologies Roundtable (FRTR) Treatment Technologies Screening Matrix. The FRTR is result of collaboration between various United States agencies and regulatory bodies, which are directly and indirectly involved with a majority of contaminated site clean-up operations (FRTR, 2008). The involved agencies are: U.S. Department of Defense, U.S. Department of Energy, U.S. Department of the Interior, U.S. Environmental Protection Agency and the National Aeronautics and Space Administration (NASA). Within the matrix, 64 in-situ and ex-situ technologies were ranked as being above average, average, or below average in the following categories: development status, treatment train, cost and performance (including operation and maintenance, capital, reliability, relative cost and time), availability and its ability to destroy specific contaminants (FRTR, 2008). The contaminant groups described within the matrix were previously introduced and have been utilized within the adapted table. Although the tool does not account for specific site conditions and catchment characteristics, it is useful for initial technology screening. For the purposes of remediating SWM pond sediments, the matrix presented in Table 1 has been curtailed to this specific use. The screening matrix rates specific remedial options as above average (1), average (2) and below average (3). Table 2 describes the conditions the FRTR uses to define its criterion (FRTR, 2008). This screening matrix is used as part of the decision support tool.

Table 1: Adapted FRTR screening matrix for the remediation of SWM pond sediments

\begin{tabular}{|c|c|c|c|c|c|c|c|c|c|c|c|c|c|c|c|c|}
\hline & 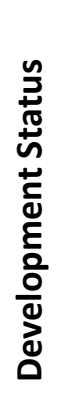 & 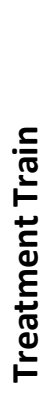 & $\sum_{\infty}^{\infty}$ & $\begin{array}{l}\bar{\pi} \\
\frac{\pi}{0} \\
\frac{\pi}{0} \\
0\end{array}$ & 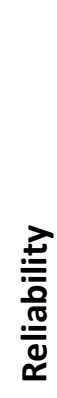 & 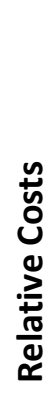 & $\stackrel{\mathscr{\Xi}}{\underline{E}}$ & 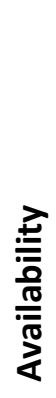 & 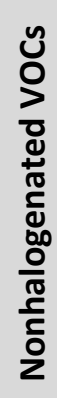 & 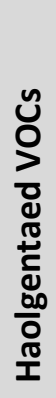 & 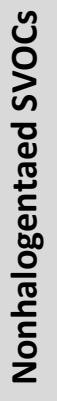 & 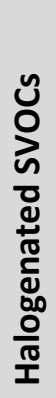 & $\frac{n}{\frac{\omega}{2}}$ & 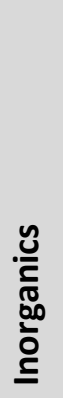 & 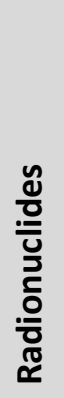 & 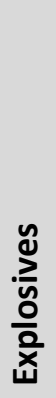 \\
\hline \multicolumn{17}{|l|}{ Biological Treatments } \\
\hline $\begin{array}{l}\text { Biostimulation and } \\
\text { Bioaugmentation (in-situ) }\end{array}$ & 1 & 1 & 3 & 2 & 2 & 1 & 2 & 1 & 1 & $*$ & 1 & 3 & 2 & 3 & $*$ & 3 \\
\hline Phytoremediation (in-situ) & 1 & 1 & 1 & 1 & 3 & 1 & 3 & 2 & 1 & 2 & 2 & 2 & 2 & 2 & 3 & 3 \\
\hline
\end{tabular}




\begin{tabular}{|c|c|c|c|c|c|c|c|c|c|c|c|c|c|c|c|c|}
\hline Composting (ex-situ) & 1 & 1 & 1 & 1 & 1 & 1 & 2 & 1 & 2 & 2 & 2 & * & 1 & 3 & 3 & 1 \\
\hline Landfarming (ex-situ) & 1 & 2 & 3 & 1 & 2 & 2 & 3 & 1 & 2 & 1 & 1 & $*$ & 1 & $*$ & 3 & 1 \\
\hline \multicolumn{17}{|l|}{ Chemical Treatments } \\
\hline Chemical Oxidation (in-situ) & 1 & 1 & 3 & 2 & 2 & 2 & 1 & 1 & 2 & 2 & 3 & 2 & 3 & $*$ & 3 & 2 \\
\hline Chemical Oxidation (ex-situ) & 1 & 2 & 2 & 3 & 1 & 2 & 1 & 1 & 2 & 2 & 2 & 2 & 2 & 1 & 3 & 2 \\
\hline S/S (in-situ) & 1 & 1 & 2 & 3 & 1 & 1 & 1 & 1 & 3 & 3 & 2 & 2 & 3 & 1 & 1 & 3 \\
\hline S/S (ex-situ) & 1 & 1 & 2 & 3 & 1 & 1 & 1 & 1 & 3 & 3 & 2 & 2 & 3 & 1 & 1 & 3 \\
\hline Solvent Extraction (ex-situ) & 1 & 3 & 3 & 3 & 1 & 2 & 1 & 1 & 2 & 2 & 2 & 2 & 2 & 2 & 1 & 3 \\
\hline \multicolumn{17}{|l|}{ Physical Treatments } \\
\hline Thermal Desorption (ex-situ) & 1 & 1 & 3 & 3 & 2 & 2 & 1 & 1 & 1 & 1 & 1 & 1 & 1 & 3 & 3 & 1 \\
\hline $\begin{array}{l}\text { Risk-Management measures } \\
\text { (ex-situ or in-situ) }\end{array}$ & 2 & 2 & 1 & 3 & 1 & 1 & 2 & 1 & - & - & - & - & - & - & - & - \\
\hline Incineration & 1 & 1 & 3 & 3 & 2 & 3 & 1 & 1 & 1 & 1 & 1 & 1 & 1 & 3 & 3 & 1 \\
\hline Excavation and Disposal & 1 & 1 & 1 & 1 & 1 & $*$ & 1 & 1 & 2 & 2 & 2 & 2 & 2 & 1 & 3 & 2 \\
\hline
\end{tabular}

Table 2: Criteria definition of terms used in screening matrix (FRTR, 2008)

\begin{tabular}{|c|c|c|c|}
\hline & Above Average & Average & Below Average \\
\hline Development Status & $\begin{array}{l}\text { Well-understood and } \\
\text { currently employed on } \\
\text { many sites }\end{array}$ & $\begin{array}{l}\text { Has been implemented } \\
\text { on full-scale projects } \\
\text { but improvements } \\
\text { required }\end{array}$ & $\begin{array}{l}\text { Only pilot testing } \\
\text { utilized }\end{array}$ \\
\hline Treatment Train & Stand-alone technology & $\begin{array}{l}\text { Requires more than one } \\
\text { technology, but widely } \\
\text { applied }\end{array}$ & $\begin{array}{l}\text { Complex (i.e. requires } \\
\text { additional off-gas } \\
\text { treatment }\end{array}$ \\
\hline O\&M & Low degree intensity & $\begin{array}{l}\text { Average degree } \\
\text { intensity }\end{array}$ & High degree intensity \\
\hline Capital & Low capital needs & Average capital needs & High capital needs \\
\hline Reliability & High & Average & Low \\
\hline Relative Costs & Low & Average & High \\
\hline Time & $\begin{array}{l}\text { In-situ: }<1 \text { year } \\
\text { Ex-situ: }<0.5 \text { year }\end{array}$ & $\begin{array}{l}\text { In-situ: } 1-3 \text { years } \\
\text { Ex-situ: } 0.5-1 \text { year }\end{array}$ & $\begin{array}{l}\text { In-situ: }>3 \text { years } \\
\text { Ex-situ: }>1 \text { year }\end{array}$ \\
\hline Availability & $>4$ vendors & 2-4 vendors & $<2$ vendors \\
\hline Contaminants & $\begin{array}{l}\text { Effective at full scale } \\
\text { and pilot tests }\end{array}$ & $\begin{array}{l}\text { Limited at full scale and } \\
\text { pilot tests }\end{array}$ & $\begin{array}{l}\text { Not effective at full } \\
\text { scale and pilot tests }\end{array}$ \\
\hline
\end{tabular}

The presence of an asterisk $\left({ }^{*}\right)$ in Table 1 indicates that the level of effectiveness is highly dependent on site-specific conditions and size of the contaminant plume (FRTR, 2008). In addition, all ex-situ remedial options assume initial dredging of the pond, prior to treatment. 
The decision-support tool is a simple flow chart, which attempts to systematically capture the suggested course of action to be taken by practitioners when addressing the accumulated SWM pond sediments. The decision-support tool utilizes an easy-to-follow flow chart shown in Figures 8 and 9, complimented with the use of the previously provided matrix. The diagram begins with the physical and chemical characterization of the SWM pond sediments to determine physical dredging operations (Figure 8). The user can then select one of four choices, all of which are dependent on the chemical analyses; if the sediment passes the Table 1 standards, it can be subject to direct disposal at a registered landfill or beneficial uses options; and if the sediment does not pass Table 1 standards, it can be disposed of in a registered hazardous landfill or remediated (Figure 9).

It is highly recommended that the Municipality and associated operators utilize the matrix and flow chart concurrently and in unison to attain their remedial goals. The internal logic of the aforementioned tools suggests that the type of contaminant is the integral component to remediation, as specific remedial techniques can only address a small range of contaminants. As a result, the operator has the ability to identify a specific constraint, such as budget (in the matrix), identify a potential remedial option (in the flow chart), verify its ability to mineralize a contaminant (in the matrix), or choose another route of action (flow chart). The use of both tools concurrently allows for a flexible decision-making process and allows the operator to continually evaluate their own specific needs. The tools are constrained in their use, as they cannot provide a single analysis of all criterions to obtain one or two ideal remedial options, but they contain the ability to highlight remedial option applicability individually with a visible ranking system. This system does not allow the tool to make a choice itself, but gives the Municipality the ability to assess each decision variable individually, apply its own internal logic to the decision-making process, and consequently obtain an optimal remedial option for its own SWM ponds. The first part of the flow chart (Figure 8) utilizes a flow chart adapted from the previous sediment management pond maintenance guidelines (GCI, 1999). Initially, the physical characterization of sediment will determine the dredging option; generally, coarser materials are subjects to mechanical dredging, while silts and clay removal often requires hydraulic or hydrodynamic dredges. It is recommended that all SWM ponds with a substrate that contains $>50 \%$ of sediment smaller than the coarsest silt particle size $(62.5 \mu \mathrm{m})$ utilize hydraulic or hydrodynamic dredging to remove sediment. As a result, this would preclude that a vast majority of SWM ponds require the use of a hydraulic removal method (high percentage of silt and clay), as opposed to traditional mechanical dredging methods, which can be retained for ponds with high concentration in sands, gravels and pebbles, or when dredging operations are planned for the winter season, which decreases the probability of plume 
development. It is reported that the presence of resuspended sediments and residuals can account for up to $9 \%$ of the initial bulk removed (Patmont, 2006), and mechanical dredging is much more likely to resuspend sediments and promote plume development than are hydraulic dredging methods (Bridges et al., 2008; Hayes, 2006; Anchor, 2003). If a Municipality can only utilize mechanical dredging due to availability and area constraints, care must be taken when dredging SWM ponds that outlet into receiving water with sensitive habitats (e.g. Redside Dace). Mechanical dredging has the ability to be utilized in wet and dry conditions, but it has a propensity to disrupt biological communities. As a result, if sensitive habitats are located within receiving waters, care should be taken to limit resuspension of sediment or hydraulic dredging should be utilized.

Recent work suggests that dredging performance can be affected by seasonal conditions and, in particular, winter pond maintenance has gained credence within academic and regulatory circles. Initially, frozen ground would allow mechanized equipment to move freely throughout the SWM pond, with little disturbance. Furthermore, as very little water needs to be pumped due to frozen water, the removal and redistribution of large ice chunks could facilitate easier sediment removal, as dredging equipment moves from the forebay to the permanent pool. Finally, although working days may be lessened, the dredged sediment can be left in piles to freeze overnight to ease transport from the site on the following day. Given the various benefits of winter pond maintenance, its use should be considered by all operators and engineers. Not only would this allow for construction work in nontraditional time periods (Dec.-Feb.) but also limits the disturbance potential of mechanical dredging operations, which are the easiest to employ. 


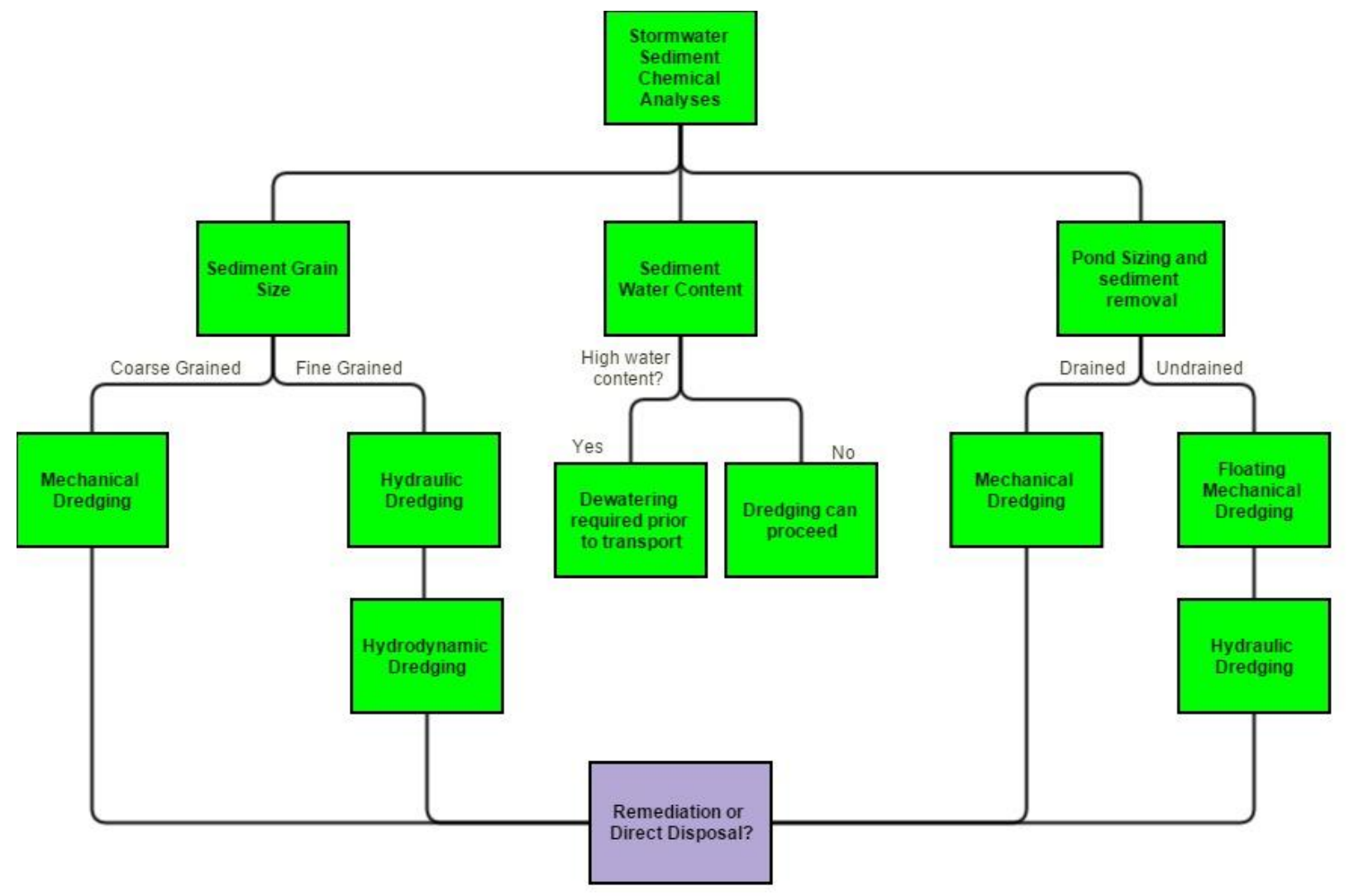

Figure 8: DST - Sediment Characterization and Dredging (Part 1)

Access to the SWM pond and ample room for removal activities to occur are necessary for the success of dredging operations. The Cities of Barrie, Brampton and Pickering have included the requirement for space required for sediment removal activities in their SWM Guidelines recently, . Here, the Cities require a Sediment Drying Area, which is intended to facilitate access to the pond, with respect to dredging removal activities, and for temporary (or permanent) sediment storage once removal is complete (City of Pickering, 2015; City of Barrie, 2010). The Sediment Drying Area has a series of requirements, including; sizing for a minimum of 10 years of sediment accumulation, designed for a maximum sediment height of $1.5 \mathrm{~m}$ and an associated slope of 10:1, and at an elevation above the predicted 2 year water level (City of Pickering, 2015; City of Barrie 2010). The City of Brampton also has requirements for a sediment drying area, but their provisions require a storage area above the predicted 5 year water level (City of Brampton, 2008). With regards to remediation, sediment drying areas could allow for the in-situ clean-up of sediments. A municipality may be averse to the accumulation of piles of sediment on such sites; however, when coupled with phytoremediation and the use of biota, sediments could be vegetated, undergo contaminant removal and provide aesthetic value to the area. 
Subsequently, such storage areas would have to comply with Municipal and Regional design standards as they relate to maintenance road access. Although sediment drying areas are referenced within planting guidelines (TRCA, 2007), within SWM pond maintenance guidelines (Aquafor Beech Ltd., 2009), and within guidelines for SWM-related submissions (LSCRA, 2013), the inclusion of their design requirements within regional guidelines would provide guidance to operators, as many SWM ponds need maintenance in the near future and, subsequently, require access by heavy machinery and storage for dredged sediment.

Following dredging, the operator must subject the stormwater sediment to a chemical analysis to determine the presence of contaminants and the extent of contamination. Currently, there are accepted practices to sample bed material and regulated analyses following sampling; however, there are few guidance documents available regarding the frequency, depth and/or spatial distribution of samples taken at SWM ponds. At present, it is the discretion of the consultant to develop a comprehensive sampling program and conduct repeated samples to determine possible contamination. If exceedances are not present and the contaminant levels have passed the Table 1 standards, the first disposal location for the sediment is a registered landfill, which is the most common practice. 'Dig and dump' methods are applied quite liberally when faced with dredged stormwater sediments, even though they often result in ecological disturbances and are potentially quite expensive compared to other options. A more environmentally conscious and sustainable option would be to employ the beneficial reuse of stormwater sediments. There are several options available to the operator once this avenue is selected, as described in detail in Chapters 7 and 8. If the dredged sediment has a high nutrient content and has been deemed as potentially beneficial to biotic communities, agricultural spreading and soil amendments would be easily utilized alternative to simple direct disposal. In addition, soil amendments could be developed into compost heaps over the course of time and if the operator chooses so, soil amendments could be again transported to landfills and subsequently used as daily fill. For other dredged sediment bulks with lower nutrient contents, the use of dredged sediments in construction materials (i.e. Portland Cement) or as road fill are both economically and environmentally viable alternatives that have not only proven to pass stress and resistance tests, but would allow SWM pond operators to recoup some resources spent during dredging operations. The final displayed option is the use of dredged sediment in shoreline-related restoration activities, such as bank stabilization, channel realignment projects or in bioengineering methods. This method is the least employed, but, with proper discourse, could gain traction in a growing field. 


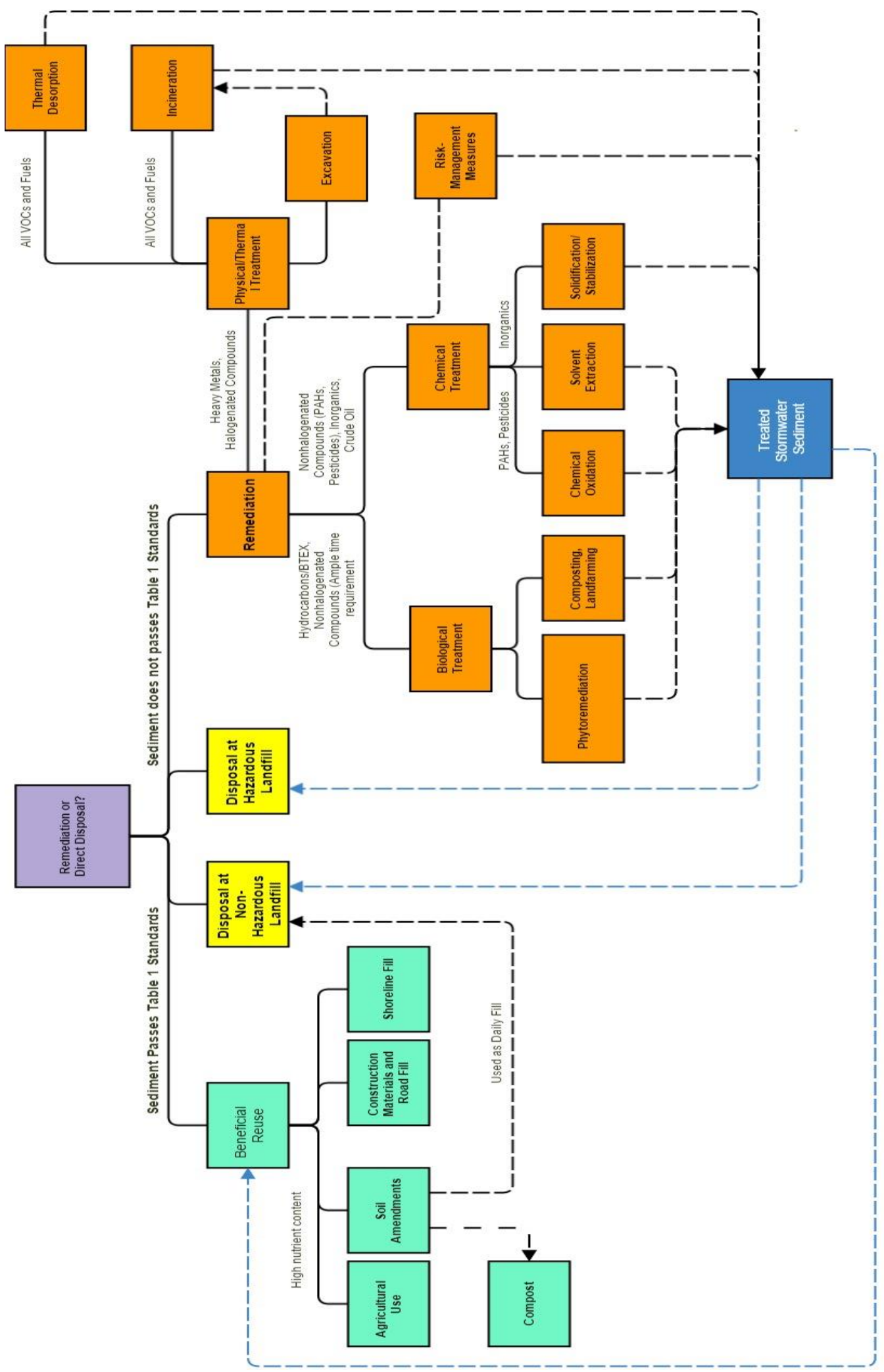

Figure 9: DST - Options for Beneficial Reuse, Remediation and Disposal (Part 2) 
The second set of options is available if tested sediment does not pass Table 1 standards. If exceedances are present, it is recommended that Phase 1 and Phase 2 site assessments are overseen by a Qualified Person, under the EPA, and subsequently file a Record of Site Condition prior to any further action. Phase 2 site assessments would specifically highlight the contaminants requiring clean-up and point to various technologies that could be used to remediate the site. The first option available to operators is direct disposal at a registered hazardous landfill facility, which would also incur high transportation costs and tipping fees. With regards to reporting, the entire chain of custody should be documented from the transportation of sediment to final disposal at the registered hazardous or nonhazardous landfill. Current practices do not require contractors and operators to specify the location of disposal and provide final assurance of disposal to the relative regulatory agency. A succinct chain of custody would not only ensure the contractor has followed all necessary steps to remove material, but also provides a guarantee that highly contaminated sediment would only be disposed of in landfills designed to handle their toxicity.

Another option available is the use of conventional remediation to improve the quality of dredged sediments to the level that they can be disposed in a registered landfill or potentially utilized for beneficial reuse options. Depending on the contaminant(s) to be removed, certain remedial options will be better suited than others. Furthermore, when costs, time needed and rate of destruction are factored in, the decision maker is left with a group of technologies that are suited to their own needs. For example, if the operator has relatively small budget available or long-term clean-up deadlines, biological technologies are the most feasible. In addition, bioremediation are better suited to sensitive environments and promote sustainable remedial practices. However, if shorter deadlines are anticipated, chemical or physical methods should be utilized, as their contaminant destruction and removal rates are high and can be attained fairly quickly. However, both physical and chemical treatments have high incurred costs and, in the case of physical treatment, have high incidences of disturbance to surrounding habitats. The transport of contaminated material must be factored into any decision process, as transport routes could affect bottom-line costs as well as factor into public acceptance. In conclusion, with each remedial technology comes the option of remediating in-situ or exsitu, which can play a role in cost savings. For example, the City of Kitchener has undertaken the composting of stormwater sediments within a local landfill; however, without the necessary area to stockpile the material, this option would not be feasible.

Determining a suitable technology is sometimes quite difficult, as a decision maker would need 
to weigh numerous factors. If the rate of destruction is the most integral element, the screening matrix can indicate which contaminants are susceptible to destruction for each suitable option (Table 1). It is important to note that one remedial option may not be adequate to completely mineralize a contaminant and a second option should be employed. Consequently, in such situations, further chemical analysis may be required following the initial corrective action (remediation) or additional clean-up practices could be included within the initial scope of work, which is subject to the type of contaminant and extent of it mobility. Within SWM ponds, the most common exceedances are often fuels and inorganics and often require a combination of biological and chemical methods to address their toxicity. For example, bioremediation can extensively destroy fuels and hydrocarbons, as they are naturally occurring compounds with associated enzymes. As a result, petroleum hydrocarbons can be degraded quite well by microorganisms in the presence of oxygen through aerobic respiration. Here, it is imperative to maintain adequate moisture levels and that oxygen and nutrients are distributed evenly within the sediment bulk. In certain circumstances hydrophobic compounds (most fuels) will sorb to particles and thus require the use of a chemical treatment (surfactants) to assist in the degradation process. With regards to chemical treatment options, they are most effective at removing inorganics, such as heavy metals, due to their ability to isolate and immobilize heavy metals. Although the destruction of heavy metals is fairly difficult using conventional and commercial methods, their separation from the sediment bulk could allow for future reuse of stormwater sediments and complete heavy metal removal. If either biological or chemical treatment methods are unsuitable, physical methods are well-suited to remove contaminants from sediments, especially thermal desorption, which can destroy highly toxic compounds and allow for the treatment of off-gases. Physical methods, such as excavation and incineration, have the ability to remove and mineralize various contaminants, however, at high incurred costs, their employment will have to be balanced with a series of other factors.

Once remediation has cleaned stormwater sediments to an accepted level, the operator will be left a bulk of treated SWM pond sediments. Here, there are three further options available for the final destination of stormwater sediment, which ultimately rely on the degree and level of clean-up. Following the treatment of SWM pond sediments, an additional series of chemical analyses are required to determine the presence of exceedances. If the sediment bulk passes the Table 1 standards following remediation, there is a potential for its reuse or, at the least, disposal in a registered non-hazardous landfill. This would allow operators the opportunity to remediate all contaminated sediment, prior to final disposal. As a result, the screening matrix and the flow chart can be used in succession or unison to identify a suitable remedial option or prove that simple excavation and disposal options are the most 
feasible. If remediation is chosen, the level of clean-up will determine the type of proposal available to the operator; stakeholders can choose whether to remediate a bulk of stormwater sediment to the level suitable for disposal at a landfill or to the level where future land application is possible. Consequently, adequate monitoring is required throughout the remedial process to ensure successful performance of the decision-support tool. The screening matrix and flow chart are meant to complement each other when identifying clean-out needs and concerns with regards to SWM pond maintenance and are encouraged to be used in unison or cyclically depending on ongoing Municipal and/or contractor needs. They can be used as preliminary tools, but are meant to highlight the need to create a succinct guideline to assist operators when faced with SWM pond maintenance concerns.

\subsection{Conclusions and Recommendations}

As SWM ponds continue to mature, their preservation will become a larger issue within the Municipal conscience. Municipalities have a responsibility to not only maintain the water quality discharging from SWM ponds, but also to protect the downstream habitats of receiving waters. Furthermore, as SWM ponds continue to be a mainstay in residential, commercial and industrial developments design practices, their scheduled maintenance should become a mandated provision, as stormwater sediments have proven to have an affinity for numerous nutrients and organic micropollutants. A failure to remove contaminated sediments from SWM pond could have biological implications for immediate and local biotic communities and a potential to affect humans within close proximity to residential ponds. Recently, there have been advances into the issue, as various municipalities have acknowledged the issue of SWM pond maintenance and are addressing the needs in their annual budgets.

The first recommendation is the notion to implement a monitoring program specifically catered to SWM ponds and, in particular, stormwater sediments. The Town of Richmond Hill, for example, has developed a largely successful SWM pond monitoring program. Through the understanding of local sediment accumulation and hydraulic conditions, the program has been able to assess the performance of each of its ponds with the implementation of an inspection program. In addition, it has been noted by Nemeth (2007) that the municipality has an ability to predict the level of contamination in many of its ponds, which would allow for thorough budget preparation and potential clean-out. In the future, the focus should be directed to the development of sediment accumulation models, as continuous physical sampling of SWM ponds will adversely affect budgets and employee management. Accurate, simulated 
results of sediment accumulation within SWM ponds have been reported by Richard (2012) and Gregory (2014); however, physical models better suited to specific catchment could greatly assist municipalities in the management of their stormwater facilities. Furthermore, a calibrated and locally-tested sediment accumulation model could be implemented into future planning guidelines and assist CA with zoning bylaws and development. As an initial step, there has been an impetus to develop and regulate monitoring programs. For example, the City of Guelph advises that SWM ponds within 2 years of construction should be monitored four times per year and annually, thereafter (TSH, 2008).

Furthermore, the City of Guelph has discussed the development of a long term maintenance plan for all ponds within their jurisdiction and subsequent sediment removal plans (TSH, 2008).

Currently, municipalities do not have guidelines for monitoring practices, which is an inherent issue with stormwater management. Initially, municipalities should make a concerted effort to determine the number of designed SWM ponds within their respective jurisdiction, with the hope of developing a monitoring program in the future. Some Municipalities have begun not only begun taking inventory of ponds, but developing Master Plans for the future direction of SWM-related operations. In particular, the City of Vaughan recently completed a Stormwater Management Master Plan Municipal Class Environmental Assessments (Cole, 2014), which highlights the needs to develop a framework for all future SWM within the city. Furthermore, the document identifies the need to develop control strategies, update design criteria, introduce phasing requirements to the year 2051, and facilitate the growth of drainage and stormwater runoff related to increased population density. In particular, the document proposes preferred solutions to SWM pond issues, which include complete pond clean-out every $10-20$ years and proposed costs for such implementations (Cole, 2014). Monitoring programs should not only address the quantity of sediment accumulating on the beds of such ponds, but also take into account the quality of sediment not only entering these end-of-pipe options, but also exiting from the outfall, as depicted in Figure 2. Periodic sampling and subsequent TCLP analyses may be able to highlight potential contamination from nearby sources. In 2009, the MOECC inspected nearly 150 stormwater discharges from SWM ponds and concluded that a large majority of non-compliance instances (such as increased TSS, TN, or TP) were related to monitoring and inspection issues. Not only is this important for identifying an area of deficiency, but also highlights a relatively simple solution; improving SWM pond monitoring programs can directly improve the water quality of discharges to receiving waters.

Remediation has had a history of assisting with the redevelopment of brownfield sites, but has yet to make a foray within SWM ponds. With the help of the Ontario conservation authorities, the 
incorporation of remedial options into a stormwater pond maintenance guide would promote its distribution into the engineering and policy-making landscape. The education of operators and stakeholders could curtail remediation practices to SWM ponds and promote the possibility of being included into future provincial guidelines. The first concept of a maintenance guide was developed by Greenland Consulting International (1999), with very little sediment remediation mentioned within the document. In the late 1990s, as SWM ponds were only recently becoming a standard practice in municipal stormwater design and already constructed stormwater ponds were in their infancy, maintenance, let alone remediation was a large concern at the time (and still is). Currently, as SWM ponds begin to require clean-out or have a presence of contaminants, municipalities and operators are not equipped with the tools to tackle expensive clean-out.

Decision-support tools have not been used for remedial option selection, with regards to SWM ponds, within southern Ontario. Currently, engineers and managers alike will depend on tried and tested methods when remediating soil, groundwater and sediment; however, there are many instances when cost savings can be accrued if selection criteria were streamlined. This report includes a flow chart, with an adapted screening matrix to ascertain a feasible remediation method for SWM pond maintenance. It is this author's assertion that this method is modest; however, its use and access could be utilized by a larger community, without the use of complex software or supporting manuals. The future direction of decision-support will undoubtedly involve the marriage of national written guidelines and software-based tools. Current software-based tools utilize a Multiple Criteria Analysis (MCA), which gives a weighted average to specific criteria. This would be quite beneficial in the future as operators would be able to determine and weight the importance of cost, reliability, performance or time to remediate. In a Canadian context, a systematic approach facilitated by a regional conservation authority or Provincial authority could direct the collection of information from sediment removal operations, which can then be used to develop guidelines and, subsequently, assist future removal efforts. A comprehensive effort from various levels of government would not only promote knowledge sharing in a fragmented field but also promote an iterative process where new information on sediment removal could assist future design procedures.

In particular, a number of software-based decision support tools have been developed in Europe, both in-house and under other regional funding programs. One example is the Italian DESYRE (Decision Support System for the Requalification of Contaminated Sites), which is a GIS-based system designed to assess contaminated sites (Carlon et al., 2007). The great benefit of DESRYE is its ability to analyze social and economic benefits and constraints (in addition to remediation method assessment), 
which national written protocols do not address. DESRYE consist of two steps, where the initial step lists all the available technologies and the second step, which by using an environmental database step, utilizes MCA to produce a ranking (Carlon et. al, 2007). Currently the database can assess site management using 60 different technologies, which is fairly close to the 64 technologies the FRTR used for its own screening matrix. The use of a screening matrix with a MCA could be beneficial to SWM pond maintenance, given the impending need to dredge and the underutilization of sediment remediation to address contamination issues.

\subsection{Future Directions}

The intention of this project is to not only highlight concerns related to SWM pond maintenance, but also provide some direction with their management and upkeep. In particular, it is recommended to not only develop semi-annual and annual monitoring programs, but also the development of a central database to track maintenance schedules and sediment accumulation. An example of such effort is a program called SWMSoft (Storm Water Management Operations and Maintenance Software) (Civica, 2014). SWMSoft is a program that serves as a central database for all SWM pond data, such as: bathymetric surveys, sediment accumulation, inspections or merely inventory (Civica, 2014). This program would be very beneficial to public and private entities (if provided as a general access web site, for example), as it would not only assist with inventory controls of SWM ponds, but also assist with the development of maintenance schedules and future upkeep. Furthermore, tables can be updated to include other parameters such as water quality and sediment quality, which would assist all parties with detailed cost itemization and potential future dredging. The concept of a central database is not novel; however, its inclusion within stormwater management would benefit an industry largely dependent on best-management practices. A potential database tool could include:

- Sediment accumulation rates and frequency and locations of concerns within the permanent pool or sediment forebay

- Highlight contaminants of concern at levels below exceedances

- If remediation is ongoing, the rate of mineralization and progress

- Compilations of all operator and contractor correspondence

- Description of catchment properties, including:

- Climatic conditions (rainfall data) 
○ Imperviousness

○ Storm sewer density and capacity

○ Land-use patterns

○ Drainage area management activities (e.g. street sweeping, catchbasin cleaning)

- $\quad$ Space to upload all associated drawings, future land-use plans and associated permitting

- $\quad$ Opportunity for ongoing compliance. A municipality may be required to keep all SWM pond data and clean-out schedules up to date, per Ministry or CA requests.

- Municipalities a system to track and schedule future clean-outs

- $\quad$ Approach to control budget and delegate remaining funding

A future central database could be as simple or as complex as the operator requires. Regardless of its content, a database tool could assist all associated parties with all stages of SWM pond clean-out and promote knowledge sharing within firms. Long-term maintenance programs and practices could greatly benefit from a tool that provides records on past performance, even after employee turnover; a succinct and organized database, thus, becomes akin to a SWM Pond's medical record.

In conclusion, the maintenance of SWM ponds should be considered a solution to an issue that is arriving at a head. Historically, municipalities have failed to address the impacts associated with reductions in SWM pond efficiency, let alone their impending clean-outs. Recently, however, promising steps have been made by a majority of municipalities within the GTA in the form of Master Plans, operation manuals, stormwater management guidelines, pilot project research and costing analyses. A central database would allow for potential prediction and forecasting, yet the need should quickly shift to source control options, once clean-out, beneficial reuse or remediation of sediments is undertaken. Without addressing the source of runoff, and associated contaminants, the clean-outs of SWM ponds would become more prevalent, as population, urbanization and relative imperviousness increase. Although SWM ponds are considered end-of-pipe solutions to water quality issues, they should be considered the last line of defence. The impetus to create a framework that allows for integrated stormwater management will not only alleviate ecological stressors, but ultimately improve water quality and protect receiving waters. 


\section{Appendices}

\section{Appendix 1.1: Full Depth Background Site Condition Standards (MOE, April 2011)}

\begin{tabular}{|c|c|c|c|c|}
\hline Table 1 & $\begin{array}{r}\text { Soil (other } \\
\mu \mathrm{g} / \mathrm{g}\end{array}$ & than sediment) & $\begin{array}{c}\text { Ground Water } \\
\text { (ug/L) }\end{array}$ & $\begin{array}{c}\text { Sediment } \\
\text { ( } \mu \mathrm{g} / \mathrm{g})\end{array}$ \\
\hline Contaminant & $\begin{array}{c}\text { Agricultural or Other } \\
\text { Property Use }\end{array}$ & \begin{tabular}{|c|} 
Residential/ \\
Parkland/Institutional/ \\
Industrial/Commercial/ \\
Community Property \\
Use
\end{tabular} & $\begin{array}{l}\text { All Types of } \\
\text { Property Uses }\end{array}$ & $\begin{array}{l}\text { All Types of } \\
\text { Property Uses }\end{array}$ \\
\hline Acenaphthene & 0.05 & 0.072 & 4.1 & $\overline{\text { NV }}$ \\
\hline Acenaphthylene & 0.093 & 0.093 & 1 & NV \\
\hline Acetone & 0.5 & 0.5 & 2700 & NV \\
\hline Aldrin & 0.05 & 0.05 & 0.01 & 0.002 \\
\hline Anthracene & 0.05 & 0.16 & 0.1 & 0.22 \\
\hline Antimony & 1 & 1.3 & 1.5 & NV \\
\hline Arsenic & 11 & 18 & 13 & 6 \\
\hline Barium & 210 & 220 & 610 & NV \\
\hline Benzene & 0.02 & 0.02 & 0.5 & NV \\
\hline Benzlajanthracene & 0.095 & 0.36 & 0.2 & 0.32 \\
\hline Benzo[a]pyrene & 0.05 & 0.3 & 0.01 & 0.37 \\
\hline Benzo[b]fluoranthene & 0.3 & 0.47 & 0.1 & NV \\
\hline Benzo[ghi]perylene & 0.2 & 0.68 & 0.2 & 0.17 \\
\hline Benzo[k]fluoranthene & 0.05 & 0.48 & 0.1 & 0.24 \\
\hline Beryllium & 25 & 2.5 & 0.5 & NV \\
\hline Biphenyl 1,1". & 0.05 & 0.05 & 0.5 & NV \\
\hline Bis 2-chlorocthyl)ether & 0.5 & 0.5 & 5 & NV \\
\hline Bis 2-chloroisopropyl)ether & 0.5 & 0.5 & 120 & NV \\
\hline Bis(2-ethylhexyl)phthalate & 5 & 5 & 10 & NV \\
\hline Boron (Hot Water Soluble) & NA & NA & $\mathrm{NA}$ & NA \\
\hline Boron (total) & 36 & 36 & 1700 & NV \\
\hline Bromodichlaramethane & 0.05 & 0.05 & 2 & NV \\
\hline Bromoform & 0.05 & 0.05 & 5 & NV \\
\hline Bromomethane & 0.05 & 0.05 & 0.89 & NV \\
\hline Cadmium & 1 & 1.2 & 0.5 & 0.6 \\
\hline Carbon Tetrachloride & 0.05 & 0.05 & 0.2 & NV \\
\hline Chlordane & 0.05 & 0.05 & 0.06 & 0.007 \\
\hline Chlarauniline pe & 0.5 & 0.5 & 10 & NV \\
\hline Chlarobenzene & 0.05 & 0.05 & 0.5 & NV \\
\hline Chlaroform & 0.05 & 0.05 & 2 & NV \\
\hline Chlorophenol, $2 *$ & 0.1 & 0.1 & 8.9 & NV \\
\hline Chromium Total & 67 & 70 & 11 & 26 \\
\hline Chromium VI & 0.66 & 0.66 & 25 & NV \\
\hline Chrysene & 0.18 & 2.8 & 0.1 & 0.34 \\
\hline Cobalt & 19 & 21 & 3.8 & 50 \\
\hline Copper & 62 & 92 & 5 & 16 \\
\hline Cyanide (CN-) & 0.051 & 0.051 & 5 & $\overline{0.1}$ \\
\hline Dibenz $[\mathrm{a}$ b]anthracene & 0.1 & 0.1 & 0.2 & 0.06 \\
\hline Dibromochloromethane & 0.05 & 0.05 & 2 & NV \\
\hline Dichlorobenzene, 1,2 & 0.05 & 0.05 & 0.5 & NV \\
\hline Dichlorobervene, 1,3. & 0.05 & 0.05 & 0.5 & NV \\
\hline Dichlorobenzene, 1,4* & 0.05 & 0.05 & 0.5 & NV \\
\hline Dichlorobenvidine, 3,3 . & 1 & 1 & 0.5 & NV \\
\hline Dichlorodifluoromethane & 0.05 & 0.05 & 590 & NV \\
\hline DDD & 0.05 & 0.05 & 1.8 & 0.008 \\
\hline $\mathrm{DDE}$ & 0.05 & 0.05 & 10 & 0.005 \\
\hline DDT & 0.078 & 1.4 & 0.05 & 0.007 \\
\hline Dichloroethane, 1,1. & 0.05 & 0.05 & 0.5 & NV \\
\hline Dichloroethane, 1,2 . & 0.05 & 0.05 & 0.5 & NV \\
\hline Dichloroethylene, 1,1- & 0.05 & 0.05 & 0.5 & NV \\
\hline Dichloroethylenc, 1,2-cis- & 0.05 & 0.05 & 1.6 & NV \\
\hline Dichloroethylene, 1,2-trans- & 0.05 & 0.05 & 1.6 & NV \\
\hline Dichlorophenol, 2,4. & 0.1 & 0.1 & 20 & NV \\
\hline Dichloropropane, 1,2 . & 0.05 & 0.05 & 0.5 & NV \\
\hline Dichloropropene, 1,3. & 0.05 & 0.05 & 0.5 & NV \\
\hline Dieldrin & 0.05 & 0.05 & 0.05 & 0.002 \\
\hline
\end{tabular}




\begin{tabular}{|c|c|c|c|c|}
\hline Table 1 & $\begin{array}{r}\text { Soil (other } \\
\mu \mathrm{g} / \mathrm{g}\end{array}$ & than sediment) & $\begin{array}{c}\text { Ground Water } \\
\text { (ug/L) }\end{array}$ & $\begin{array}{c}\text { Sediment } \\
(\mu \mathrm{g} / \mathrm{g})\end{array}$ \\
\hline Contaminamt & $\begin{array}{c}\text { Agricultural or Other } \\
\text { Property Use }\end{array}$ & \begin{tabular}{|c|} 
Residential/ \\
Parkland/Institutional/ \\
Industrial/Commercial/ \\
Community Property \\
Use \\
\end{tabular} & $\begin{array}{l}\text { All Types of } \\
\text { Property Uses }\end{array}$ & $\begin{array}{l}\text { All Types of } \\
\text { Property Uses }\end{array}$ \\
\hline Diethyl Phthalate & 0.5 & 0.5 & 30 & NV \\
\hline Dimethylphthalate & 0.5 & 0.5 & 30 & NV \\
\hline Dimethylphenol, 2,4 & 0.2 & 0.2 & 10 & NV \\
\hline Dinitrophenol, $2,4 *$ & 2 & 2 & 10 & NV \\
\hline Dinitrotoluene, $2,4 \& 2,6$ & 0.5 & 0.5 & 5 & NV \\
\hline Dioxane, 1,4 & 0.2 & 0.2 & 50 & NV \\
\hline Dioxin/Furan (TEQ) & 0.000007 & 0.000007 & 0.000015 & NV \\
\hline Endosulfan & 0.04 & 0.04 & 0.05 & NV \\
\hline Findrin & 0.04 & 0.04 & 0.05 & 0.003 \\
\hline Ethylbenzene & 0.05 & 0.05 & 0.5 & NV \\
\hline Ethylene dibromide & 0.05 & 0.05 & 0.2 & NV \\
\hline \begin{tabular}{|l|} 
Fluoranthene \\
\end{tabular} & 0.24 & 0.56 & 0.4 & 0.75 \\
\hline \begin{tabular}{|l} 
Fluarene \\
\end{tabular} & 0.05 & 0.12 & 120 & 0.19 \\
\hline Heptachlor & 0.05 & 0.05 & 0.01 & NV \\
\hline Heptachlor Epoxide & 0.05 & 0.05 & 0.01 & 0.005 \\
\hline Hexachlorobenzene & 0.01 & 0.01 & 0.01 & 0.02 \\
\hline Hexachlorobutadiene & 0.01 & 0.01 & 0.01 & NV \\
\hline Hexachlorocyclohexane Gamma. & 0.01 & 0.01 & 0.01 & NV \\
\hline Hexachloroethane & 0.01 & 0.01 & 0.01 & NV \\
\hline Hexane (n) & 0.05 & 0.05 & 5 & NV \\
\hline Indenso[ 12 23-ed]pyrene & 0.11 & 0.23 & 0.2 & 0.2 \\
\hline Lead & 45 & 120 & 1.9 & 31 \\
\hline Mercury & 0.16 & 0.27 & 0.1 & 0.2 \\
\hline \begin{tabular}{|l} 
Methoxychlor \\
\end{tabular} & 0.05 & 0.05 & 0.05 & NV \\
\hline Methyl Ethyl Ketone & 0.5 & 0.5 & 400 & NV \\
\hline Methyl Isobutyl Ketane & 0.5 & 0.5 & 640 & NV \\
\hline Methyl Mercury ** & NV & NV & 0.12 & NV \\
\hline Methyl tert-Butyl Ether (MTBE) & 0.05 & 0.05 & 15 & NV \\
\hline Methylene Chloride & 0.05 & 0.05 & 5 & NV \\
\hline Methlynaphthalene, $2 \cdot(1 \cdot)^{* * *}$ & 0.05 & 0.59 & 2 & NV \\
\hline Molybdenum & 2 & 2 & 23 & NV \\
\hline Naphthalene & 0.05 & 0.09 & 7 & NV \\
\hline \begin{tabular}{|l|l|} 
Nickel \\
\end{tabular} & 37 & 82 & 14 & 16 \\
\hline Pentachlorophenol & 0.1 & 0.1 & 0.5 & NV \\
\hline Petroleum Hydrocarbons F1*\$** & 17 & 25 & 420 & NV \\
\hline Petroleum Hydrocarbons F2 & 10 & 10 & 150 & NV \\
\hline Petroleum Hydrocarbons F3 & 240 & 240 & 500 & NV \\
\hline Petroleum Hydrocarbons $\mathrm{F} 4$ & 120 & 120 & 500 & NV \\
\hline Phenanthrene & 0.19 & 0.69 & 0.1 & 0.56 \\
\hline Phend & 0.5 & 0.5 & 5 & NV \\
\hline Polychlorinated Biphenyls & 0.3 & 0.3 & 0.2 & 0.07 \\
\hline Pyrene & 0.19 & 1 & 0.2 & 0.49 \\
\hline \begin{tabular}{|l|} 
Selenium \\
\end{tabular} & 12 & 1.5 & 5 & NV \\
\hline Silver & 0.5 & 0.5 & 0.3 & 0.5 \\
\hline Styrene & 0.05 & 0.05 & 0.5 & NV \\
\hline Tetrachloroethane, $1,1,1,2$ - & 0.05 & 0.05 & 1.1 & NV \\
\hline Tetrachloroethane, $1,1,2,2$ - & 0.05 & 0.05 & 0.5 & NV \\
\hline Tetrachloroethylene & 0.05 & 0.05 & 0.5 & NV \\
\hline Thallium & 1 & 1 & 0.5 & NV \\
\hline \begin{tabular}{|l} 
Toluene \\
\end{tabular} & 0.2 & 0.2 & 0.8 & NV \\
\hline Trichlorobenzene, 1,2,4- & 0.05 & 0.05 & 0.5 & NV \\
\hline Trichloroethane, $1,1,1$ - & 0.05 & 0.05 & 0.5 & NV \\
\hline Trichloroethane, $1,1,2-$ & 0.05 & 0.05 & 0.5 & NV \\
\hline \begin{tabular}{|l|} 
Trichloroethylene \\
\end{tabular} & 0.05 & 0.05 & 0.5 & NV \\
\hline Trichlorofluorcmethane & 0.05 & 0.25 & 150 & NV \\
\hline Trichlorophenol, 2,4,5. & 0.1 & 0.1 & 0.2 & $\overline{N V}$ \\
\hline Trichlorophenol, $2,4,6$ & 0.1 & 0.1 & 0.2 & NV \\
\hline Uranium & 1.9 & 2.5 & 8.9 & NV \\
\hline Vansadium & 86 & 86 & 3.9 & NV \\
\hline Vinyl Chloride & 0.02 & 0.02 & 0.5 & NV \\
\hline
\end{tabular}




\begin{tabular}{|c|c|c|c|c|}
\hline Table 1 & $\begin{array}{r}\text { Soil (other } \\
\mu \mathrm{g} / \mathrm{g}\end{array}$ & than sediment) & $\begin{array}{c}\text { Ground Water } \\
(\mu \mathrm{g} / \mathrm{L})\end{array}$ & $\begin{array}{c}\text { Sediment } \\
(\mu g / g)\end{array}$ \\
\hline Contaminant & $\begin{array}{c}\text { Agricultural or Other } \\
\text { Property Use }\end{array}$ & \begin{tabular}{c|} 
Residential/ \\
Parkland/Institutional// \\
Industrial/Commercial// \\
Community Property \\
Use
\end{tabular} & $\begin{array}{l}\text { All Types of } \\
\text { Property Uses }\end{array}$ & $\begin{array}{l}\text { All Types of } \\
\text { Property Uses }\end{array}$ \\
\hline Xylene Mixture & 0.05 & 0.05 & 72 & $\overline{\mathrm{N}}$ \\
\hline Zine & 290 & 290 & 160 & 12 \\
\hline Electrical Conductivity $(\mathrm{mS} / \mathrm{cm})$ & 0.47 & 0.57 & $\mathrm{NA}$ & $\bar{N}$ \\
\hline Chloride & $\mathrm{NA}$ & $\mathrm{NA}$ & 790000 & $\mathrm{~N}$ \\
\hline Sodium Adsorption Ratio & 1 & 2.4 & $\mathrm{NA}$ & $\mathrm{N}$ \\
\hline Sodium & $\mathrm{NA}$ & $\mathrm{NA}$ & 490000 & $\mathrm{~N}$ \\
\hline
\end{tabular}

Notes

() Standard in bracket applies to medium and fine textured soils

$\mathrm{N} / \mathrm{N}=$ No value derived. $\mathrm{N} / \mathrm{A}=$ Not applicable

- The boron standards are for hot water soluble extract for all surface soils. For subsurface soils the standards are for total boron (mixed strong acid digest), since plant protection for soils below the root zone is not a significant concern.

* Analysis for methyl mereury only applies when mercury (total) standard is exceeded

*** The methyl naphthalene standards are appliable to both 1-methyl naphthallene and 2- methyl naphthalene , with the provision that if both are detected the sum of the two must not exceed the standard.

*** F1 fraction does not include BTEX; however, the proponent has the choice as to whether or not to subtract BTEX from the analytical result. 


\section{References}

Abramovitch, Rudolph A., et al. "In situ decomposition of PAHs in soil and desorption of organic solvents using microwave energy." Chemosphere 39.1 (1999): 81-87.

Aggregates Act, R.S.O. 1990, c. A. 8. Retrieved from Service Ontario E-laws: http://www.elaws.gov.on.ca/html/statutes/english/elaws_statutes_90a08_e.htm

Agostini, Paola. "Decision support systems for contaminated land management: a review." Decision support systems for risk-based management of contaminated sites. Springer US, 2009. 1-20.

Al-Tabbaa, A. and A.S.R. Perera. "UK Stabilization/Solidification Treatment and Remediation, Part I: Binders, Technologies, Testing and Research". Land Contamination and Reclamation 14(1):1-22 (2006).

Anchor Environmental (Anchor). "Literature Review of Effects of Resuspended Sediments Due to Dredging Operations". Prepared for Los Angeles Contaminated Sediments Task Force (June 2003).

Aquafor Beech Ltd. "City of Hamilton Operation and Maintenance Report for Stormwater Management Facilities". Prepared for City of Hamilton (May, 2009).

Axtmann, Ellen V., and Samuel N. Luoma. "Large-scale distribution of metal contamination in the finegrained sediments of the Clark Fork River, Montana, USA." Applied Geochemistry 6.1 (1991): 75-88.

Barnett, F., S. Lynn, and D. Reisman." Technology Performance Review: Selecting and Using Solidification/Stabilization Treatment for Site Remediation". EPA 600-R-09-148 (2009)

Beds of Navigable Waters Act, R.S.O. 1990, c. B.4. Retrieved from Service Ontario E-Laws: http://www.elaws.gov.on.ca/html/statutes/english/elaws_statutes_90b04_e.htm

Besalatpour, A., Hajabbasi, M. A., Khoshgoftarmanesh, A. H., \& Dorostkar, V.. "Landfarming process effects on biochemical properties of petroleum-contaminated soils." Soil and Sediment Contamination 20.2 (2011): 234-248.

Blazquez, Carola A., Teresa M. Adams, and Philip Keillor. "Optimization of mechanical dredging operations for sediment remediation." Journal of Waterway, Port, Coastal, and Ocean Engineering 127.6 (2001): 299-307.

Bert, V., Girondelot, B., Quatannens, V., \& Laboudigue, A. "A Phytostabilisation of a metal polluted dredged sediment deposit-Mesocosm experiment and field trial." Proceedings ConSoil Bordeaux(2005): 1544-1550.

Bert, V., Seuntjens, P., Dejonghe, W., Lacherez, S., Thuy, H. T. T., \& Vandecasteele, B. "Phytoremediation as a management option for contaminated sediments in tidal marshes, flood control areas and dredged sediment landfill sites." Environmental Science and Pollution Research 16.7 (2009): 745-764. 
Björklund, Erland, Anne Müller, and Christoph von Holst. "Comparison of fat retainers in accelerated solvent extraction for the selective extraction of PCBs from fat-containing samples." Analytical Chemistry 73.16 (2001): 4050-4053.

Berti, William R., and Scott D. Cunningham. "Phytostabilization of metals."Phytoremediation of toxic metals: using plants to clean-up the environment. New York, John Wiley \& Sons, Inc (2000): 71-88.

Bobechko, Janet. "Sustainable Soil and Materials Management". Region of Waterloo. Ontario Environment Industry Association - Excess Soil Session, (September 9, 2014).

Boving, Thomas B., and Kevin Neary. "Attenuation of polycyclic aromatic hydrocarbons from urban stormwater runoff by wood filters." Journal of Contaminant Hydrology 91.1 (2007): 43-57.

Bray, Richard Nicholas, A. D. Bates, and John M. Land. "Dredging: a handbook for engineers." (1997).

Bridges, T. S., Gustavson, K. E., Schroeder, P., Ells, S. J., Hayes, D., Nadeau, S. C., \& Patmont, C. “The Four Rs of Environmental Dredging: Resuspension, Release, Residual, and Risk; U.S. Army Engineer Research and Development Center: Vicksburg, MS (2008).

Burken, Joel G., and Jerald L. Schnoor. "Predictive relationships for uptake of organic contaminants by hybrid poplar trees." Environmental Science \& Technology 32.21 (1998): 3379-3385.

Butler, D and J. Davies. “Urban Drainage”. T\&F Books UK; $3^{\text {rd }}$ Edition (2010).

Canada Water Act, R.S.C 1985, c. C-11. Retrieved from the Department of Justice Website: http://lawslois.justice.gc.ca/eng/acts/c-11/index.html

Canadian Council of Ministers of the Environment (CCME). "Canadian sediment quality guidelines for the protection of aquatic life: Polycyclic aromatic hydrocarbons (PAHs)". Canadian Environmental Quality Guidelines (1999).

Canadian Environmental Assessment Act, R.S.C. 1992, c. 37 (CEAA). Retrieved from the Department of Justice Website: http://laws-lois.justice.gc.ca/eng/acts/C-15.21/index.html

Canadian Environmental Protection Act, 1999, S.C. 1999, c. 33 (CEPA). Retrieved from the Department of Justice Website: http://laws-lois.justice.gc.ca/eng/acts/c-15.31/

Carlon, C., Critto, A., Ramieri, E., \& Marcomini, A. "DESYRE: Decision support system for the rehabilitation of contaminated megasites." Integrated Environmental Assessment and Management 3.2 (2007): 211-222.

Cho, Y. M., Smithenry, D. W., Ghosh, U., Kennedy, A. J., Millward, R. N., Bridges, T. S., \& Luthy, R. G.. "Field methods for amending marine sediment with activated carbon and assessing treatment effectiveness." Marine Environmental Research 64.5 (2007): 541-555.

City of Barrie. "Storm Drainage and Stormwater Management Policies and Design Guidelines". In association with Valdor Engineering Inc. (November, 2009) 
City of Brampton. "Subdivision Design Manual". Planning Design and Development Department (2008).

City of Kitchener. "Beyond the Landfill: Beneficial Reuse of Sediment from Stormwater Management Facilities". Showcasing Water Innovation (2011).

City of Pickering. "Stormwater Management Design Guidelines". Water Resources and Development Services. Retrieved from: http://www.pickering.ca/en/business/resources/SWM_Guidelines.pdf , 2015.

City of Portland, "Soil Specification for Vegetated Stormwater Facilities", Portland Stormwater Management Manual (2008).

Civica Infrastructure. "Software: SWMSoft". Retrieved from: http://www.civi.ca/software-swmsoft/, 2014.

CL:AIRE (Contaminated Land: Applications in Real Environments). "Treatability Bulletin: Soil Washing" (2011).

Clarifica Inc. "Preliminary Assessment for an Improved Design Criteria for Construction Sediment Control Ponds". Prepared for TRCA and DFO (March 2003).

Cole Engineering (Cole). "Stormwater Management Master Plan Municipal Class Environmental Assessment". Prepared for the City of Vaughan (June, 2014).

Conservation Authorities Act, R.S.O. 1990, c. C. 27. Retrieved from Service Ontario E-Laws: http://www.e-laws.gov.on.ca/html/statutes/english/elaws_statutes_90c27_e.htm

Collins, K. A., Lawrence, T. J., Stander, E. K., Jontos, R. J., Kaushal, S. S., Newcomer, T. A., \& Ekberg, M. L. C. "Opportunities and challenges for managing nitrogen in urban stormwater: A review and synthesis". Ecological Engineering (2010).

Crane, Judy L. "Source apportionment and distribution of polycyclic aromatic hydrocarbons, risk considerations, and management implications for urban stormwater pond sediments in Minnesota, USA." Archives of Environmental Contamination and Toxicology 66.2 (2014): 176-200.

Cunningham, Scott D., and William R. Berti. "Phytoextraction and phytostabilization: Technical, economic and regulatory considerations of the soil-lead issue." Phytoremediation of contaminated soil and water (2000).

Davis, Brian. "Landscapes and Instruments: Dredge Landscape Taxonomies". Masters Project, University of Virginia (2014).

Dalton, J. L., Gardner, K. H., Seager, T. P., Weimer, M. L., Spear, J. C., \& Magee, B. J. "Properties of Portland cement made from contaminated sediments." Resources, Conservation and Recycling 41.3 (2004): 227-241. 
De Groot, A. V., Van der Klis, M. M. I. P., Van Wesenbeeck, B. W., Ten Have, R., De Meijer, R. J., \& Bakker, J. P.. "Natural radionuclides in salt marsh sediments: revealing spatial sediment patterns." KVI annual report 62 (2002).

de Percin, Paul R. "Application of thermal desorption technologies to hazardous waste sites." Journal of hazardous materials 40.2 (1995): 203-209.

Dietz, Annette C., and Jerald L. Schnoor. "Advances in phytoremediation." Environmental Health Perspectives 109.Suppl 1 (2001): 163.

Drake, Jennifer and Yiping Guo. "Maintenance of Wet Stormwater Ponds in Ontario". Canadian Water Resources Journal (2008). Vol. 33(4): 351-368

Drainage Act, R.S.O. 1990.c. D. 17. Retrieved from Service Ontario E-Laws: http://www.elaws.gov.on.ca/html/statutes/english/elaws_statutes_90d17_e.htm

DUKE, M. L., FOWLER, J., SCHMIDT, M. L., \& ASKEW, A. C.. "Dredging and Dewatering of Hazardous Impoundment Sediment Using the Dry DREdge ${ }^{\mathrm{TM}}$ and Geotubes." Dredged Material Management (2000): 84.

Durmusoglu, Ertan, Fatih Taspinar, and Aykan Karademir. "Health risk assessment of BTEX emissions in the landfill environment." Journal of Hazardous Materials 176.1 (2010): 870-877.

Eelkema, Menno. "Measuring sediment properties in the field using MEDUSA RhoC. Diss. MSc Thesis, Delft University of Technology". Available at: http://www. citg. tudelft. nl/live/pagina. jsp, 2008.

Environment Agency UK (EAUK). "An illustrated handbook of DNAPL transport and fate in the subsurface". Environment Agency, Bristol, UK (June 2003).

Environment Canada (EC). “TAB\#22: In-situ Remediation Technologies for Contaminated Sites”. EC, 2002. Retrieved from: http://publications.gc.ca/collections/collection_2014/ec/En163-1-22-eng.pdf

Environment Canada (EC). "TAB\#23: Ex-situ Remediation Technologies for Contaminated Sites". EC, 2002. Retrieved from: http://publications.gc.ca/collections/collection_2014/ec/En163-1-23-eng.pdf

Environment Canada (EC). "Interprovincial movement of hazardous waste and hazardous recyclable material regulation. Retrieved from http://www.ec.gc.ca/lcpe-cepa/default?lang=En\&n=2058D8011\&offset=7\&toc=show\#anchor1.1 (2002).

Environmental Security Technology Certification Program (ESTCP). "Bioaugmentation for Remediation of Chlorinated Solvents: Technology Development Status and Research Needs" (2005).

ESTCP. "In Situ Chemical Oxidation for Remediation of Contaminated Groundwater: Summary of Proceedings of an ISCO Technologies Practices Workshop", ESTCP Project ER-0623 (June, 2008).

European Standard, NF EN 13286-2. Unbound and hydraulically bound mixtures. Test methods for the determination of the laboratory reference density and water content. Proctor compaction, European 
Committee for standardization (2005).

European Standard, NF EN 13286-47. Unbound and hydraulically bound mixtures. Test method for the determination of California bearing ratio, immediate bearing index and linear swelling. European Committee for standardization (2003).

Federal Remediation Technologies Roundtable (FRTR). "Remediation Technologies Screening Matrix Section 2: Contaminant Perspectives". Retrieved from http://www.frtr.gov/matrix2/section2/2_intro.html (November, 1999)

Ferrarese, Elisa, Gianni Andreottola, and Irina Aura Oprea. "Remediation of PAH-contaminated sediments by chemical oxidation." Journal of Hazardous Materials 152.1 (2008): 128-139.

Fisheries Act, R.S.C. 1985, c. F-14. Retrieved from the Department of Justice Website: http://lawslois.justice.gc.ca/eng/acts/f-14/

Fredette, T.J. “Why Confined Disposal Cells Often Make Sense”. Integr. Environ. Assess. Manage., Vol. 2(No. 1), pp. 35-38 (2006).

Förstner, Ulrich, and Wim Salomons. "Sediment research, management and policy." Journal of Soils and Sediments 10.8 (2010): 1440-1452.

Förstner, Ulrich, and Sabine E. Apitz. "Sediment remediation: US focus on capping and monitored natural recovery." Journal of Soils and Sediments 7.6 (2007): 351-358.

Fowler, J. "Use of Geotubes in Columbia, South America". Geotec Associates (2000).

Gan, S., E. V. Lau, and H. K. Ng. "Remediation of soils contaminated with polycyclic aromatic hydrocarbons (PAHs)." Journal of Hazardous Materials172.2 (2009): 532-549.

Gates, Dianne D., and Robert L. Siegrist. "In-situ chemical oxidation of trichloroethylene using hydrogen peroxide." Journal of Environmental Engineering 121.9 (1995): 639-644.

Ghosh, U., Weber, A. S., Jensen, J. N., \& Smith, J. R.. "Relationship between PCB desorption equilibrium, kinetics, and availability during land biotreatment." Environmental Science \& Technology34.12 (2000):

2542-2548.

Ghosh, U., Luthy, R. G., Cornelissen, G., Werner, D., \& Menzie, C. A. "In-situ sorbent amendments: a new direction in contaminated sediment management." Environmental science \& technology 45.4 (2011):

1163-1168.

Golder Associates. "Stormwater Pond Sediment Strategy, Mississauga, ON". Submitted to City of Mississauga and TRCA, (2003). 
Gomes, Helena I., Celia Dias-Ferreira, and Alexandra B. Ribeiro. "Overview of in situ and ex situ remediation technologies for PCB-contaminated soils and sediments and obstacles for full-scale application." Science of the Total Environment 445 (2013): 237-260.

Graham, Edward I., and Jian H. Lei. "Stormwater management ponds and wetlands sediment maintenance." WATER QUALITY RES J CANADA. 35.3 (2000): 525-539.

Greater Golden Horseshoe Area Conservation Authorities (GGHA). "Erosion and Sediment Control Guideline for Urban Construction". (December 2006).

Gregory, Michael. "Stormwater Pond Sediment Loading and Accumulation Analysis." Journal of Water Management Modeling (2014).

Greenland International Consulting In. (GIC). "Storm water management facility sediment maintenance guide. Concord, ON (1999).

Gouleau, D., Jouanneau, J. M., Weber, O., \& Sauriau, P. G. "Short-and long-term sedimentation on Montportail-Brouage intertidal mudflat, Marennes-Oleron Bay (France)." Continental Shelf Research 20.12 (2000): 1513-1530.

Gu, C., Bai, Y., Tao, T., Chen, G., \& Shan, Y. "Effect of sewage sludge amendment on heavy metal uptake and yield of ryegrass seedling in a Mudflat soil." Journal of Environmental Quality 42.2 (2013): 421-428.

Hayes, D.F. “Dredging Contaminated Sediments”. University of Utah, prepared for the USEPA (2006).

Hazen, T.C. "In Situ Groundwater Bioremediation". Chapter 13 in Part 24 of the Handbook of Hydrocarbon and Lipid Microbiology. Springer-Verlag Berlin Heidelberg, ISBN: 978-3-540-77587-4, p 2584-2596 (2010).

Houle, J. J., Roseen, R. M., Ballestero, T. P., Puls, T. A., \& Sherrard Jr, J. "Comparison of Maintenance Cost, Labor Demands, and System Performance for LID and Conventional Stormwater Management". Journal of Environmental Engineering 139.7 (2013): 932-938.

Hosseini, Masood S. "In-situ thermal desorption of heavy hydrocarbons in vadose zone." U.S. Patent No. 5,769,569. 23 Jun. 1998.

Hubert, A., Wenzel, K. D., Manz, M., Weissflog, L., Engewald, W., \& Schüürmann, G. "High extraction efficiency for POPs in real contaminated soil samples using accelerated solvent extraction." Analytical Chemistry 72.6 (2000): 1294-1300.

Huling, Scott G., and Bruce E. Pivetz. "In-situ chemical oxidation". No. EPA/600/R-06/072. ENVIRONMENTAL PROTECTION AGENCY WASHINGTON DC OFFICE OF WATER, 2006.

Hvitved-Jacobsen et al. "Urban and Highway Stormwater Pollution: Concepts and Engineering”. CRC Press (2012). 
International Centre for Soil and Contaminated Sites (ICSCS). "Manual for Biological Remediation Techniques". (2006).

Interstate Technology Regulatory Council (ITRC). "Evaluating LNAPL Remedial Technologies for Achieving Project Goals". ITRC (December, 2009).

ITRC. "Phytotechnology Technical and Regulatory Guidance and Decision Trees, Revised" (2009).

Jackson, W. Andrew, and John H. Pardue. "Potential for enhancement of biodegradation of crude oil in Louisiana salt marshes using nutrient amendments." Water, Air, and Soil Pollution 109.1-4 (1999): 343355.

Jacobs, W., Eelkema, M., Limburg, H., \& Winterwerp, J. C. "A new radiometric instrument for in situ measurements of physical sediment properties." Marine and Freshwater Research 60.7 (2009): 727-736.

Janes, Meggen. "Risk Management Measures". Soil and Groundwater Remediation Lecture, Ryerson University (March 2014)

Jones, K.W., E.A. Stern, K.R. Donato, and N.L. Clasceri. "Sediment Decontamination Treatment Train: Commercial-Scale Demonstration for the Port of New York/New Jersey". Proceedings of the $19^{\text {th }}$

Karlsson, K., Viklander, M., Scholes, L., \& Revitt, M. "Heavy metal concentrations and toxicity in water and sediment from stormwater ponds and sedimentation tanks." Journal of hazardous materials 178.1 (2010): 612-618.

Koch, B. J., Febria, C. M., Gevrey, M., Wainger, L. A., \& Palmer, M. A.. "Nitrogen Removal by Stormwater Management Structures: A Data Synthesis." JAWRA Journal of the American Water Resources Association 50.6 (2014): 1594-1607.

Krause, Paul R., and Kathleen A. McDonnell. "The beneficial reuse of dredged material for upland disposal." Harding Lawson Associates, Novato, CA 23 (2000).

Kwon, S., Thomas, J., Reed, B. E., Levine, L., Magar, V. S., Farrar, D., ... \& Ghosh, U.. "Evaluation of sorbent amendments for in situ remediation of metal-contaminated sediments." Environmental Toxicology and Chemistry 29.9 (2010): 1883-1892.

Lake Simcoe Region Conservation Authority (LSRCA). "Stormwater Pond Maintenance and Anoxic Conditions Investigations - Final Report" (2010).

Lake Simcoe Region Conservation Authority (LSRCA)." LSRCA Technical Guidelines for Stormwater Management Submissions". (April 26, 2013).

Lakes and Rivers Improvement Act, R.S.O. 1990, c. L.3. Retrieved from Service Ontario E-Laws: http://www.e-laws.gov.on.ca/html/statutes/english/elaws_statutes_90l03_e.htm 
Landrum, Peter F., and John A. Robbins. "Bioavailability of sediment-associated contaminants to benthic invertebrates." Sediments: chemistry and toxicity of in-place pollutants. CRC Press, Inc., Boca Raton, Florida, USA(1990): 237-263.

Lee, G.F., A. Jones-Lee. “Disposal of Contaminated Sediments/Soils in MSW Landfills: Need to Consider the True Cost". Remediation 15(3): pp. 95-101, (2005)

Li, James. "Sediment Control Pond Monitoring Study". Ryerson University (March 2003).

Liu, Ling, James A. Tindall, and Michael J. Friedel. "Biodegradation of PAHs and PCBs in soils and sludges." Water, Air, and Soil Pollution 181.1-4 (2007): 281-296.

LSRCA. "Retrofitting of Urban Stormwater Management Facilities Using Innovative Technologies: Comparison of Three Innovative Solutions"(2009).

LSRCA. "Stormwater Pond Maintenance and Anoxic Conditions Investigation". Final Report, (2011) Magar, Victor S. "PCB treatment alternatives and research directions." Journal of Environmental Engineering 129.11 (2003): 961-965.

Magar, V. S., Chadwick, D. B., Bridges, T. S., Fuchsman, P. C., Conder, J. M., Dekker, T. J., ... \& Mills, M. A. "Monitored natural recovery at contaminated sediment sites". ENVIRON INTERNATIONAL CORP ARLINGTON VA (2009).

Marsalek J, Rochfort Q, Grapentine L, Brownlee B. 2002. "Assessment of stormwater impacts on an urban stream with a detention pond". Water Science \& Technology 45:255-263.

Marsalek, J., and P. M. Marsalek. "Characteristics of sediments from a stormwater management pond." Water Science and technology 36.8 (1997): 117-122.

Marsalek, J., W. E. Watt, and B. C. Anderson. "Maintenance and Retrofit of an On-stream Stormwater Management Pond". 11 $1^{\text {th }}$ International Conference on Urban Drainage, Edinburgh, Scotland, UK, 2008.

Marsalek, J., W. E. Watt, and D. Henry. "Retrofitting stormwater ponds for water quality control." Water Pollution Research Journal of Canada 27.2 (1992): 403-422.

Marsalek, J. "Road salts in urban stormwater: an emerging issue in stormwater management in cold climates." Water Science \& Technology 48.9 (2003): 61-70.

Maryland Department of the Environment, "Maryland Stormwater Design Manual, Volumes I \& II", (May 2009).

Mastin, Brian J., Gregg E. Lebster, and L. L. C. WaterSolve. "Use of Geotube ${ }^{\circledR}$ Dewatering Containers in Environmental Dredging." Proceedings of GeoAmericas 2008 (2008). 
Mayer, T., Rochfort, Q., Borgmann, U., \& Snodgrass, W.. "Geochemistry and toxicity of sediment porewater in a salt-impacted urban stormwater detention pond." Environmental Pollution 156.1 (2008): 143-151.

M.J. Mann, et al. “Innovative Site Remediation Technologies: Design and Application, Vol. 3: Liquid Extraction Technologies Soil Washing, Soil Flushing, Solvent/Chemical". American Academy of Environmental Engineers, Annapolis, MD. ISBN: 1-883767-19-9, 432 pp. (1998).

MacRae, C.R., "Experience From Morphological Research on Canadian Streams: Is Control of the TwoYear Frequency Runoff Event the Best Basis for Stream Protection", Effects of Watershed Development and Management on Aquatic Systems, Engineering Foundation of Utah (1996).

Marsalek, J., W. E. Watt, and D. Henry. "Retrofitting stormwater ponds for water quality control." Water Pollution Research Journal of Canada 27.2 (1992): 403-422.

Mendez, Monica O., and Raina M. Maier. "Phytostabilization of mine tailings in arid and semiarid environments-an emerging remediation technology."Environmental Health Perspectives 116.3 (2008): 278.

Ministry of Municipal Affairs and Housing (MMAH). "A Practical Guide to Brownfield Redevelopment in Ontario", (Fall 2007).

Minnesota Pollution Control Agency (MPCA). “Minnesota Stormwater Manual”. March, 2000.

Mulligan, C. N., R. N. Yong, and B. F. Gibbs. "Surfactant-enhanced remediation of contaminated soil: a review." Engineering Geology 60.1 (2001): 371-380.

Mulligan, Catherine N., Raymond N. Yong, and Bernard F. Gibbs. "An evaluation of technologies for the heavy metal remediation of dredged sediments." Journal of hazardous materials 85.1 (2001): 145-163.

Mundle, K., Reynolds, D. A., West, M. R., \& Kueper, B. H. "Concentration rebound following in situ chemical oxidation in fractured clay." Groundwater 45.6 (2007): 692-702.

Murphy, T. P., Lawson, A., Kumagai, M., \& Babin, J.. "Review of emerging issues in sediment treatment." Aquatic Ecosystem Health \& Management 2.4 (1999): 419-434.

Narayanan, Arvind, and Robert Pitt. "Costs of urban stormwater control practices". Diss. University of Alabama (2006).

Naval Facilities Engineering Service Centre (NFESC). "Application Guide for Thermal Desorption Systems" Technical Report TR-2090-ENV (1998).

Navigable Waters Protection Act, R.S.C. 1985, c. N-22. Retrieved from Department of Justice Website: http://laws-lois.justice.gc.ca/eng/acts/N-22/ 
National Research Council (NRC). "Sediment Dredging at Superfund Megasites: Assessing the Effectiveness". Committee on Sediment Dredging at Superfund Megasites, Board on Environmental Studies and Toxicology, Division on Earth and Life Studies (2007).

New Jersey Department of Environmental Protection, “ New Jersey Stormwater BMP Manual - Standard for Wet Ponds", February 2004

New York Department of Environmental Conservation, "New York State Stormwater Management Design Manual", August 2010.

New York Department of Environmental Conservation, "New York State Stormwater Management Design Manual", August 2010.

New Zealand Transport Agency (NTA). "Sediment Accumulation Monitoring Techniques". Auckland Motorways (2010).

Nutrient Management Act, S.O. 2002, c. 4. Retrieved from Service Ontario E-Laws: http://www.elaws.gov.on.ca/html/regs/english/elaws_regs_030267_e.htm

OMOE. "Handbook for Dredging and Dredged Material Disposal in Ontario -Legislation, Policies, Sediment Classification and Disposal Options". Standards Development Branch, OMOE (January 2011)

OMOE. "Fill Quality Guide and Good Management Practices for Shore Infilling in Ontario". Ontario Ministry of the Environment, Toronto, Ontario (2011).

OMOE. "Management of Excess Soil - A Guide for Best Management Practices". OMOE, Operations Division (2014).

OMOE. "Guidelines for the Utilization of Biosolids and other Wastes on Agricultural Land". OMOE and Ontario Ministry of Agriculture, Food and Rural Affairs, (March 1996).

OMOE. "Guideline for Use at Contaminated Sites in Ontario". OMOE (1997)

OMOE. "Guidelines for Identifying, Assessing and Managing Contaminated Sediments in Ontario: An Integrated Approach". Ontario Ministry of the Environment, Toronto, Ontario (2008).

OMOE. "Rationale for the Development of Soil and Ground Water Standards for Use at Contaminated Sites in Ontario". Standards Development Branch, OMOE. PIBS $7386 \mathrm{e} 01$ (April, 2011)

OMOE. "Records of Site Condition: A Guide on Site Assessment, the Cleanup of Brownfield Sites and the Filing of Records of Site Condition". (October 2004)

OMOE. "Stormwater Management Planning and Design Manual" (March 2003).

Ontario Water Resources Act, R.S.O. 1990, c. 0.40. Retrieved from Service Ontario E-Laws: http://www.e-laws.gov.on.ca/html/statutes/english/elaws_statutes_90040_e.htm 
Palermo, Michael R. "Design considerations for < i> in-situ</i> capping of contaminated sediments." Water Science and Technology 37.6 (1998): 315-321.

Palermo, M., and C. Patmont. "Considerations for monitoring and management of environmental dredging residuals." Proceedings, Fourth International Conference on Remediation of Contaminated Sediments, Savannah, GA, USA, January. 2007.

Palermo, M. R., N. R. Francingues, and D. E. Averett. "Operational characteristics and equipment selection factors for environmental dredging." Journal of Dredging Engineering, Western Dredging Association 5.4 (2004).

Palermo, M. R., Francingues, N. R., Schroeder, P. R., \& Estes, T. O. "Guidance for environmental dredging of contaminated sediments, Draft." DOER TRX-X. Prepared for Office of Solid Waste and Emergency Response, Washington, DC, by US Army Engineer Research and Development Center, Vicksburg, MS, USA (2006).

Pantazidou, M., Katsiri, A., \& Reddy, K.. "Evaluating Management Options for the Disposal of Dredged Sediments". Journal of STM International V. 6(No. 6), (2009).

Paria, Santanu. "Surfactant-enhanced remediation of organic contaminated soil and water." Advances in Colloid and Interface Science 138.1 (2008): 24-58.

Paria, S. and P.K. Yuet. "Solidification/stabilization of organic and inorganic contaminants using portland cement: A literature review". Environmental Reviews 14(4):217-255 (2006).

Patmont, C. "Contaminated sediment dredging residuals: Recent monitoring data and management implications." National Research Council Committee on Sediment Dredging at Superfund Megasites (2006).

Palermo, Michael, and Donald F. Hays. "Sediment Dredging, Treatment and Disposal." Processes, Assessment and Remediation of Contaminated Sediments. Springer New York, 2014. 365-391.

Palermo, M., and C. Patmont. "Considerations for monitoring and management of environmental dredging residuals." Proceedings, Fourth International Conference on Remediation of Contaminated Sediments, Savannah, GA, USA, January. 2007.

Paria, Santanu, and Pak K. Yuet. "Solidification-stabilization of organic and inorganic contaminants using portland cement: a literature review."Environmental Reviews 14.4 (2006): 217-255.

Parsons. "Principles and Practices of Enhanced Anaerobic Bioremediation of Chlorinated Solvents". AFCEE, NFEC, ESTCP 457 pp, (August 2004).

Peng, J. F., Song, Y. H., Yuan, P., Cui, X. Y., \& Qiu, G. L. "The remediation of heavy metals contaminated sediment." Journal of Hazardous Materials 161.2 (2009): 633-640. 
Pennekamp, J. G., Epskamp, R. J. C., Rosenbrand, W. F., Mullie, A., Wessel, G. L., Arts, T., \& Deibel, I. K. "Turbidity caused by dredging: viewed in perspective." Terra et Aqua (1996): 10-17.

Penseart, Stany. "Stabilisation/Solidification of Sediments and Soils: Overview of Technologies and Experience." Urban Sediment Management and Port Redevelopment/Sediment in River Basin Management Plans. SEDNET Conference 27th-29th May 2008, Oslo, Norway.

Pensaert, Stany, et. al. "The Svartsjo Project: The Application of Geotubes for Dewatering and Storage of Dredged Pulp-and-paper Sludges." $15^{\text {th }}$ Innovatieforum Geotechniek Proceedings (2008).

Perelo, Louisa Wessels. "Review: In situ and bioremediation of organic pollutants in aquatic sediments." Journal of hazardous materials 177.1 (2010): 81-89.

Petavy, F., Ruban, V., Conil, P., Viau, J. Y., \& Auriol, J. C. "Two treatment methods for stormwater sediments-pilot plant and landfarming-and reuse of the treated sediments in civil engineering." Environmental Technology 30.8 (2009): 825-830.

Planning Act, R.S.O. 1990, c. P13. Retrieved from Service Ontario E-Laws: http://www.elaws.gov.on.ca/html/statutes/english/elaws_statutes_90p13_e.htm

Portland Cement Association. "Industry Overview: Economics of the U.S. Cement Industry". Portland Cement Association, http://www.portcement.org/econ/econ_overview.asp (2003).

Public Lands Act, R.S.O. 1990, c. P.43. Retrieved from Service Ontario E-Laws: http://www.elaws.gov.on.ca/html/statutes/english/elaws_statutes_90p43_e.htm

Rhodes, Steven L., and Karen B. Wiley. "Great Lakes toxic sediments and climate change: implications for environmental remediation." Global Environmental Change 3.3 (1993): 292-305.

Richard, Rishon. "Investigation of the Sediment Removal Frequency for Wet-Detention Stormwater Management Ponds". MASc. Thesis, Ryerson University (2013).

Rienks, Johan. "Comparison of results for chemical and thermal treatment of contaminated dredged sediments." Water science and technology 37.6 (1998): 355-362.

Schott, John R. "Remote Sensing". Oxford University Press, 2007.

Schnoor, J. L., Light, L. A., McCutcheon, S. C., Wolfe, N. L., \& Carreia, L. H. "Phytoremediation of organic and nutrient contaminants." Environmental Science \& Technology 29.7 (1995): 318A-323A.

Schueler, T. R., and J. Lugbill, "Performance of Current Sediment Control Measures at Maryland Construction Sites", Report, Department of Environmental Programs, Metropolitan Washington Council of Governments, Washington DC, 1990.

Siegrist, Robert L., et al. "Chemical oxidation for clean up of contaminated ground water." Methods and Techniques for Cleaning-up Contaminated Sites. Springer Netherlands, 2008. 45-58. 
Siegrist, Robert L., et al. "In situ chemical oxidation." Chlorinated Solvent Source Zone Remediation. Springer New York, 2014. 253-305.

Simpson, Mark, and Frank Suppa. "Evaluation of a Geotube and Hydraulic Dredging Approach to SWM Pond Cleanout in the City of Vaughan." Trieca, 2014. Toronto. 25 Mar. 2014. Presentation.

Siham, K., Fabrice, B., Edine, A. N., \& Patrick, D. "Marine dredged sediments as new materials resource for road construction." Waste Management 28.5 (2008): 919-928.

Smith, Marline T., Franco Berruti, and Anil K. Mehrotra. "Thermal desorption treatment of contaminated soils in a novel batch thermal reactor." Industrial \& Engineering Chemistry Research 40.23 (2001): 54215430.

Sorvari, Jaana, and Jyri Seppälä. "A decision support tool to prioritize risk management options for contaminated sites." Science of the Total Environment 408.8 (2010): 1786-1799.

Sprenger, James. "Application of Risk Assessment". Soil and Groundwater Remediation Lecture, Ryerson University (February 2014).

Stanley, Donald W. "Pollutant removal by a stormwater dry detention pond." Water Environment Research (1996): 1076-1083.

Stern E.A., Donato K.R., Cieschi K.W. "Integrated sediment decontamination for the NY/NJ Harbor, in: Proceedings of the National Conference on Management and Treatment of Contaminated Sediments, $\mathrm{OH}$ (2000), pp. 71-81

Straube, W. L., Nestler, C. C., Hansen, L. D., Ringleberg, D., Pritchard, P. H., \& Jones-Meehan, J. "Remediation of polyaromatic hydrocarbons (PAHs) through landfarming with biostimulation and bioaugmentation." Acta Biotechnologica 23.2-3 (2003): 179-196.

Susarla, Sridhar, Victor F. Medina, and Steven C. McCutcheon. "Phytoremediation: an ecological solution to organic chemical contamination." Ecological Engineering 18.5 (2002): 647-658.

Toronto Port Lands Company (TPLC). "Cherry Beach Sports Fields". http://tplc.ca/portfolio/projects/cherry-beach-sports-fields/ (2014).

Trapp et. al. "A Guide to Vegetation Sampling for Screening of Subsurface Pollution". BIOTOOL Project (2010).

Tsitonaki, A., Petri, B., Crimi, M., Mosbæk, H., Siegrist, R. L., \& Bjerg, P. L. "In situ chemical oxidation of contaminated soil and groundwater using persulfate: a review." Critical Reviews in Environmental Science and Technology 40.1 (2010): 55-91.GOCE 003998 (2007).

TRCA. 'Stormwater Management Pond Planting Guidelines. (September 2007).

TRCA. “Anionic Polyacrylamide Application Guide for Urban Construction in Ontario". Sustainable Technologies Evaluation Program, TRCA (June 2013). 
TRCA. "Water Quality Risk Management Catalogue Manual”. Prepared for: Ontario Ministry of the Environment and Climate Change (2014).

TRCA. "Guide: Water Quantity Risk Management Measures Evaluation Process". Prepare for: The use of Source Protection Committees in preparation of the Source Protection Plans under the Clean Water Act (2014).

TRCA (2012). " Stormwater Management Criteria”. August 2012, Version 1.0

TSH Inc. "Stormwater Management Facility Inventory and Maintenance Needs Plan Final Report". City of Guelph (October 2008).

Tymecki, Mark, and Mark Simpson. "Geotubes Successfully Used for Stormwater Pond Sediment Dewatering." Environmental Science \& Engineering Oct. 2013: 62-63. Web.

United Nations Environment Programme (UNEP), Chemicals Branch. "Compilation of an inventory of existing risk management measures: lead and cadmium" (November 2008).

United States Army Corps of Engineers (USACE). "Beneficial uses of Dredged Material - Engineering Manual. USACE. Washington, D.C. EM 1110-2-5026 (1987)

Urban Water Resources Research Council (UWRRC). "Pathogens in Urban Stormwater Systems". Environmental and Water Resources Institute of the American Society of Civil Engineers (August 2014).

Urynowicz, M. A., West, O. R., Crimi, M. L., \& Lowe, K. S. "Principles and practices of in situ chemical oxidation using permanganate". Vol. 505. Columbus, OH: Battelle Press (2001).

USACE. "Soil washing through separation/solubilisation: Guide specification for construction" CEGS-02 5423 (2006).

USEPA (1997). “Analysis of Selected Enhancements for Soil Vapour Extraction". EPA-542-R-97-007. (September 1997).

USEPA (1995). "Bioventing Principles and Practice Volume I and II: Bioventing Design". EPA-625-001. (September 1995).

USEPA. "Brownfields Technology Primer: Selecting and Using Phytoremediation for Site Cleanup". EPA 542-R-01-006 (2001).

USEPA (United States Environmental Protection Agency). “Contaminated Sediment Remediation Guidance for Hazardous Waste Sites". EPA-540-R-05-012, Office of Solid Waste and Emergency Response (2005a)

USEPA (United States Environmental Protection Agency). "Contaminated Sediment in Superfund." US Environmental Protection Agency (2006a). 
USEPA. "Contaminated Sediment Remediation Guidance for Hazardous Waste Sites". Office of Solid Waste and Emergency Response, EPA 540/R-05/012, (2005)

USEPA (2000). "Engineering Approaches to In Situ Bioremediation of Chlorinated Solvents:

Fundamentals and Field Applications". EPA 542-R-00-008.

USEPA and USACE. "Evaluating Environmental Effects of Dredged Material Management Alternatives - A Technical Framework". EPA 842/B-92/008, (1992)

USEPA. "Remediation Technology Cost Compendium - Year 2000". Solid Waste and Emergency Response, EPA-542-R-01-009 (September 2001).

USEPA. "Engineered Approaches to In Situ Bioremediation of Chlorinated Solvents: Fundamentals and Field Applications. EPA 542-R-00-008 (2000).

USEPA. "In-Situ Groundwater Bioremediation". Chapter 10 in How to Evaluate Alternative Cleanup Technologies for Underground Storage Tank Sites: A Guide for Corrective Action Plan Reviewers. EPA 510-R-04-002 (2004)

USEPA. "Solidification/Stabilization Use at Superfund Sites". Office of Solid Waste and Emergency Response, EPA-542-R-00-010 (2000).

USEPA. 'Storm Water O\&M Fact Sheet: Handling and Disposal of Residuals'. Office of Water, EPA 832-F99-015, September 1999.

USEPA, "Stormwater Wet Pond and Wetland Management Guidebook", Centre for Watershed Protection, Ellicot, February 2009.

United States Geological Survey. "User's Guide to the Collection and Analysis of Tree Cores to Asses the Distribution of Subsurface Volatile Organic Compounds". (2008)

Van der Graaf, E. R., Koomans, R. L., Limburg, J., \& De Vries, K.. "In situ radiometric mapping as a proxy of sediment contamination: Assessment of the underlying geochemical and-physical principles." Applied Radiation and Isotopes 65.5 (2007): 619-633.

Van Wijngaarden, M., Venema, L. B., De Meijer, R. J., Zwolsman, J. J. G., Van Os, B., \& Gieske, J. M. J. "Radiometric sand-mud characterisation in the Rhine-Meuse estuary: Part A. Fingerprinting." Geomorphology 43.1 (2002): 87-101.

Van Wijngaarden, M., L. B. Venema, and R. J. De Meijer. "Radiometric sand mud characterisation in the Rhine-Meuse Estuary: Part B. In situ mapping." Geomorphology 43.1 (2002): 103-116.

Vassilev, A., Schwitzguébel, J. P., Thewys, T., van der Lelie, D., \& Vangronsveld, J. "The use of plants for remediation of metal-contaminated soils." The Scientific World Journal 4 (2004): 9-34. 
Vervaeke, P., Luyssaert, S., Mertens, J., Meers, E., Tack, F. M. G., \& Lust, N. "Phytoremediation prospects of willow stands on contaminated sediment: a field trial." Environmental Pollution 126.2 (2003): 275282.

Vironex. "In Situ Chemical Oxidation for Groundwater and Soil Rmediation - Technology Practices Manial (TPM), (2011).

Wang, D. X., Abriak, N. E., Zentar, R., \& Xu, W. "Solidification/stabilization of dredged marine sediments for road construction." Environmental Technology 33.1 (2012): 95-101.

Wang, D., Abriak, N. E., Zentar, R., \& Chen, W. "Effect of lime treatment on geotechnical properties of Dunkirk sediments in France." Road Materials and Pavement Design 14.3 (2013): 485-503.

Watershed Management Institute, "Operation, Maintenance, and Management of Stormwater Management Systems", USEPA Office of Water (1997).

Weinstein, John E. et al. "Chemical and Biological Contamination of Stormwater Detention Pond Sediments in Coastal South Carolina". South Carolina Department of Health and Environmental Control Office of Ocean and Coastal Resource Management, Charleston, SC (2008).

Weinstein, J. E., Crawford, K. D., \& Garner, T. R. "Screening-level ecological and human health risk assessment of polycyclic aromatic hydrocarbons in stormwater detention pond sediments of Coastal South Carolina, USA." Journal of hazardous materials178.1 (2010): 906-916.

Western Dredging Association (WEDA XIX) Annual Meeting and Conference and $31^{\text {st }}$ Texas A\&M University Dredging Seminar (TAMU 31), Louisville, Kentucky (1999).

Withgott, J., Brennan, S., and Murck, B. "Environment: the science behind the stories, Canadian edition. Toronto, ON: Pearson Canada Inc, (2010).

Wick, A.F., Haus, N.W. "Remediation of PAH- Contaminated Soils and Sediments: A Literature Review". Virginia Polytechnic Institute and State University, Department of Crop and Soil Science (2011).

Yousef, Y. A., Hvitved-Jacobsen, T., Sloat, J., \& Lindeman, W. "Sediment accumulation in detention or retention ponds." Science of the Total Environment 146 (1994): 451-456.

Yousef, Yousef A., David M. Baker, and T. Hvitved-Jacobsen. "Modeling and impact of metal accumulation in bottom sediments of wet ponds." Science of the total environment 189 (1996): 349354.

Zentar, Rachid, Vincent Dubois, and Nor Edine Abriak. "Mechanical behaviour and environmental impacts of a test road built with marine dredged sediments."Resources, Conservation and recycling 52.6 (2008): 947-954.

Zhang, B. Y., J. S. Zheng, and R. G. Sharp. "Phytoremediation in engineered wetlands: mechanisms and applications." Procedia Environmental Sciences 2 (2010): 1315-1325. 